\title{
DETERMINATION OF SOME PHYTOESTROGENS \\ IN ALFALFA SPROUTS
}

\author{
by \\ SYLVIA ANN (DUFFEK) YADA \\ B.Sc.(Agr.), University of British Columbia, 1978
}

A thesis submitted in partial fulfillment of

the requirements for the degree of

Master of Science

in

THE FACULTY OF GRADUATE STUDIES

Department of Food Science

We accept this thesis as conforming

to the required standard

THE UNIVERSITY OF BRITISH COLUMBIA

February 1984

(C) Sylvia Ann (Duffek) Yada, 1984 
In presenting this thesis in partial fulfilment of the requirements for an advanced degree at the University of British Columbia, I agree that the Library shall make it freely available for reference and study. I further agree that permission for extensive copying of this thesis for scholarly purposes may be granted by the head of my department or by his or her representatives. It is understood that copying or publication of this thesis for financial gain shall not be allowed without my written permission.

Department of Food Science

The University of British Columbia 1956 Main Mall Vancouver, Canada V6T $1 Y 3$

Date March 14, 1984 


\section{ABSTRACT}

Alfalfa sprouts were grown under selected conditions in order to determine the effect of growth period, light duration, rinse volume and rinse frequency on the accumulation of phytoestrogens. The phytoestrogens were isolated from a crude methanol extract of alfalfa sprouts using ethyl ether. The residue remaining following ethyl ether evaporation was redissolved in methanol for high-performance liquid chromatography (HPLC). A method for HPLC was developed using an octadecylsilane reversed-phase column, UV detection at $254 \mathrm{~nm}$ and a gradient methanol/ water solvent system containing $1.0 \%$ acetic acid and $0.1 \mathrm{M}$ ammonium acetate. Baseline resolution of the phytoestrogens daidzein, formononetin and coumestrol from the alfalfa sprout extracts was achieved with an elution time of 30 minutes. Total phytoestrogen content ranged from 1 to $22 \mathrm{ppm}$ dry weight alfalfa (or less than $2 \mathrm{ppm}$ fresh weight alfalfa) depending on the growth conditions employed. Alfalfa sprouts grown in the dark ( $0 \mathrm{~h}$ light) for the longer growth period (148 h) had significantly greater $(P \leq 0.05)$ contents of daidzein, formononetin and coumestrol than those sprouts from other chosen treatment combinations. Although the contribution of phytoestrogens to the human diet from alfalfa sprouts would appear to be markedly higher than from other common vegetables, the physiological significance of such an intake has not yet been determined. 


\section{TABLE OF CONTENTS}

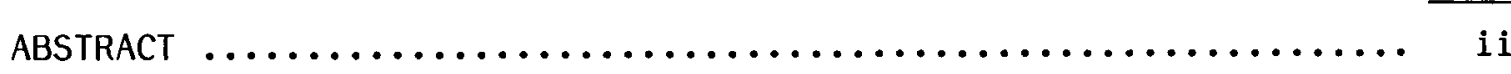

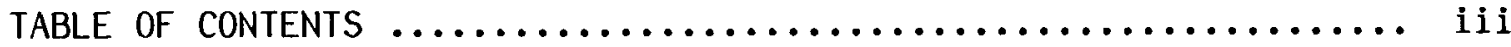

LIST OF FIGURES $\ldots \ldots \ldots \ldots \ldots \ldots \ldots \ldots \ldots \ldots \ldots \ldots \ldots \ldots \ldots \ldots \ldots \ldots \ldots$

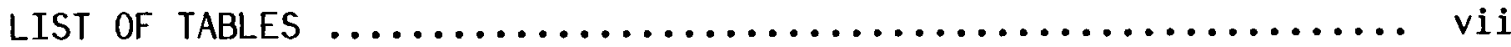

LIST OF APPENDICES $\ldots \ldots \ldots \ldots \ldots \ldots \ldots \ldots \ldots \ldots \ldots \ldots \ldots \ldots \ldots \ldots \ldots$

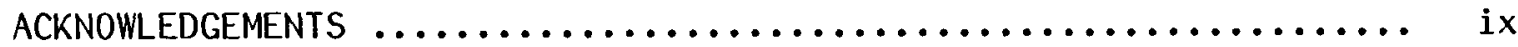

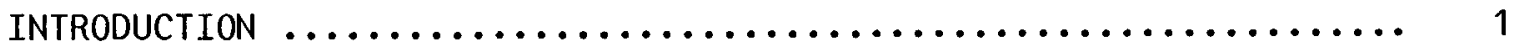

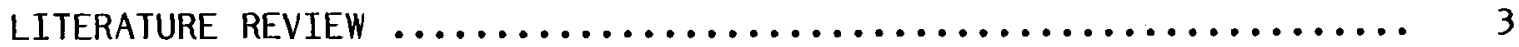

A. Nature and distribution of phytoestrogens $\ldots \ldots \ldots \ldots \ldots . . \ldots$

B. Biosynthesis and accumulation ................... 14

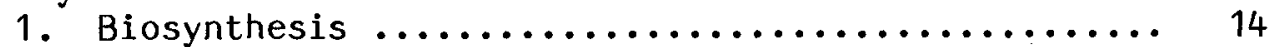

2. Effects of microbial infection $\ldots \ldots \ldots \ldots \ldots \ldots \ldots . \ldots \ldots$

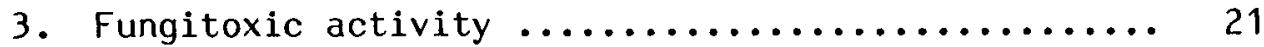

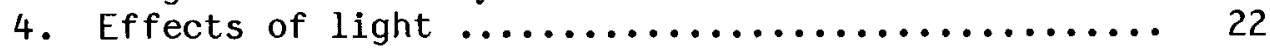

C. Metabolism .............................. 23

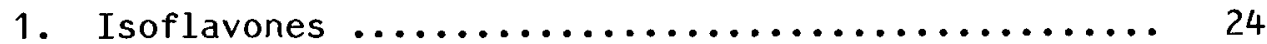

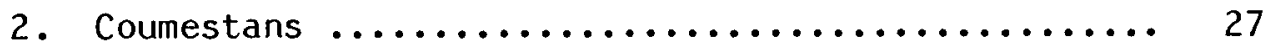

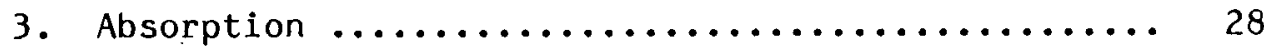

D. Extraction of phytoestrogens $\ldots \ldots \ldots \ldots \ldots \ldots \ldots \ldots \ldots \ldots$

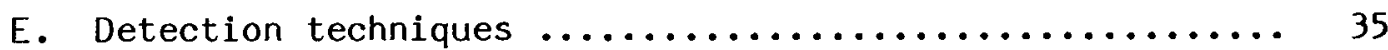

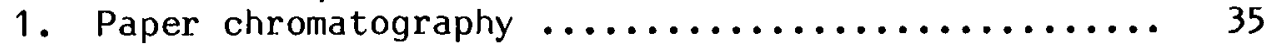

2. Thin-layer chromatography ................ 38

3. Column chromatography/UV spectrophotometry ....... 39

4. High-performance liquid chromatography .......... 41

MATERIALS AND METHODS $\ldots \ldots \ldots \ldots \ldots \ldots \ldots \ldots \ldots \ldots \ldots \ldots \ldots \ldots \ldots \ldots \ldots$

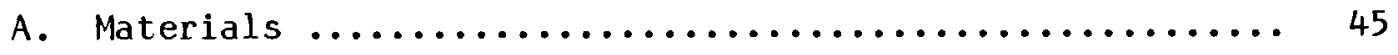

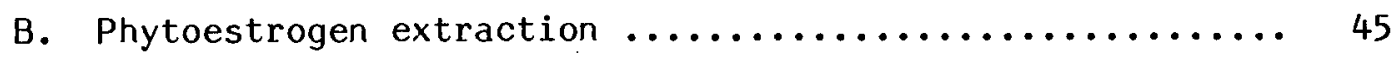

C. Moisture determination ...................... 48

D. Measurement of phytoestrogens by HPLC $\ldots \ldots \ldots \ldots \ldots \ldots . . . \ldots 9$

E. Germination of alfalfa seeds ................... 53

1. Sprouting preparation .................. 53

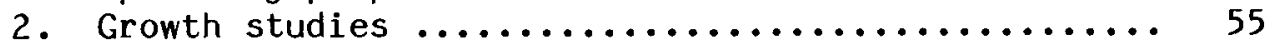

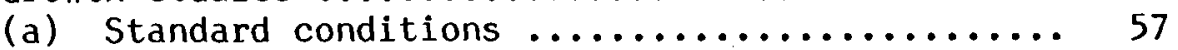

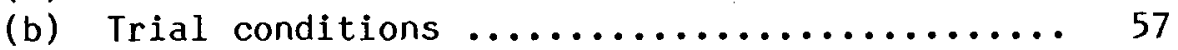

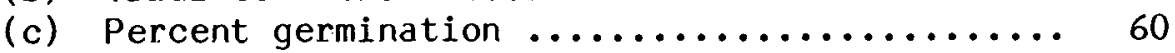

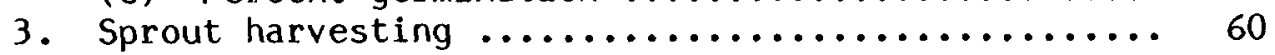

F. Statistical analysis ....................... 62

1. Single factor analysis of variance ............... 62

2. Factorial analysis of variance ............... 62 
RESULTS AND DISCUSSION $\ldots \ldots \ldots \ldots \ldots \ldots \ldots \ldots \ldots \ldots \ldots \ldots \ldots \ldots \ldots \ldots$

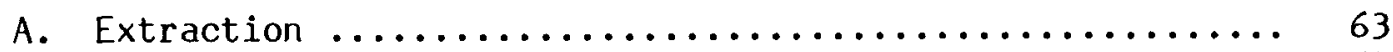

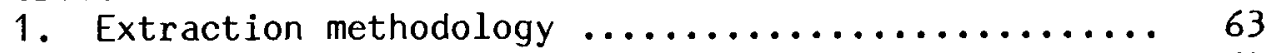

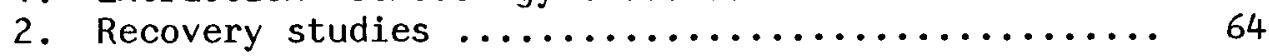

B. High-performance liquid chromatography $\ldots \ldots \ldots \ldots \ldots \ldots \ldots 6$

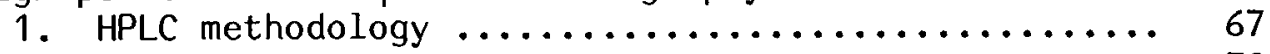

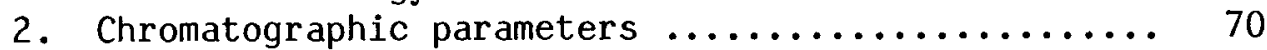

3. Linear regression analysis $\ldots \ldots \ldots \ldots \ldots \ldots \ldots \ldots \ldots \ldots$

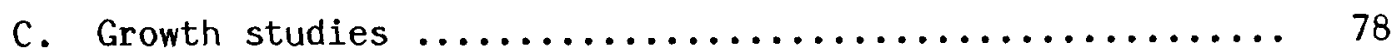

1. Moisture determination ................. 78

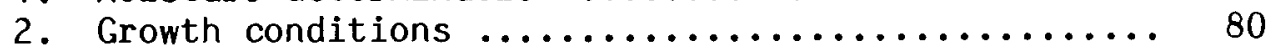

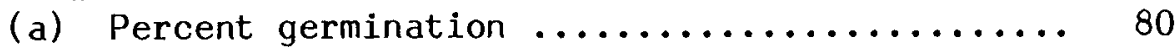

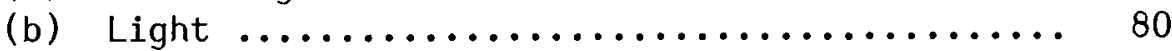

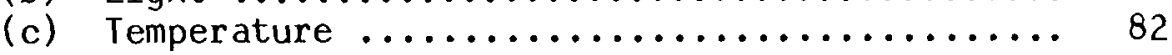

3. Alfalfa sprout development $\ldots \ldots \ldots \ldots \ldots \ldots \ldots \ldots \ldots, 82$

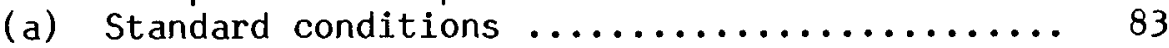

(b) Trial conditions $\ldots \ldots \ldots \ldots \ldots \ldots \ldots \ldots \ldots \ldots \ldots$

D. Phytoestrogen analysis...................... 86

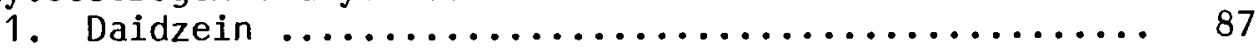

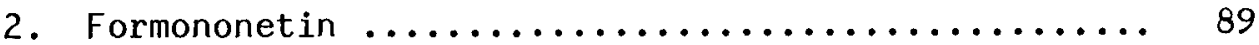

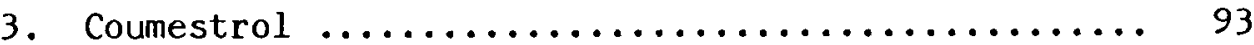

4. General discussion ....................... 98

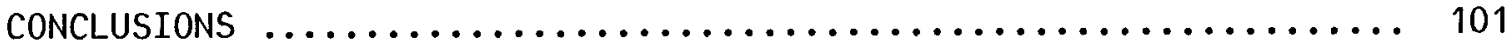

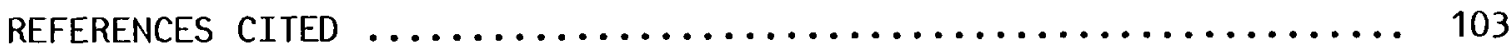

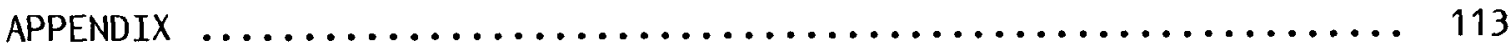




\section{LIST OF FIGURES}

Page

Figure 1. Structural formulas for steroid estrogens ......... 4

Figure 2. Structural formulas for estrogenic isoflavones ...... 9

Figure 3. Structural formulas for estrogenic coumestans ....... 10

Figure 4. Proposed biosynthetic pathway of isoflavones

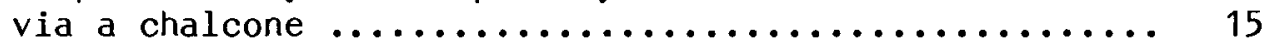

Figure 5. Possible biogenetic relationships among isoflavonoids .......................... 20

Figure 6. Metabolism of some estrogenic isoflavones in sheep .... 25

Figure 7. Germination and development of alfalfa seed to

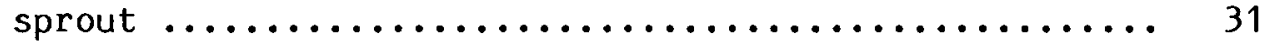

Figure 8. Phytoestrogen extraction scheme for alfalfa sprouts ... 46

Figure 9. Retention time and peak width at base measurements ... 51

Figure 10. Rack used for draining sprouting jars ........... 54

Figure 11. Alfalfa sprouts growing under fluorescent lamps (light treatment) and under aluminum foil covers (dark treatment) .......................... 56

Figure 12. Draining of alfalfa sprouts prior to sampling and

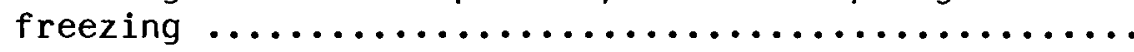

Figure 13. HPLC chromatogram of phytoestrogen standards.

Peaks: $D=$ daidzein, $F=$ formononetin, $C=$ coumestrol ..... 73

Figure 14. HPLC chromatogram of phytoestrogen standards extract. Peaks: $D=d a i d z e i n, F=$ formononetin,

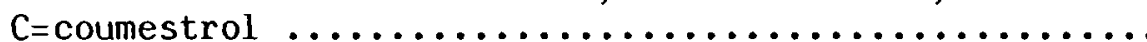
74

Figure 15. HPLC chromatogram of alfalfa extract spiked with phytoestrogen standards prior to extraction. Peaks: $D=$ daidzein, $F=$ formononetin, $C$ =coumestrol ..... 75

Figure 16. HPLC chromatogram of alfalfa extract (Treatment $X$ ) Peaks: $D=$ daidzein, $F=$ formononetin, $C=$ coumestrol ..... 76 
Figure 17. Effect curve of growth and light $(G \times L)$ interaction for daidzein accumulation in alfalfa sprouts ........ 91

Figure 18. Effect curve of light and volume $(L \times V)$ interaction for daidzein accumulation in alfalfa sprouts ........ 92

Figure 19. Effect curve of growth and light $(G \times L)$ interaction for formononetin accumulation in alfalfa sprouts ..... 94

Figure 20. Effect curve of growth and frequency $(G \times F)$ interaction for formononetin accumulation in alfalfa

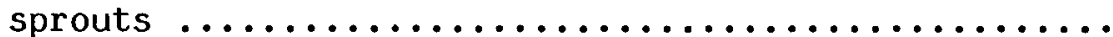

Figure 21. Effect curve of growth and light $(G \times L)$ interaction for coumestrol accumulation in alfalfa sprouts ........ 


\section{LIST OF TABLES}

Table 1. Relative binding affinity of some naturally occurring estrogens for mammalian estrogen receptors ................................ 11

Table 2. Standard growth conditions for alfalfa sprouts ...... 58

Table 3. Trial growth conditions for alfalfa sprouts ........ 59

Table 4. Recovery of phytoestrogens using developed extraction method

Table 5. Retention times $\left(t_{R}\right)$, capacity factors $(k)$, separation factors $(\alpha)$ and resolution $\left(R_{S}\right)$ of selected phytoestrogens on MicroPak $\mathrm{MCH}-10$ using linear gradient elution as described ............. 71

Table 6. Moisture content of alfalfa sprouts grown under standard and trial conditions ................ 79

Table 7. Phytoestrogen contents of alfalfa sprouts grown under standard and trial conditions ............ 88

Table 8. Significance of calculated F-values from germination factors and factor interactions for phytoestrogen accumulation as determined by factorial analysis of variance 


\section{LIST OF APPENDICES}

Page

Appendix A-1. Analysis of variance for daidzein content of alfalfa sprouts from Treatments AA to

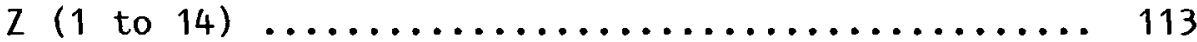

Appendix A-2. Analysis of variance for daidzein content of alfalfa sprouts from Treatments AA to Z ( 1 to 14 without $\mathrm{C}-3$ or $\mathrm{Y}-1$ values) $\ldots \ldots \ldots \ldots \ldots \ldots \ldots \ldots \ldots . \ldots 114$

Appendix B. Analysis of variance for formononetin content of alfalfa sprouts from Treatments $A A$ to $Z$

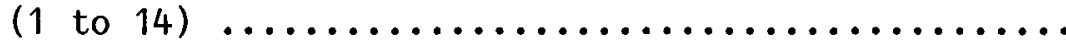

Appendix C. Analysis of variance for coumestrol content of alfalfa sprouts from Treatments AA to $Z$

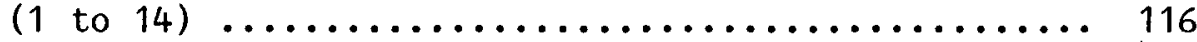

Appendix D. Factorial analysis of variance for daidzein, formononetin and coumestrol contents of alfalfa sprouts from Treatments $A$ to $Z$............... 117 


\section{ACKNOMLEDGEMENTS}

I wish to express my deep appreciation to Dr. John Vanderstoep for his patience and support, moral as well as financial, throughout the course of this research project. I also wish to thank the members of the committee, Dr. Shuryo Nakai, Dr. Brent Skura and Dr. Bob Bose, for their suggestions and assistance.

Finally I would like to thank my families, both Duffek and Yada, for their constant support and understanding during the past several years, and a special thanks to my husband Rickey for his invaluable criticism, inspiration and encouragement. 


\section{INTRODUCTION}

Several plants of the Leguminosae (also known as Fabaceae) family contain isoflavonoids which are estrogenically active in diverse animal species (Wong, 1975). Two main groups, the isoflavones and the coumestans, comprise the majority of these "phytoestrogens".

Alfalfa, clover and soybeans are important sources of phytoestrogens in the feeds of grazing and domestic animals. Soybeans and soybean products as well as alfalfa sprouts are a potential dietary source of phytoestrogens for humans. However, the effect on man of longterm dietary exposure to these plant constituents is as yet unknown.

The estrogenic isoflavones and coumestans can accumulate in plants in apparent response to microbial infestation and have been shown to be toxic to invading fungi and bacteria (Naim et al., 1974; Lyon and Wood, 1975). Lookhart et al. (1979a) demonstrated that the phytoestrogen coumestrol accumulated during the germination of soybeans to soy sprouts, possibly also as a result of fungal infection.

Isoflavones and coumestrol occur naturally as water-soluble glycosides but are hydrolyzed to aglycones in infected plants (0lah and Sherwood, 1973). Many methods previously used to extract phytoestrogens from plant tissues are only useful for qualitative purposes, because they primarily isolate the alcohol-soluble aglycones. In order to quantitate the estrogenic potential of a food or feed, both aglycone and glycoside forms of the isoflavonoids must be extracted.

A variety of chromatographic techniques have been developed to detect and measure these estrogenic compounds. Thin-layer chromatography 
has predominated, however, several high-performance liquid chromatography (HPLC) systems have recently been demonstrated to provide the means for rapid, quantitative analysis of flavonoid mixtures (Carlson and Dolphin, 1980; Murphy, 1981; Daigle and Conkerton, 1982; Eldridge, 1982a). The application of HPLC to resolve a mixture of estrogenic isoflavones and coumestans in actual plant extracts requires further study.

The object of the present research was: first, to develop an extraction procedure for alfalfa with high extraction efficiencies for the most predominant phytoestrogens, coumestrol, daidzein and formononetin; secondly, to develop an HPLC system to resolve these compounds for isolation and quantitation; and thirdly, to apply these techniques to study the effect of selected sprouting conditions (growth period, light duration, rinse volume and rinse frequency) on the accumulation of phytoestrogens in alfalfa sprouts. 


\section{LITERATURE REVIEW}

\section{A. NATURE AND DISTRIBUTION OF PHYTOESTROGENS}

Estrogens can be defined as steroid hormones which are essential to the normal sexual development of the female mammal and are secreted primarily by the ovary (Prosser, 1973). The principal estrogenic hormones in the circulation are estradiol, estrone and estriol, all incorporating the 18 carbon steroid nucleus as shown in Figure 1 . The term estrogen can also be more broadly used to describe any substance which will produce characteristics of estrus, a series of changes in the female reproductive system associated with ovulation (Prosser, 1973).

The first reports of estrogenic substances being present in plants were made in 1926 by Loewe, Dohrn et al., and Fellner ${ }^{1}$. Since that time numerous workers have examined various plants for their ability to induce estrus in animals, and have attempted to identify these plant or phytoestrogens. Bennetts et al. (1946) reported that a strain of subterranean clover (Trifolium subterraneum L.) was responsible for reproductive abnormalities of grazing sheep in western Australia. Bradbury and White (1951) subsequently demonstrated the presence of two isoflavones, genistein (5,7,4'-trihydroxyisoflavone) and formononetin (7-hydroxy-4'-methoxyisoflavone), in subterranean clover extracts. Biggers and Curnow (1954) showed that genistein was estrogenically active in mice, and therefore could be a factor affecting normal reproduction if consumed by other animals. Cheng et al. (1955) determined that isoflavones occurring naturally in subterranean and red clovers,

\footnotetext{
${ }^{1}$ As cited by Bradbury and White (1954).
} 
Figure 1. Structural formulas for steroid estrogens.

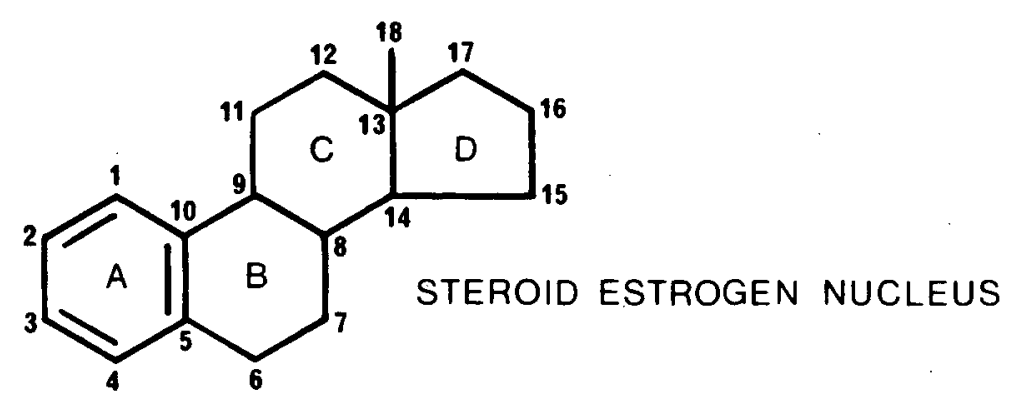<smiles>CC12CCC3c4ccc(O)cc4CCC3C1CCC2O</smiles><smiles>CC12CCC3c4ccc(O)cc4CCC3C1C[C@H](O)C2O</smiles><smiles>CC12CCC3c4ccc(O)cc4CCC3C1CCC2=O</smiles> 
including daidzein (7,4'-dihydroxyisoflavone), biochanin A (5,7-dihydroxy-4'-methoxyisoflavone), formononetin and genistein, have estrogenic activity in mice.

Over 40 species of plants which showed some estrogenic potency were reported by Bradbury and White (1954). The common forages alfalfa (Medicago sativa L.) and ladino clover (Trifolium repens L.) were at that time listed as non-estrogenic plants. However, later experiments established that both alfalfa and ladino clover displayed significant estrogenic activity (Pieterse and Andrews, 1956; Engle et al., 1957). The isolation and partial characterization of the ladino clover estrogen(s) revealed that the major estrogenic component was not an isoflavone, but a benzofurocoumarin derivative which was named coumestrol (Bickoff et al., 1957; Bickoff et al., 1958). Coumestrol (7,12-dihydroxycoumestan) was subsequently detected in other leguminous forage plants (Lyman et al., 1959) and reported as the dominant estrogen in alfalfa (Livingston et al., 1961).

Reports of estrogenic activity were based primarily on the measurement of uterine enlargement of ovariectomized or immature female mice or rats after treatment with plant extracts (Biggers and Curnow, 1954; Cheng et al., 1955; Pieterse and Andrews, 1956; Bickoff et al., 1957; Bickoff et al., 1958; Lyman et al., 1959). An earlier detection method, known as the Allen-Doisy test, was based on the evidence of cornified vaginal epithelial cells in the test animal in response to estrogen stimulation (Bickoff et al., 1969). Both of these assays have been subject to criticisms (Verdeal and Ryan, 1979), and misleading results are possible due to the method of treatment and the metabolism 
of the compounds being studied. Nevertheless, the organ and tissue changes induced by phytoestrogens are observed as the characteristics of normal estrus induced by endogenous estrogens in rats and mice.

An endogenous estrogen, such as estradiol-17 $\beta$, exerts its effect on the uterus by binding to a specific protein receptor in the cytoplasm of the uterine cells. It is then transported into the nucleus while still bound to the protein receptor (Gorski et al., 1968). Gorski and coworkers (1968) further hypothesized that this estrogen-protein complex triggers messenger RNA synthesis, which was later established to be necessary for synthesis of a specific estrogen induced protein (IP) (Gorski et al., 1975). Only those compounds which will bind to the uterine estrogen receptor proteins can regulate the synthesis of this induced protein (Ruh et al., 1973). The estrogen estradiol-17 $\beta$ was observed by Ruh et al. (1973) to be most effective in inducing protein synthesis, followed by the other endogenous estrogens estriol and estrone.

Another more immediate effect of estrogen administration is the imbibition of water by the uterine tissues, resulting in enlargement of the uterus (Notebloom and Gorski, 1963). The measurement of increased uterine weight and size in determining estrogenic activity is thus based on a combination of induced protein synthesis and water uptake by the uterine tissues.

Studies on the phytoestrogens have shown that these compounds can also complex with the estrogen-protein receptors in the uterine cytosol, and in turn induce protein synthesis and water imbibition (Notebloom and Gorski, 1963; Shemesh et al., 1972; Kitts, 1974; Martin et al., 1978). 
In order to be recognized by estrogen receptors in target cells, it is believed that a compound must meet specific structural requirements. Plant isoflavones and coumestans that demonstrate estrogenic activity possess a varying degree of structural similarity to estrogenic steroids. The high binding affinity of steroids is related to the presence of at least one aromatic ring, the presence and position of a phenolic hydroxyl group on this ring, and the nature and position of oxygen functions on ring $D$.

More specifically, a free phenolic hydroxyl at $\mathrm{C}-3$ on the aromatic ring $A$ is considered to be essential for receptor binding (Hähnel et al., 1973). Busetta et al. (1977) reported that the pentagonal ring $D$ of an estrogen steroid cannot be modified without an important decrease in binding affinity to receptor proteins. Hähnel et al. (1973) demonstrated that the highest binding affinity for a steroid occurs with an alcoholic hydroxyl on C-17 ( $r$ ing D) in the $\beta$ configuration and a phenolic hydroxyl on $\mathrm{C}-3$ of an unsaturated ring $\mathrm{A}$, as in estradiol-17B (Figure 1). The attachment of the estrogenic steroid to the binding site may depend on these two hydrogen bonding centres being about $10 \AA$ apart (Hähnel et al., 1973). Binding affinity is decreased upon removal or methylation of the C-3 hydroxyl, by the addition of other oxygen functions on ring $D$ or alkyl groups on ring $A$, and by further unsaturation of the steroid nucleus (Korenman, 1969; Shutt and Cox, 1972; Hähnel et al., 1973).

The structural similarity among estrogenic isoflavones, coumestans and estrogenic steroids is evident by comparing Figures 1, 2 and 3 . The important aromatic ring $A$ with a phenolic hydroxyl group at $\mathrm{C}-3$ ( $\mathrm{C}-7$ in 
isoflavone and coumestan numbering) is common to all structures (with the exception of the isoflavone prunetin). In addition, these isoflavones and coumestans have an oxygen function (either a hydroxyl or methoxyl group) at opposite ends of the molecule. Coumestrol and genistein are able to significantly compete for uterine cytosol binding sites due largely to the presence of two hydroxyl groups positioned at opposite ends of the molecules (Shemesh et al., 1972). Bickoff et al. (1969) reviewed the estrogenic activity of coumestrol and closely related compounds and reported that the furan ring $(C)$ was an important factor contributing to the estrogenicity of some coumestans; opening of this ring greatly decreased estrogenic activity. 0verall, the binding affinity of isoflavones and coumestans would be expected to be less than that of steroid estrogens because of additional substituent groups and a more unsaturated nucleus.

The relative binding affinity of an estrogenic compound to uterine receptors has been reported to parallel the uterotrophic properties of that compound Korenman, 1969; Shemesh et al., 1972; Ruh et al., 1973; Martin et al., 1978). Results from competitive binding assays carried out with uterine cytosol (Shutt and Cox, 1972; Verdeal et al., 1980) and human tumor cell estradiol receptors (Martin et al., 1978) support this relationship in terms of the order of estrogenic potency (Table 1). However, relative binding affinity values indicate a much higher potency for the non-steroid estrogens than do in vivo uterine weight assays (Bickoff et al., 1962). Presumably, the differences are due to species variation and metabolic effects, but it is not yet clear which method of determining estrogenic potency is most applicable to humans (Verdeal and Ryan, 1979). 
Figure 2. Structural formulas for estrogenic isoflavones.

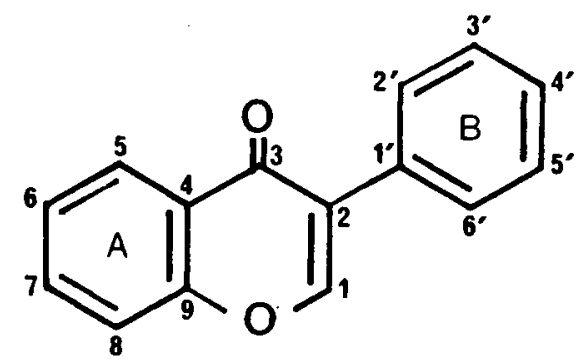

ISOFLAVONE NUCLEUS<smiles>COc1ccc(-c2coc3cc(O)cc(O)c3c2=O)cc1</smiles>

BIOCHANIN A<smiles></smiles><smiles>COc1ccc(-c2coc3cc(O)ccc3c2=O)cc1</smiles>

FORMONONETIN<smiles>O=c1c(-c2ccc(O)cc2)coc2cc(O)cc(O)c12</smiles>

GENISTEIN<smiles>COc1ccc(-c2coc3cc(O)cc(O)c3c2=O)cc1O</smiles><smiles>COc1cc(O)c2c(=O)c(-c3ccc(O)cc3)coc2c1</smiles> 
Figure 3. Structural formulas for estrogenic coumestans.

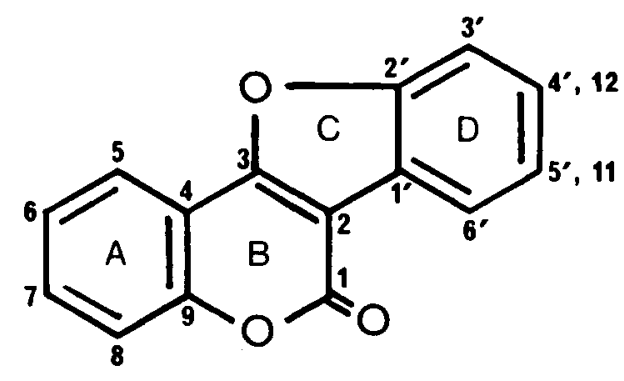

COUMESTAN NUCLEUS<smiles>CO[Pb](C)(C)OC(C)=O</smiles><smiles>COc1ccc2c(c1)oc1c3ccc(O)cc3oc(=O)c21</smiles>

4"-METHOXYCOUMESTROL<smiles>O=c1oc2cc(O)ccc2c2oc3cc(O)cc(O)c3c12</smiles>

REPENSOL 
Table 1. Relative binding affinity of some naturally occurring estrogens for mammalian estrogen receptors.

\begin{tabular}{l|c|c|c}
\hline \multirow{2}{*}{ Estrogens } & \multicolumn{3}{|c}{ Receptors } \\
\cline { 2 - 4 } & $\begin{array}{c}\text { Rat uterine } \\
\text { cytosol }\end{array}$ & $\begin{array}{c}\text { Sheep uterine } \\
\text { cytosol }\end{array}$ & $\begin{array}{c}\text { Human cancer cell } \\
\text { line MCF-7 }\end{array}$ \\
estradiol-17B & 100 & 100 & 100 \\
coumestrol & 4.9 & 5 & 10 \\
genistein & 1.3 & 0.9 & 2 \\
daidzein & 0.09 & 0.1 & - \\
formononetin & -4 & $<0.01$ & - \\
biochanin A & 0.07 & - & 0.01 \\
\hline
\end{tabular}

${ }^{\mathrm{l}}$ From Verdeal et al. (1980).

${ }^{2}$ From Shutt and Cox (1972).

${ }^{3}$ From Martin et al. (1978).

${ }^{4}$ Not determined. 
Very few naturally occurring isoflavones, coumestans or related flavonoids have been reported in the literature as demonstrating estrogenic activity, aside from those already mentioned. Flavonoids are ubiquitous constituents of green plants, and characteristic flavonoid types are often encountered only in particular plant groups (Markham, 1982). Isoflavones are flavonoids generally restricted to one subfamily of the Leguminosae (Harborne et al., 1975); within this subfamily are the common forage crops alfalfa and clover, as well as soybeans. Wong (1975) listed over 70 isoflavones and 40 isoflavone glycosides which have been isolated from plants.

In addition to the reported estrogenic activities for genistein, daidzein, formononetin and biochanin A, Cheng et al. (1955) found that genistin, the glucoside of genistein, was equally as estrogenic in mice as genistein itself. Bradbury and White (1954) demonstrated that prunetin (5,4'-dihydroxy-7-methoxyisoflavone) was estrogenic when injected in mice. The isoflavone pratensein (5,7,3'-trihydroxy-4'-methoxyisoflavone) isolated from clovers by Wong (1963) was shown to be slightly less estrogenic in mice than biochanin A (Flux et al., 1964). Another isoflavone which has been isolated as an important component of soybeans (Naim et al., 1973), namely glycitein (7,4'-dihydroxy-6-methoxyisoflavone), has not been examined for estrogenic activity.

Coumestans are biogenetically related to isoflavones and have been isolated primarily from alfalfa and ladino clover (Bickoff et al., 1969). Of the naturally occurring coumestans, Bickoff et al. (1960) reported significant estrogenic activity for coumestrol and lesser activity for 4'-methoxycoumestrol. Livingston et al. (1964) demonstrated that repensol (7,10,12-trihydroxycoumestan) had comparable 
estrogenic activity to coumestrol in mice, while another coumestan, trifoliol (7,10-dihydroxy-12-methoxycoumestan) was relatively inactive. There are no reports in the literature citing estrogenic activity of other coumestans identified in alfalfa and clover, namely lucernol, sativol, medicagol, 3'-methoxycoumestrol or 7-hydroxy-11,12-dimethoxycoumestan. A 7-monoglycoside of coumestrol has, been isolated from alfalfa roots and leaves (0lah and Sherwood, 1971), however, its estrogenic activity has not been evaluated to date.

Presumably because of the very real importance of leguminous forage crops to livestock, and the observed estrogenic effects of several isoflavones and coumestrol isolated from these crops, research into phytoestrogens has focussed primarily on those specific compounds. 0ther classes of flavonoids appear to be relatively inactive in comparison (Verdeal and Ryan, 1979).

Research into identification and quantification of phytoestrogens in legumes has recently expanded to include: common vegetables, legumes and grains (Knuckles et al., 1976); leaf protein concentrates from alfalfa (Knuckles et al., 1976); and other food products prepared from soybeans (Lookhart et al., 1979a; Eldridge, 1982b; Murphy, 1982) or Bengalgram pulses (Dziedzic and Dick, 1982), all for use by humans. Samples of alfalfa and soybean products were found to contain markedly higher quantities of coumestrol than most non-leguminous food plants (Knuckles et al., 1976). Murphy (1982) reported a significant carryover of genistein, daidzein and their respective glucosides from soybeans into processed soy protein products. The significance of the levels of phytoestrogens in these foods is not yet understood, and must await 
further studies on how phytoestrogens are metabolized in man (Verdeal and Ryan, 1979).

\section{B. BIOSYNTHESIS AND ACCUMULATION}

\section{Biosynthesis}

The common biosynthetic pathway for the basic $c_{6}-C_{3}-c_{6}$ skeleton of all flavonoids involves the condensation of separate ring intermediates to form a chalcone (Grisebach, 1959). As shown in Figure 4, the two rings ( $A$ and $B$ ) of the chalcone have different origins. Ring $A$ is formed by the condensation of three acetate units, while ring $B$ and the three carbon linkage arise from a conversion of phenylalanine to an activated cinnamic acid (Hahlbrock and Grisebach, 1975). Studies using labelled ${ }^{14} \mathrm{C}$ have shown that other less effective precursors of ring $B$ can include tyrosine and p-coumaric acid derived from shikimic acid. Ribéreau-Gayon (1972) reviewed the common synthesis of these aromatic compounds from glucose via the shikimic acid pathway in plants.

Ring closure of the chalcone leads to the formation of a flavone where ring $B$ is positioned at carbon-1 (Figure 4). An aryl migration has been shown to occur (Grisebach and Doerr, 1960) at, or after, the chalcone stage where ring B migrates from $C-1$ to $C-2$ for synthesis of an isoflavone.

In the formation of an isoflavone glycoside from the corresponding aglycone, the sugar moiety is transferred via a glycosyl transferase (Hahlbrock and Grisebach, 1975). Naim et al. (1974) established that the glycosidic isoflavones in soybeans were 7-0-glucosides. Glycosylation serves to convert the flavonoid into a less reactive and more water soluble form, for storage in the cell vacuole (Markham, 1982). 
Figure 4. Proposed biosynthetic pathway of isoflavones via a chalcone ${ }^{1}$.

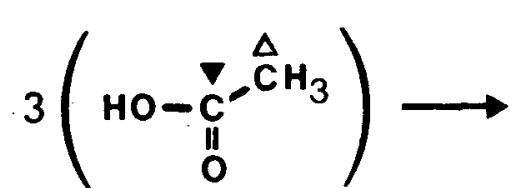
ACETATE
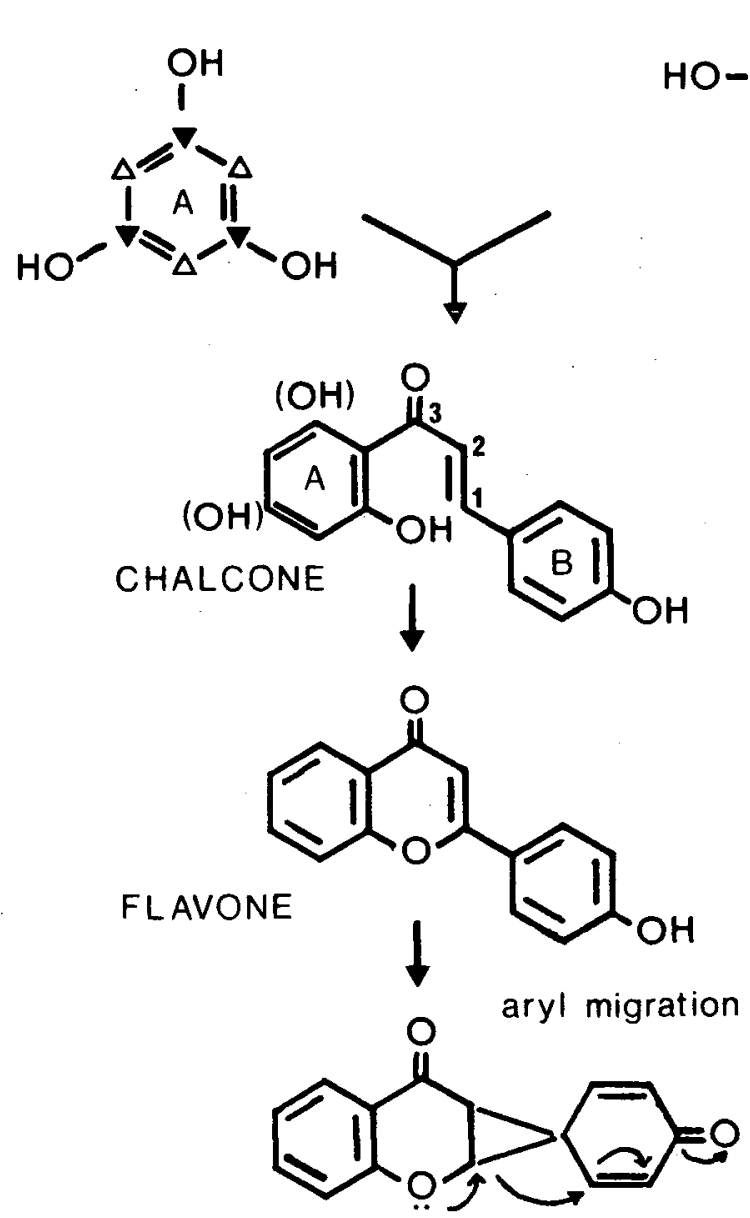

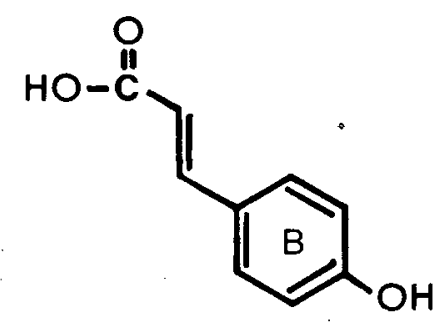

P-COUMERIC ACID

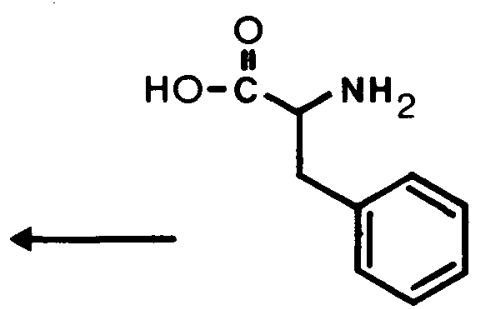

PHENYLALANINE

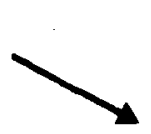

${ }^{1}$ Adapted from Hahlbrock and Grisebach (1975).

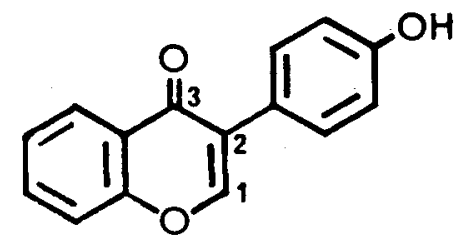

ISOFLAVONE 
Grisebach and Barz (1963a; 1963b) further demonstrated that the biosynthesis of coumestrol was analogous to that of the isoflavones, rather than to that of the coumarins. Coumestans as a group represent the highest oxidation level possible for the isoflavonoid skeleton (Wong, 1975). The isoflavone daidzein was shown to be a wellincorporated precursor for coumestrol, whereas formononetin with its methyl group intact was a more efficient precursor of 4'-methoxycoumestrol (Dewick and Martin, 1979a). The authors proposed that methylation could occur during the aryl migration step associated with isoflavonoid biosynthesis; a 4'-methoxyisoflavone would then be more readily converted to a 4'-methoxycoumestan.

\section{Effects of microbial infection}

Hanson and coworkers (1965) extensively reviewed the variation in coumestrol content of alfalfa and reported that coumestrol content was influenced by stage of growth, variety and location. 0ther studies reviewed by Bickoff et al. (1969) and Livingston (1978) noted increased levels of coumestrol as alfalfa and clover hays matured, and variations in coumestrol content depending on the geographical location where alfalfa was grown.

These variables affecting coumestrol accumulation were observed to be ultimately related to disease incidence in the plants (Hanson et al., 1965). Furthermore, 99 percent of the variation in coumestrol content was determined to be non-genetic. Advancing maturity in plant growth is commonly associated with increased disease incidence; differences in coumestrol content among varieties may be due to varietal differences in 
resistance to foliar pathogens, and certain geographical areas are often associated with less foliar disease (Bickoff et al., 1969).

Bickoff et al. (1967) studied the effect of the common leafspot organism Pseudopeziza medicaginis on coumestan and flavone content of two alfalfa varieties. The workers found that there was a significant increase in coumestrol over a 14 day growth period which correlated with the visible extent of plant infection. Several other coumestans (sativol, 3'-methoxycoumestrol, medicagol and $4^{\prime}$-methoxycoumestrol) as well as 7,4'-dihydroxyflavone were also shown to accumulate in the infected plants.

Loper et al. (1967) found that coumestrol levels in healthy alfalfa tissue averaged less than $3 \mathrm{ppm}$ whereas diseased leaflet areas could contain 2,600 ppm coumestrol. However, Francis and Millington (1965a) reported an increase in coumestrol in maturing medic species even in the absence of fungal pathogens. Stuthman et al. (1966) examined several species of alfalfa including Medicago sativa L. which contained levels of coumestrol up to $26 \mathrm{ppm}$ but had no obvious fungal pathogens. In contrast to Hanson et al. (1965), these workers suggested that genetic variation was implicated in the coumestrol concentrations among alfalfa cultivars. Selection of alfalfa cultivars for resistance to the common leafspot organism by Loper et al. (1967) resulted in significantly lowered coumestrol contents.

Coumestrol was shown to accumulate in alfalfa in direct response to infection by several pathogenic fungi (Sherwood et al., 1970). These workers found that coumestrol was not translocated from infected areas to other parts of the plant, which indicated that coumestrol synthesis 
could be carried out independently at the site of infection. Injury of alfalfa leaves simply by mechanical means did not result in coumestrol accumulation. Increased coumestan and flavone levels found in diseased white clover (Wong and Latch, 1971; Saba et al., 1974) provided further support for the hypothesis of pathogen-induced flavonoid accumulation.

Germination of legumes has been shown to cause a marked increase in coumestrol compared to the ungerminated bean or seed (Knuckles et al., 1976; Lookhart et al., 1979b; Murphy, 1982). Lookhart et al. (1979a) associated the highest coumestrol concentration with those soybean sprouts most noticeably infected, but could not identify the infecting organisms. The authors also noted a marked reduction in coumestrol concentration when soybean sprouts were rinsed periodically with distilled water ( 4 times daily) during germination as compared to unrinsed controls. It was suggested that the rinsing served to cleanse the beans, thus limiting infection.

Pathogen-induced accumulation of the estrogenic isoflavones in legumes has also been observed by numerous workers (Olah and Sherwood, 1971 and 1973; Saba et al., 1974; Biggs, 1975). Earlier studies reported wide varietal differences in isoflavone contents of forages, and large variations in isoflavone patterns between cultivars grown in separate geographical regions (Beck, 1964; Francis and Millington, 1965b; Sachse, 1974). Again, the relationship between disease and flavonoid accumulation, although it had not yet been recognized for isoflavones as it had for coumestans, may have played a role. 
Plants have been shown to accumulate antimicrobial compounds, known as phytoalexins, in response to infection by pathogenic fungi and bacteria (Hare, 1966; Kuć, 1972; Pueppke and Van Etten, 1974). Many phytoalexins are flavonoids, including those produced by plants of the Leguminosae family (McClure, 1975). The most abundant classes of isoflavonoid phytoalexins produced by leguminous plants are the pterocarpans and 2'-hydroxyisoflavans (Dewick and Martin, 1979b). As indicated in Figure 5, the isoflavans represent the most reduced group of isoflavonoids, probably derived from the pterocarpans by reductive ring opening (Wong, 1975).

The observation that coumestans and isoflavones accumulate in leaf tissue in response to microbial infection is presumably related to the microbially induced accumulation of phytoalexins. The difficulty in studying isoflavonoid biosynthesis in microbially infected plants, however, is in separating the metabolic processes of the plant from those of the infecting organism (Dewick and Martin, 1979b).

Sherwood et al. (1970) extensively studied the effect of fungal disease and other stress on coumestrol accumulation in alfalfa. These workers demonstrated that fungi do not independently synthesize flavonoid compounds, but likely produce enzymes or metabolites that enter the infected plant tissue and cause coumestrol and other flavonoid aglycones to be released.

olah and Sherwood (1971) were only able to isolate flavonoid glycosides from healthy alfalfa plant tissue, but during the development of fungal infection, flavonoid aglycones were detected in increasing concentrations. It was suggested that infection could have impaired 
Figure 5. Possible biogenetic relationships among isoflavonoids. ${ }^{1}$

$\left.2\right|_{O H} ^{O}$

CHALCONES

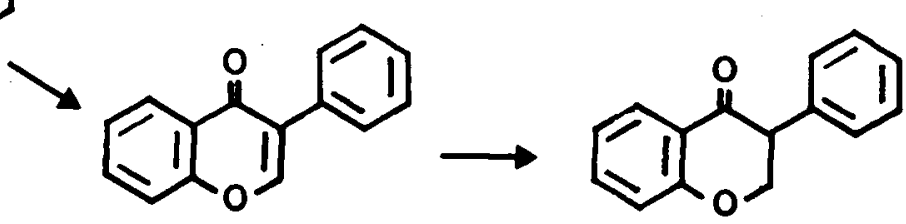

ISOFLAVONES
ISOFLAVONONES

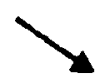

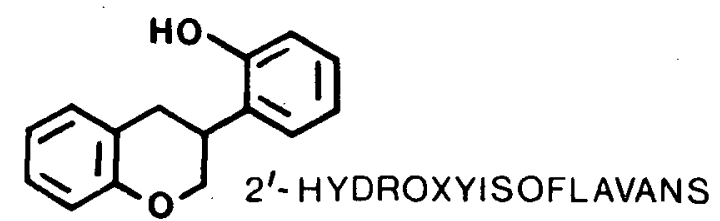

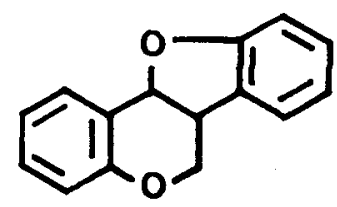

PTEROCARPANS

\footnotetext{
${ }^{1}$ Adapted from Wong (1975).
}

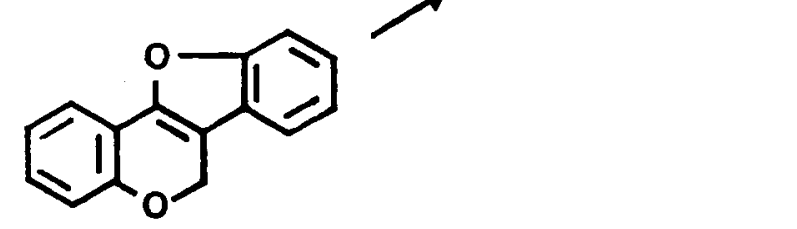

DEHYDROPTEROCARPANS

$\downarrow$

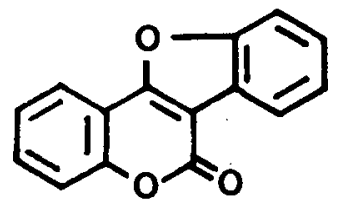

COUMESTANS 
glycosylation at the final stages of flavonoid biosynthesis or more likely, that the infecting organism via a glycosidase enzyme caused release of aglycones from glycosides. In a subsequent study 0lah and Sherwood (1973) found that $\beta$-glucosidase activity, probably of fungal origin, increased during infection. In the plant's disease resistance mechanism the aglycones released by fungal glycosidase activity may in turn inhibit further fungal growth (McClure, 1975).

Additional support for the glycosidase theory was provided when the concentrations of flavonoid glycosides did not decrease during the infection but rather remained the same or increased (0lah and Sherwood, 1971). Moreover, the increase in enzyme activity had been shown to precede the appearance of the aglycones (0lah, 1970) ${ }^{3}$, implying that these two events were closely related. The increased levels of both glycosides and aglycones suggests that normal pathways of flavonoid glycoside synthesis are stimulated during fungal infection (0lah and Sherwood, 1973).

\section{Fungitoxic activity}

Lyon and Wood (1975) demonstrated that coumestrol accumulated in bean leaves infected with Pseudomonas spp. and that the coumestrol acted like a phytoalexin by inhibiting the growth of these bacterial pathogens. Unlike phytoalexins, coumestans do not appear to have fungitoxic activity. Screening tests have been performed with coumestrol, 4'-methoxycoumestrol, medicagol and trifoliol for mycelial

\footnotetext{
${ }^{3}$ As cited by 0lah and Sherwood (1971).
} 
growth inhibition of numerous pathogenic fungi, with negative results (Bickoff et al., 1969; Perrin and Cruickshank, 1969). The fungal-induced accumulation of coumestans may then simply reflect by-product or precursor formation for the production of anti-fungal phytoalexins via a common biosynthetic pathway (Wong and Latch, 1971; Olah and Sherwood, 1973; McClure, 1975; Dewick and Martin, 1979a).

In contrast, Naim et al. (1974) demonstrated that the isoflavones daidzein, genistein and glycitein exert pronounced fungistatic activity. The corresponding methylated isoflavones showed a significantly higher fungistatic activity, whereas the 7-0-glucosides had only limited activity. These findings suggest that the more lipophilic compounds (methylated $>$ hydroxylated $>$ glycosylated) would pass more easily through the cytoplasmic membranes of the fungus (Naim et al., 1974).

Thus the accumulation of these fungitoxic isoflavones in fungally infected plants may have a greater role to play in pathogen resistance than do coumestans. A better understanding of the metabolic pathways involved in isoflavonoid biosynthesis, both in healthy and diseased plants, will be needed before the mechanism of phytoalexin induction can be explained (Wong, 1975).

\section{Effects of light}

In the studies by Hanson et al. (1965) no correlation could be found between light intensity and coumestrol content of alfalfa in field tests. The majority of reported research on the effect of light on flavonoid accumulation in plants has pertained to anthocyanins, and is 
reviewed by McClure (1975). The observed effects were reported to vary according to the plant and anthocyanins under study and no generalizations were made regarding the role of light in flavonoid formation.

Rossiter and Beck (1967) found that light was not essential for estrogenic isoflavone formation in clover. Substantial concentrations of formononetin, genistein and biochanin A were detected in leaves of plants grown in daylight and also for those grown in complete darkness. Some stimulation of isoflavone synthesis was attributed to high intensity light, however, the authors concluded that light environment did not markedly affect isoflavone levels in clover.

However, light can influence germination, either via stimulation or inhibition dependng on the light requirements of particular seeds (Mayer and Poljakoff-Mayber, 1975). The different spectral ranges of light can also have quite different effects on germination, as demonstrated by inhibition with light below $290 \mathrm{~nm}$ and promotion with light in the visible range $400-700 \mathrm{~nm}$, especially with red light (Mayer and Poljakoff-Mayber, 1975).

\section{c. METABOLISM}

Although a biosynthetic relationship exists between coumestans and isoflavones, the metabolic pathways of these two groups of flavonoids appear to be different (Bickoff et al., 1969). There are also differences among animal species in their metabolism of estrogenic isoflavones which can profoundly affect the estrogenic potency of particular isoflavones (Lindner, 1967; Shutt, 1976). 
As mentioned previously, early studies to evaluate estrogenicity of plant compounds were primarily carried out using rats and mice as the test animal species. Both in vivo uterine weight assays (Bradbury and White, 1954; Bickoff et al., 1962) and in vitro cytosol binding studies (Verdeal et al., 1980) indicated that in rats coumestrol was the most potent phytoestrogen, followed by genistein, daidzein, biochanin A and formononetin in order of decreasing potency.

\section{Isoflavones}

Both genistein and formononetin were isolated from the subterranean clover (Bradbury and White, 1954) which had been implicated in infertility of "clover disease" in grazing sheep (Bennetts et al., 1946). Since formononetin did not demonstrate significant estrogenic activity in rats or mice, it was thought that genistein was the major factor responsible for clover disease (Biggers and Curnow, 1954).

Millington et al. (1964), however, correlated the estrogenic activity of subterranean clover strains with the amount of formononetin in the clover, not with its genistein content. The finding that formononetin was a more potent estrogen than genistein, was shown to be due to a different metabolic pathway for formononetin in sheep (Shutt and Braden, 1968).

A comparison of circulating isoflavones in sheep plasma to the isoflavone composition of clover ingested, indicated that genistein and biochanin A were degraded more rapidly than formononetin and daidzein in sheep (Shutt et al. 1967; Shutt and Braden, 1968). The results also suggested that formononetin and biochanin $A$ were demethylated to 
Figure 6. Metabolism of some estrogenic isoflavones in sheep. ${ }^{1}$
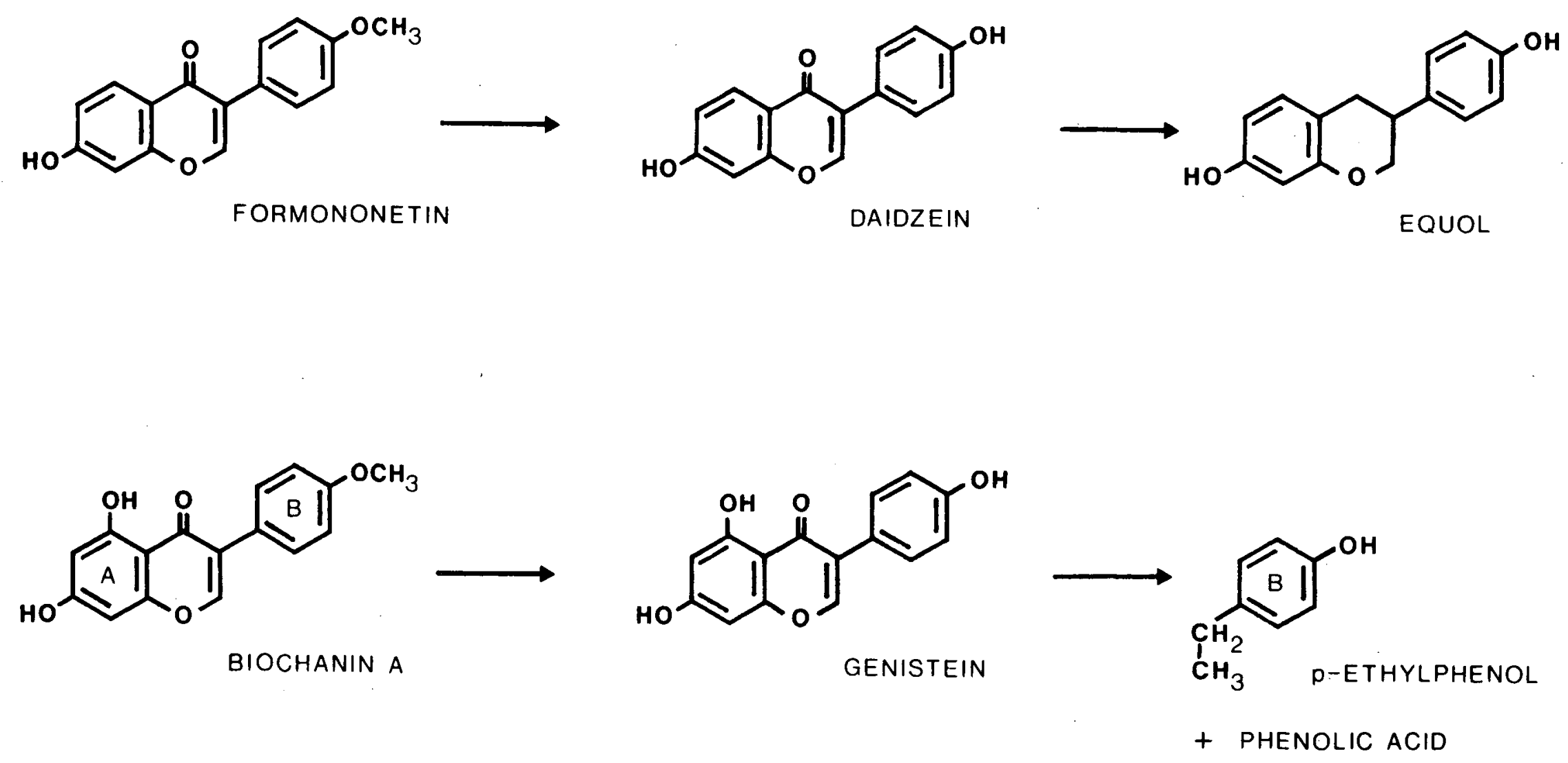

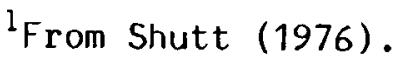


daidzein and genistein respectively, a finding supported by Lindner (1967) and Braden et al. (1967).

The metabolism of estrogenic isoflavones in sheep, as indicated in Figure 6, occurs primarily in the rumen (Batterham et al., 1965; Lindner, 1967). Formononetin undergoes 0-demethylation at the C-4' position to yield daidzein which in turn is reduced to the isoflavan, equol. Biochanin A undergoes demethylation to yield genistein which is further degraded to p-ethylphenol (from ring B) and a phenolic acid (from ring A), both estrogenically inactive metabolites (Braden et al., 1967; Shutt, 1976).

Equol, in contrast, has been reported to have an estrogenic activity equal to that of genistein in mice, and also elicits a significant estrogenic response in sheep (Shutt and Braden, 1968). Equol has been detected as a metabolite in the urine and plasma of sheep (Batterham et al., 1965; Shutt et al., 1967; Braden et al., 1971), cattle (Braden et al., 1971), guinea pigs (Shutt and Braden, 1968) and domestic fowl (Tang and Common, 1968) indicating that formononetin is converted to equol in all these species. Equol does not appear to undergo further metabolism in the rumen (Shutt et al., 1970).

It has been observed in sheep that the metabolism of biochanin $A$ and genistein to inactive phenols becomes more efficient over an "adaptive" period of about five days (Shutt, 1976). In cows this adaptive period appears to be shorter as these isoflavones are rapidly degraded, conjugated and excreted (Braden et al., 1971). In the guinea pig, degradation of biochanin $A$ and genistein is not as efficient as evidenced by high plasma concentrations of both isoflavones after 
consumption. As a result biochanin A and genistein have greater estrogenic activity in the guinea pig than in ruminants. Demethylation of biochanin A to genistein occurs also in domestic fowl (Tang and Common, 1968). These workers further reported that traces of equol were found as a metabolite of biochanin $A$ in fowl, however, this conversion has not been reported in other animal species (Cox and Braden, 1974).

Although bacterial flora in the rumen are believed to be primarily responsible for 0-demethylation of isoflavones (Shutt et al., 1970), Lindner (1967) demonstrated that some biochanin A and formononetin could be demethylated in ovine tissues following parenteral injection of these isoflavones. Griffiths (1975) showed that in vitro incubation of estrogenic isoflavones with intestinal microflora of the rat gave rise to p-ethylphenol and equol from genistein and daidzein respectively. Further experiments with germ-free rats demonstrated that orally ingested flavonoids do not undergo ring fission in the absence of normal intestinal microflora (Griffiths, 1975).

\section{Coumestans}

Metabolism of coumestrol and some related coumestans has been studied in sheep (Braden et al., 1967; Shutt et al., 1969; Kelly, 1972) and domestic fowl (Cayen and Common, 1965). Two methylated and estrogenically inactive coumestans, 4'-methoxycoumestrol and trifoliol, appear to be demethylated in sheep in a manner similar to the methylated isoflavones to give rise to estrogenically active coumestrol and repensol respectively (Shutt et al., 1969; Saba et al., 1974). The greater estrogenic activity of coumestrol compared to the isoflavones 
(Bickoff et al., 1962) may be due to slower metabolism and excretion of coumestrol (Shutt et al., 1969; Kelly, 1972; Kelly and Lindsay, 1978). Breakdown products of coumestrol metabolism do not appear to include equol (Cayen and Common, 1965) or previously identified isoflavone metabolites (Shutt, 1976). Kelly and Lindsay (1978) demonstrated that sheep appear to develop an insensitivity to coumestrol after prolonged exposure to this phytoestrogen, which is not similar to the mechanism or adaptive period reported for biochanin $A$ and genistein metabolism (Shutt, 1976).

\section{Absorption}

The relative estrogencity of formononetin and genistein in sheep and possibly also cows is then opposite to the situation in rats and mice (Verdeal and Ryan, 1979). The most potent phytoestrogen is still coumestrol, followed by daidzein, formononetin, genistein and biochanin $A$, in order of decreasing potency.

Phytoestrogens and their metabolites appear to be absorbed from the rumen (Shutt et al., 1970; Cox and Braden, 1974) or the upper part of the gut (Lindner, 1967). The major portion of absorbed estrogenic compounds are conjugated, probably in the liver, to form glucuronides (Lindner, 1967; Shutt et al., 1967; Shutt et al., 1970). Conjugation serves to inactivate the circulating compounds which are then excreted, usually via the urine (Cox and Braden, 1974; Harper, 1975).

Only the very small portion of the circulating estrogens which remain in a "free" or unconjugated form represent the biologically active forms (Lindner, 1967, Shutt et al., 1969). Factors which affect 
the liver's ability to detoxify the absorbed isoflavonoids, such as malnutrition or liver toxins, may result in marked increases in plasma levels of free estrogens (Linder, 1967).

Although phytoestrogens show low binding affinities for estrogen receptors in comparison to endogenous estrogens, they can exert significant estrogenic effects on animals when their concentration in blood plasma is maintained at high levels (Lindner, 1967; Shutt and Cox, 1972; Shutt, 1976). Very little is known of the metabolism and normal circulating levels of phytoestrogens in humans (Martin et al., 1978). Without this knowledge it is difficult to assess the significance of long term dietary exposure to phytoestrogens in man (Verdeal and Ryan, 1979).

\section{EXTRACTION OF PHYTOESTROGENS}

Bickoff et al. (1962) and others (Cheng et al., 1955; Pieterse and Andrews, 1956; Lyman et al., 1959; Wada, 1963; Saba et al., 1974) initially established the estrogenicity of certain plants by feeding the entire plant or crude plant extracts to test animals. However, in order to establish which compounds contributed to the total estrogenic activity and at what levels they occurred in plants, more specific extraction and detection methods had to be developed.

Early isolation methods usually involved a series of solvent extractions such as described by Livingston et al. (1961) for detecting coumestrol in alfalfa, and Wong (1962) for detecting phytoestrogens in clover. Fresh or rehydrated plant material was macerated and soaked in 95\% ethanol and filtered to give a crude extract. Petroleum ether was commonly employed to remove waxes and lipid material and the remaining 
mixture was evaporated and then further extracted with ethyl ether to isolate the compounds of interest. Modifications of this system were made primarily through the choice of solvents for extraction and purification (Bickoff et al., 1969; Wong and Latch, 1971; Saba et al., 1974; Sharma, 1979).

Beck (1964) modified the previous procedure after finding that bound isoflavones in the form of glycosides were not released by alcohol extraction of intact plant material. Flavonoids commonly occur as glycosides in plants in general (Markham, 1982), and as noted, in legumes (Beck, 1964; 0lah and Sherwood, 1971; Naim et al., 1974), so only the limited proportion of aglycone flavonoids would be extracted.

Hydrolysis of the glycosides was effected by crushing clover leaves prior to ethanolic extraction, indicating that a hydrolytic enzyme was present in the leaves (Beck, 1964). The enzyme was inactivated by placing intact leaves in boiling water or ethanol, and was not found in clover petioles (Figure 7). Olah and Sherwood (1973) demonstrated B-glucosidase activity in healthy alfalfa leaves and roots, which they noted could be involved along with other glucosidases in the hydrolysis of flavonoids.

Francis and Millington (1965b) compared treatments of clover leaves prior to ethanolic extraction and obtained maximum isoflavone yields if leaves were crushed and allowed to stand a maximum of 10 minutes before adding ethanol. Glencross et al. (1972) reported a two-fold increase in formononetin content when clover leaves were crushed in water before extraction with ethanol, and concluded that endogenous enzymic hydrolysis of the isoflavone glycoside had occurred. 
Figure 7. Germination and development of alfalfa seed to sprout.

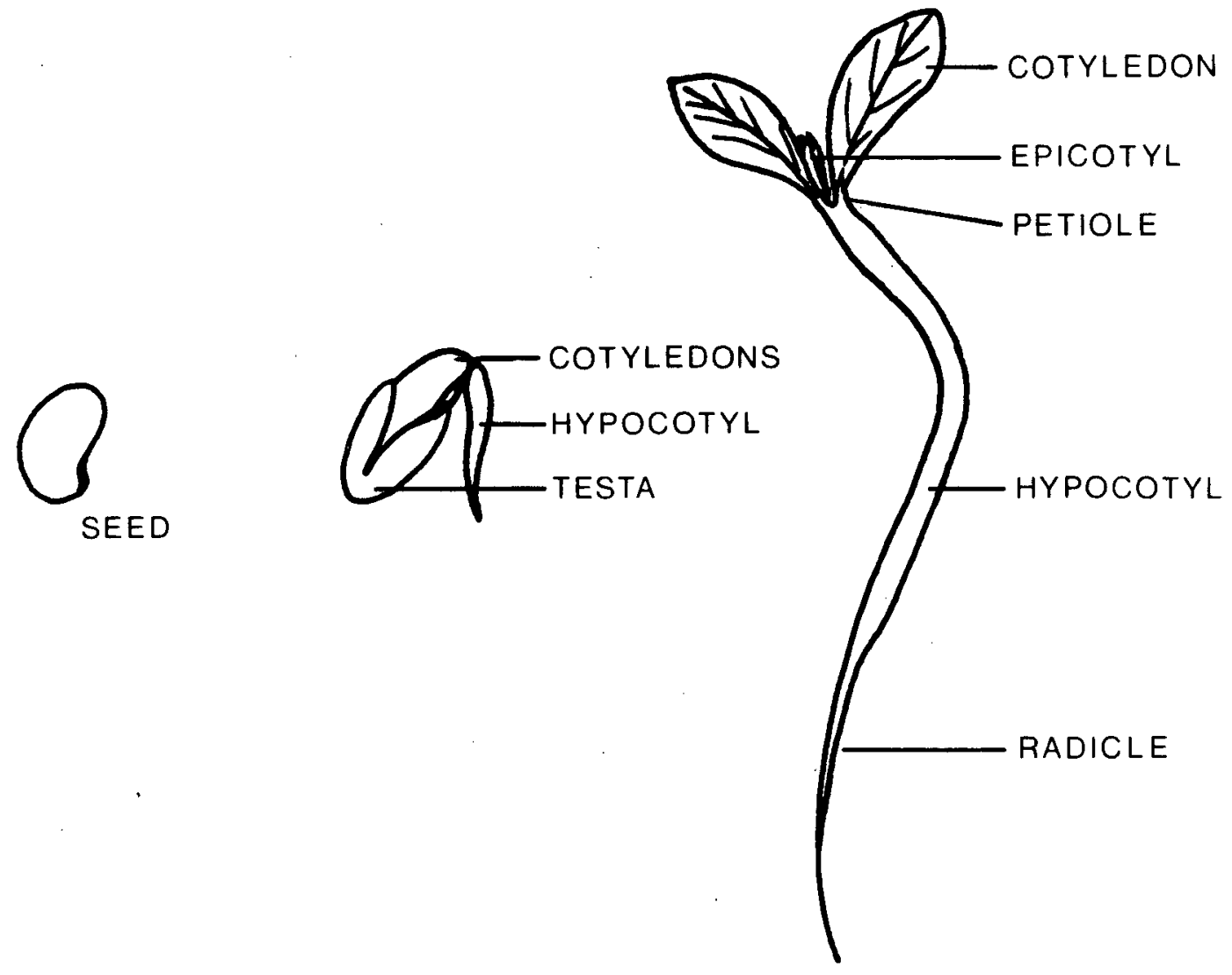


Sherwood et al. (1970) did not, however, detect increased levels of coumestrol when alfalfa leaves were ground before extraction.

Studies of the phytoestrogens in soybean products have generally not employed hydrolysis to liberate flavonoid aglycones. Ohta et al. (1979) isolated daidzein, genistein and their glucosides, daidzin and genistin, by ethanolic extraction of soy flour but did not determine whether production of the initial soy flour product affected the isoflavonoid profile. A similar analysis by Eldridge (1982a) of soybean meal also did not address this matter, although in a subsequent paper the author proposed that the decrease in isoflavone glycosides in soy protein isolates arose from water soluble losses during production (Eldridge, 1982b). Murphy (1982) attempted to explain the different isoflavonoid profiles of soybean products in terms of processing effects such as water solvation and oxidation.

In contrast, Glencross et al. (1972) noted that the preparation of a clover leaf protein concentrate involved first pulping the leaves to express juice, at which point enzymic hydrolysis would have occurred. Subsequent analysis of the protein concentrate for isoflavone aglycones would therefore not require additional hydrolysis. Nicollier and Thompson (1982) reported that some hydrolysis may have occurred during extraction of isoflavones from intact clover to account for the high levels of aglycones detected.

Hydrolysis of flavonoid glycosides can be carried out under controlled conditions employing either acidic, enzymic or alkaline treatments, as reviewed by Markham (1982). The choice of treatment depends primarily on the nature of the glycoside to be hydrolyzed. As 
mentioned previously, the glycosides of the estrogenic isoflavones and of coumestrol isolated to date have been identified as 7-0-monoglycosides. According to Markham (1982) such a linkage would be hydrolyzed completely in 15 to 40 minutes under standard acid hydrolysis conditions, namely heating at $100^{\circ} \mathrm{C}$ with $2 \mathrm{~N} \mathrm{HCl:95 \%}$ EtOH $(1: 1, v / v)$ (Harborne, 1965). Sachse (1974) found that hydrolysis of clover samples with $1 \mathrm{~N} \mathrm{HCl}$ in a hot water bath for 1 hour was adequate to achieve total levels of the estrogenic isoflavones and coumestrol as aglycones. Nicollier and Thompson (1982) obtained full hydrolysis of isoflavone glycosides in intact clover leaves using conditions of $4 \mathrm{~N} \mathrm{HCl}$ for 2 hours at $70^{\circ} \mathrm{C}$.

While earlier research reports were concerned with identification and activity of estrogenic isoflavones and coumestans in plants, much of the recent literature has emphasized quantitative determinations of phytoestrogens in feeds and foods (Naim et al., 1974; Knuckles et al., 1976; Lookhart, 1979; Murphy, 1981; Eldridge, 1982a). Several methods for the extraction of phytoestrogens have thus been developed to obtain maximum recovery from a particular plant product (Knuckles et al., 1976; Lookhart, 1979; Murphy, 1981; Eldridge, 1982b).

Lookhart (1979) examined soybeans for coumestrol content only and reported a maximum of 64 percent recovery from a coumestrol spiked soybean system. The author found enhanced extraction efficiency of coumestrol when soybeans were defatted prior to a series of methanol/ water and ethyl ether extractions. Murphy (1981) reported very low extraction efficiencies with the Lookhart procedure when applied to phytoestrogens other than coumestrol. A 2 hour mechanical agitation procedure was used instead by Murphy (1981) to extract defatted soy 
flakes, and later for dried, defatted soybeans and other soybean products (Murphy, 1982). A solvent system of acetonitrile:0.1N HCl $(25: 5, v / v)$ was reported to yield maximum recovery and minimum coextractives. Recoveries were measured for standards of genistin (91\% recovery), genistein (86\%), daidzein (57\%) and coumestrol (55\%) added to soy flakes. Eldridge (1982b) reported maximum extraction of daidzein, genistein, glycitein and their corresponding glucosides from soybean products by refluxing with 80 percent methanol for 4 hours.

Knuckles et al. (1975) developed a procedure for the quantitative determination of coumestrol in alfalfa which was also used to evaluate the coumestrol content of soybeans and soybean products (Knuckles et al., 1976). Briefly, dried samples were rehydrated, then soaked in 95 percent ethanol; chlorophyll was removed with chloroform after adjusting the alcohol extract to $\mathrm{pH} 10$, and ethyl ether was used to finally isolate the coumestrol. Recovery of added coumestrol was reported to be 98 percent, however, the standard was added just prior to the chlorophyll removal stage, and thus was not carried through the entire extraction procedure. Quantitative recoveries for estrogenic isoflavones from alfalfa have not been reported.

Sachse (1974) demonstrated several restrictions imposed by isoflavones on the development of suitable extraction techniques for phytoestrogens. Isoflavones in general were found susceptible to alkali hydrolysis, even under mild conditions, as supported by Wong (1975) and Markham (1982). Formononetin was found to be soluble in chloroform, although this solvent was reported (Bickoff et al., 1969) to be more efficient than petroleum ether for the removal of waxes and lipid 
material from plant extracts. The low polarity of isoflavone aglycones renders these compounds more soluble in solvents such as ethyl ether and chloroform, and only moderately soluble in ethanol, methanol and acetone (Markham, 1982).

\section{E. DETECTION TECHNIQUES}

The simplest detection methods reported in the literature were based on observations of estrogenic stimulation in animals following consumption of specific feeds (Bennetts et al., 1946; Pieterse and Andrews, 1956; Wada, 1963). However, little information about the nature or quantities of those compounds involved in estrogenicity was revealed in such studies.

Since the initial identification of some estrogenic components as isoflavones (Bradbury and White, 1951; Cheng et al., 1955) and coumestans (Bickoff et al., 1957), a variety of chromatographic techniques have been developed for the analysis of the estrogenic flavonoids. Paper and thin-layer chromatography predominated phytoestrogen research literature up until the last several years when high-performance liquid chromatography (HPLC) emerged as a suitable quantitative technique for flavonoid analysis (eg. Wulf and Nagel, 1976; Vande Casteele et al., 1982).

\section{Paper chromatography}

The technique of paper chromatography (PC) is still extensively used for flavonoid analysis, largely because it produces acceptable separations, even of large amounts of flavonoids, at a low cost (Markham, 1975). 
Paper chromatography was easily used to detect coumestrol in legume plants because of the characteristic blue fluorescence of this compound when exposed to UV light (Lyman et al., 1959). Wong (1962) found that as little as $0.1 \mu \mathrm{g}$ coumestrol could be detected under UV light. Livingston et al. (1961) further improved a paper chromatographic system for quantitative analysis of coumestrol (in fresh and dried alfalfa) that was sensitive to $2 \mathrm{ppm}$ coumestrol. The chromatogram was developed in acetic acid/water/HCl (50:35:15, v/v). Comparisons of fluorescence readings between standard and plant extract spots on developed chromatograms were used to determine coumestrol concentrations.

Chury (1967) compared ten developing systems for the PC separation of coumestrol and reported good resolution with the Livingston system mentioned. Numerous workers made use of the fluorometric PC method of Livingston et al. (1961) for measuring coumestrol content of alfalfa in foliar disease studies (Stuthman et al., 1966; Bickoff et al., 1967; Loper et al., 1967; Sherwood et al., 1970). Loper et al. (1967) further adapted the method to two-dimensional paper chromatography for separation and detection of other coumestans and flavones in alfalfa, and reported the characteristic fluorescence intensities of these compounds relative to coumestrol.

Daidzein and formononetin were also detected as blue violet fluorescent spots under UV light (long wave, $365 \mathrm{~nm}$ ) using PC (Guggolz et al., 1961). Genistein and biochanin A could be visualized as brown spots after spraying developed chromatograms with bis-diazotized benzidine. 
Wong (1962) developed a two-dimensional paper chromatographic method for the separation and measurement of phytoestrogens in clover. The benzene/acetic acid/water $(125: 72: 3, \mathrm{v} / \mathrm{v})$ system used for the first dimension was reported to move chlorophyll and lipids near the solvent front. The second dimension system was $2 \mathrm{~N}$ aqueous ammonia, but aside from noting partial degradation of biochanin $A$, the author did not detect instability of isoflavonoids in this alkaline system. The compounds of interest were well separated on the final chromatogram; the spray reagent diazotized sulphanilic acid was found to be most suitable for visualizing the non-fluorescent dark spots corresponding to genistein and biochanin $A$. Color reactions of the isoflavones with several other spray reagents are summarized by Wong (1962). In the same study, isoflavone spots were eluted from the chromatogram and concentrations were obtained from the absorbance maxima using a UV spectrophotometer.

Subsequent studies by Wong and Latch (1971) were carried out using $30 \%$ or $60 \%$ acetic acid for the second dimension solvent system rather than the alkaline system previously reported (Wong, 1962). A mixture of twelve flavonoids was separated for identification based on UV spectra and chromatographic properties upon comparison with authentic samples.

Knuckles et al. (1975) reported that the removal of chlorophyll from alfalfa extracts prior to chromatography was necessary to prevent the pigment from enhancing the fluorescence of coumestrol or interfering with the separation of coumestrol from other fluorescing compounds. These workers chose a simple $50 \%$ acetic acid system as the developing solvent because hydrochloric acid was found to result in fragile 
chromatograms with high background fluorescence. Fluorescence measurements were carried out as per Livingston et al. (1961).

\section{Thin-layer chromatography}

The use of thin-layer chromatography (TLC) for the analysis of flavonoids has been reviewed by Markham (1975). Beginning in the mid 1960 's the development of thin-layer methods for rapid analytical and small scale chromatography began to replace paper chromatography for the separation of estrogenic isoflavonoids.

Beck (1964) tested 60 solvents and solvent mixtures to resolve the estrogenic isoflavones isolated from clover. Chloroform/methanol $(89: 11, v / v)$ was found to be the only solvent system to give a satisfactory separation on silica gel plates. Formononetin and daidzein could be visualized as blue-white fluorescent spots under UV light (257 nm). Genistein and biochanin A were made visible as orange-brown spots by spraying with diazotized sulphanilic acid and exposing to ammonia fumes. However, this solvent system could not adequately separate coumestrol from genistein. Nevertheless, numerous workers used this Beck system for semi-quantitative analysis of isoflavones in clover (Millington et al., 1964; Francis and Millington, 1965b; Shehata et al., 1982), in soybeans (Naim et al., 1974), in legumes generally (Harborne, 1969), and in plasma (Braden et al., 1967).

Dissatisfied with isoflavonoid separations on silica gel or cellulose plates, Sachse (1971) developed a system employing petroleum ether/benzene/methylethylketone/methanol/acetic acid $\quad(30: 30: 20: 20: 2$, 
$v / v)$ with polyamide TLC plates. Using this system he reported better separation of coumestrol as well as daidzein, genistein, formononetin, biochanin A and pratensein standards. Increasing the polarity of the developing solvent did not improve the separation. The same system was later also employed to separate clover extracts (Sachse, 1974), and was adapted to include development in a second dimension and finally elution for quantitative spectrophotometric analysis. However, the procedure was reported to require 3 days from the time of spotting the extract onto the plate to the final quantitative measurement.

Lookhart et al. (1978) reported a rapid, quantitative method for TLC analysis of coumestrol in soybeans. The system used silica gel plates which were developed for only 1 minute in chloroform/acetone $(88: 12, v / v)$. Fluorescence intensities of extract spots (under UV 365 $\mathrm{nm}$ ) were visually compared to those of standards to estimate coumestrol concentration in the range of 50-100 ppm. The possibility of other fluorescent compounds interfering with the barely developed coumestrol spot was not discussed.

Many workers reported using TLC primarily as a method for isoflavone purification and identification after extracts were initially separated by column chromatography (Naim et al., 1974; Sachse, 1974; Biggs, 1975; Sharma, 1979). Several chemical and physical treatments used to identify isoflavones and coumestans on the developed TLC plates are well described by Sachse (1971).

\section{Column chromatography/UV spectrophotometry}

Column chromatography has also been used as a separation technique followed by UV spectrophotometric studies for identification and often 
quantitation (Glencross et al., 1972). Ohta et al. (1979) fractionated soybean extracts by silica gel column chromatography and the isoflavone fractions were identified by UV spectra, infra red spectra and proton magnetic resonance. Naim et al. (1974) used a polyamide column to separate soybean isoflavone glycosides. Silica gel columns are reportedly most useful for the separation of less polar flavonoids such as isoflavone aglycones (Markham, 1982) but many applications using other systems are reviewed by Markham (1975).

In UV spectrum studies, the flavonoid spectrum is usually determined for a methanol solution of the flavonoid. Reference spectra of many isoflavones have been compiled by Horowitz and Jurd (1961). Typical UV absorption maxima for isoflavones include a low intensity band $I$ at $310-330 \mathrm{~nm}$ and a high intensity band II at 245-275 $\mathrm{nm}$ (Markham, 1982). The coumestans generally exhibit high intensity UV absorption in the ranges of 340-355 $\mathrm{nm}$ (band I), 230-250 $\mathrm{nm}$ (band III) and 200-215 (band IV), and low intensity absorption in the 300-320 nm range (band II) as evidenced by a shoulder peak (Bickoff et al., 1969). Certain reagents such as sodium methoxide and aluminum chloride can be added to the flavonoid-methanol solutions which cause characteristic shifts in absorption spectra. The use of these "shift reagents" and the interpretations of the resulting spectra are summarized by Markham (1982) and have been applied to the identification of estrogenic isoflavones and/or coumestrol in a number of studies (Wong, 1962; Bickoff et al., 1969; Glencross et al., 1972; Naim et al., 1974; Biggs, 1975; Ohta et al., 1979). 


\section{High-performance liquid chromatography}

High-performance liquid chromatography (HPLC) is receiving increased attention in the field of flavonoid analysis because it is a rapid quantitative technique which can provide a high level of resolution and sensitivity (Markham, 1982). The technique and theories of HPLC are well described in the literature (Snyder and Kirkland, 1979; Yost et al., 1980). In addition, Kingston (1979) extensively reviewed the literature dealing with applications of HPLC to natural plant products.

The vast majority of HPLC studies of flavonoids have been carried out using reversed-phase (RP) chromatography systems (Kingston, 1979; Markham, 1982; Andersen and Pedersen, 1983). The columns most commonly used are known as 'reversed-phase C-18' types, which consist of octadecyl hydrocarbon groups chemically bound to silica packing. The non-polar octadecylsilyl groups act as the stationary phase and are used in conjunction with a more polar mobile phase, for example methanolwater, to effect a separation of non-polar to moderately polar compounds (Yost et al., 1980).

Numerous workers (Wulf and Nagel, 1976; Daigle and Conkerton, 1982; Vande Casteele et al., 1982) have studied the mechanisms of separation of a large variety of phenolic acids and flavonoids using reversed-phase $\mathrm{C}-18$ systems. The elution sequence of a given compound was considered to be due to its hydrogen bond donating and/or accepting ability as well as its contribution to the hydrophobic interaction with the stationary phase. In isoflavones the strongest hydrogen bond acceptor is the carbonyl group at $\mathrm{C}-3$; however, an $\mathrm{OH}$ group at $\mathrm{C}-5$ will form a strong internal hydrogen bond with this C-3 carbonyl group so 
that the carbonyl can no longer interact strongly with the mobile phase (Vande Casteele et $\cdot a l ., 1982)$. As a result, the retention times $\left(t_{R}\right)$ of aglycone 5-hydroxyisoflavones (such as genistein and biochanin A) were found to be longer than those of the corresponding isoflavones without the 5-OH group (namely daidzein and formononetin). The authors further generalized that additional hydroxyl groups reduce $t_{R}$ values whereas methylation of $\mathrm{OH}$ groups prevents the effect of these groups. Glycosylation of an $\mathrm{OH}$ group introduces a more hydrophilic moiety and would also result in decreased $t_{R}$ values.

Additional HPLC studies by different workers using RP C-18 columns and methanol-water mobile phases generally support the previous findings in relation to the estrogenic isoflavones, their glycosides and coumestrol (Lookhart et al., 1978; Ohta et al., 1979; Murphy, 1981; Dziedzic and Dick, 1982; Eldridge, 1982a; Nicollier and Thompson, 1982; Patroni et al., 1982).

Carlson and Dolphin (1980) reported the use of a normal phase silica column to resolve some isoflavones in a soybean extract. The solvent system consisted of a methylene dichloride/ethanol/acetic acid/ hexane mixture. A good separation of daidzein and genistein was achieved, however, many of the isoflavone separations reported for RP systems compare favorably to this normal phase system. Vande Casteele et al. (1982) advised against the use of normal phase columns when dealing with plant extracts because other more polar flavonoids could become irreversibly adsorbed.

Although only methanol-water mixtures were employed in the aforementioned RP work with isoflavonoids, various modifiers have been added 
to the mobile phase to improve separation characteristics in studies concerning other flavonoids and phenolic acids. Acetic or formic acids were added to the solvents at levels of 1 to $5 \%$ to suppress ionization of the acid groups of the phenolic acids and flavonoids (Wulf and Nagel, 1976; Vande Casteele et al., 1982). This technique, known as ion suppression chromatography, is used to avoid ionic retention mechanisms from taking place on the column, and thus prevents severe peak tailing of the eluting compounds (Yost et al., 1980). The addition of ammonium acetate was reported to prevent intramolecular hydrogen bonding of phenolic hydroxy groups that can cause abnormal polar movement (Murphy and Stutte, 1978; Hardin and Stutte, 1980; Proksch et al., 1981). At levels of 0.019 to $0.09 \mathrm{M}$ the ammonium acetate was essential for clear separations among closely related phenolic compounds.

The detectors employed in HPLC analysis of flavonoids include primarily ultraviolet (UV) and also fluorescence (FL). As mentioned previously, the isoflavone and coumestan phytoestrogens have an absorption maxima in the $254 \mathrm{~nm}$ fixed wavelength regions. The application of $254 \mathrm{~nm}$ fixed wavelength detectors to isoflavonoid detection has thus been useful (Murphy, 1981; Patroni et al., 1982; Vande Casteele et al., 1982).

Other wavelengths of 262 and $280 \mathrm{~nm}$ have also been employed (Ohta et al., 1979; Carlson and Dolphin, 1980; Dziedzic and Dick, 1982; Eldridge, 1982a), presumably because specific isoflavones have peak maxima at these wavelengths. However, the coumestans absorb only weakly at $280 \mathrm{~nm}$, which could in turn affect detection limits. Lookhart et al. (1978) developed a sensitive UV detection method specifically for 
coumestrol at $343 \mathrm{~nm}$. The isoflavones do not exhibit significant absorption at this wavelength (Markham, 1982).

The fluorescent properties of daidzein and coumestrol were exploited using fluorescence detectors for identification of these compounds in plant extracts (Lookhart et al., 1978; Murphy, 1982). Lookhart et al. (1978) reported fluorescence excitation and emission maxima in ethanol at 348 and $411 \mathrm{~nm}$ respectively, for coumestrol. Murphy (1982) used a fluorescence detector with an excitation maximum at $360 \mathrm{~nm}$ and a secondary filter (range 460-700 nm). 


\section{MATERIALS AND METHODS}

\section{A. MATERIALS}

Daidzein (7,4'-dihydroxyisoflavone) was obtained from ICN Pharmaceuticals, Inc., Plainview, NY. Coumestrol was obtained from Eastman Kodak Co., Rochester, NY. Formononetin (7-hydroxy-4'-methoxyisoflavone) was kindly provided by Dr. R. J. Bose, University of B.C., Vancouver, B.C. Separate stock solutions for each of the above phytoestrogens were prepared to contain $30.0 \mu \mathrm{g} / \mathrm{mL}$ in HPLC grade glass-distilled methanol (Fisher Scientific Co., Fairlawn, NJ).

Both cultivars of alfalfa seeds, Moapa and Vernal, used in the germination studies were purchased from Richardson Seed Co. Ltd., Burnaby, B.C.

\section{B. PHYTOESTROGEN EXTRACTION}

A method suitable for the extraction of selected phytoestrogens from alfalfa was developed. Figure 8 illustrates the basic scheme followed to extract daidzein, formononetin and coumestrol from alfalfa sprouts. All solvents used in the extraction were analytical reagent grade, unless otherwise specified, and water was distilled and deionized before use.

Approximately $20 \mathrm{~g}$ of fresh or frozen alfalfa sprouts were ground with washed, dried sand using a mortar and pestle. The ground sample was allowed to stand for $10 \mathrm{~min}$ as per Francis and Millington (1965b) to permit hydrolysis of the phytoestrogen glycosides by the alfalfa glycosidases. The sample was then refluxed with $20 \mathrm{~mL} 2 \mathrm{~N} \mathrm{HCl}$ and 80 
Figure 8. Phytoestrogen extraction scheme for alfalfa sprouts.

ALFALFA

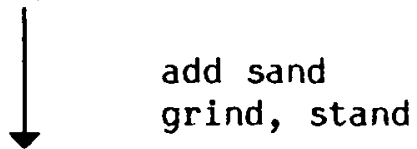

$\left\lfloor\begin{array}{l}\text { add } 2 \mathrm{~N} \mathrm{HCl}+\mathrm{MeOH} \\ \text { reflux, cool }\end{array}\right.$

$\lfloor$ filter, wash with $\mathrm{MeOH}$

alfalfa filtrate

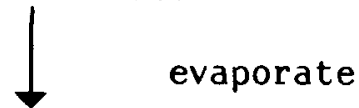

discard PE

extract with $P E$

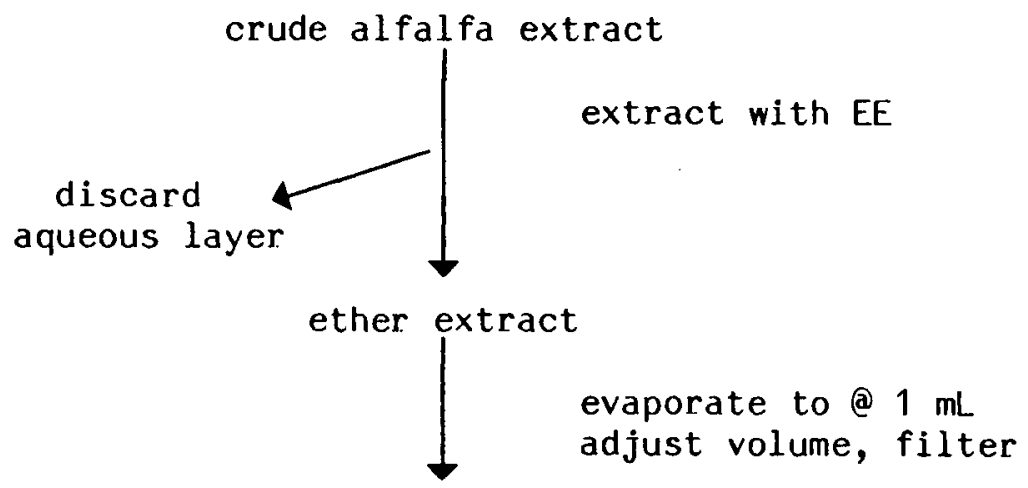

PHYTOESTROGEN EXTRACT

$\mathrm{MeOH}=$ methanol

$\mathrm{PE}$ = petroleum ether

$\mathrm{EE}$ = ethyl ether 
$\mathrm{mL}$ methanol for $30 \mathrm{~min}$ to further the hydrolysis. After a $10 \mathrm{~min}$ cooling period, the alfalfa slurry was suction filtered through Whatman No. 50 (hardened) filter paper with $4 \mathrm{~g}$ Celite filter aid "Hyflo Super-Cel" (Johns-Manville, Etobicoke, Ont.). The filter cake was washed with 50 $\mathrm{mL}$ methanol and discarded. The filtrate was transferred to a $1000 \mathrm{~mL}$ round bottom flask with rinsing $(2 \times 5 \mathrm{~mL}$ water $)$. Evaporation to remove a portion of methanol in the filtrate was carried out under vacuum for 25 min using a rotary flash evaporator (Brinkmann Instruments, Rexdale, Ont.) in conjunction with a water bath at $30^{\circ} \mathrm{C}$. This temperature allowed rapid methanol removal yet limited the amount of heat applied to the sample. The remaining aqueous methanol extract was transferred to a $250 \mathrm{~mL}$ separatory funnel, again rinsing the flask with water $(2 \times 5$ $\mathrm{mL}$ ). Volume was adjusted with water to a previously calibrated $75 \mathrm{~mL}$ mark. Lipids and chlorophyll pigments were removed by extraction with 3 $X 100 \mathrm{~mL}$ portions of petroleum ether (b.p. $37-58^{\circ} \mathrm{C}$ ). After each addition of petroleum ether the mixture was shaken vigorously for $30 \mathrm{~s}$ and allowed to stand for $10 \mathrm{~min}$ to permit the phases to settle and the pigments to transfer to the upper petroleum ether layer.

The final extraction of phytoestrogens from the crude alfalfa extract was accomplished with $4 \times 50 \mathrm{~mL}$ portions of anhydrous ethyl ether. Each ether/aqueous layer mixture was shaken for $30 \mathrm{~s}$ and allowed to stand for $10 \mathrm{~min}$ before removal of the ether layer. The ether extracts were combined and evaporated under vacuum at $32^{\circ} \mathrm{C}$ for $15 \mathrm{~min}$ to approximately $1 \mathrm{~mL}$. The remaining residue was transferred into a $10 \mathrm{~mL}$ volumetric flask with HPLC grade methanol rinses and diluted to volume. The final extract was filtered through a Swinny filter unit fitted 
with a $0.2 \mu \mathrm{m}$ Millipore Type EG filter (Millipore Corp., Bedford, MA). Samples were stored in borosilicate glass vials (Wheaton Sci., Millville, $\mathrm{NJ})$ at $5^{\circ} \mathrm{C}$ until analyzed. The entire extraction procedure required approximately $4 \mathrm{~h}$ per sample, however, several extractions could be run concurrently.

All sprouting treatments were carried out in triplicate, and duplicate extractions were performed from each sprouting jar within a treatment. The number of extractions was limited by the quantity of sprouts that could be grown in the jars used.

Recovery studies were also performed using prepared stock solutions of the three phytoestrogens. In one experiment $2.0 \mathrm{~mL}$ of each $30.0 \mu \mathrm{g} / \mathrm{mL}$ stock solution was added to the mortar and the entire extraction procedure carried out as previously described. Triplicate extractions were carried out for this study. In another experiment $2.0 \mathrm{~mL}$ of each $30.0 \mu \mathrm{g} / \mathrm{mL}$ stock solution was added to $20 \mathrm{~g}$ of alfalfa sprouts prior to grinding and completing the extraction procedure. Duplicate extractions were performed for each of the two alfalfa cultivars germinated under "standard" conditions as described in Section E.

\section{MOISTURE DETERMINATION}

Moisture content of alfalfa sprouts was determined using the ADAC method for plants (AOAC, 1980) with some modifications. Triplicate samples of alfalfa sprouts of approximately $10 \mathrm{~g}$ each had been taken from every sprouting jar for moisture analysis and stored at $-30^{\circ} \mathrm{C}$ until analyzed. Sprout samples were chopped lightly while still frozen, 
and weighed into pre-dried $(1 \mathrm{~h})$, desiccator cooled $(0.5 \mathrm{~h})$, weighed aluminum dishes (57 mm diam X $17 \mathrm{~mm}$ depth) (Canlab, Richmond, B.C.).

Samples were dried to constant weight $( \pm 0.002 \mathrm{~g})$ at $95-100^{\circ} \mathrm{C}$ in a vacuum oven (National Appliance Co., Portland, OR) under $91.5 \mathrm{kPa}$ (27 inches $\mathrm{Hg})$. Sprouts were dried for $5.5 \mathrm{~h}$ and immediately placed into a desiccator containing silica gel to cool $(0.5 \mathrm{~h})$ before weighing. Samples were returned to the oven for $1 \mathrm{~h}$, again desiccator cooled, and reweighed to check for constant weight. Final weights recorded after $6.5 \mathrm{~h}$ drying were used to calculate moisture contents.

\section{MEASUREMENT OF PHYTOESTROGENS BY HPLC}

All HPLC analyses were performed using a Varian Model 5060 Liquid Chromatograph equipped with a UV-50 variable wavelength dectector and Vista 401 data system (Varian Instrument Group, Palo Alto, CA) and a Rheodyne Model 7125 loop valve injector (10 $\mu \mathrm{L}$ loop). Separation was carried out on a reverse-phase Varian MicroPak MCH-10 (octadecylsilane) column $(4 \mathrm{~mm}$ I.D. $X 30 \mathrm{~cm})$, fitted with a Bio-Sil ODS-10 guard column (Bio-Rad Laboratories, Richmond, CA). Column temperature was maintained at $30^{\circ} \mathrm{C}$. Detection of the phytoestrogens was made at $254 \mathrm{~nm}$ (optical bandwidth $8 \mathrm{~nm}$ ).

All water for HPLC analysis was distilled, deionized and filtered through a $0.45 \mu \mathrm{m}$ Millipore filter (Millipore Corp., Bedford, MA). Methanol was glass distilled HPLC-grade (Fisher Scientific Co.). Separation was achieved by using a linear methanol-water gradient system at a flow rate of $1.0 \mathrm{~mL} / \mathrm{min}$. Methanol and water reservoirs each contained 1.0\% glacial acetic acid $(v / v)$ and $0.01 \mathrm{M}$ ammonium acetate (HPLC grade, 
Fisher Scientific Co.). The gradient was programmed to increase from 53\% to 58\% reservoir B (methanol) over $30 \mathrm{~min}$. Total analysis time per sample, including column equilibration, was $60 \mathrm{~min}$.

Peak retention times and peak areas were computed automatically by the integrator. The retention times were used to calculate several chromatographic parameters: the capacity factor, $k$ (also known as $k^{\prime}$ ); the separation factor (relative retention), $\propto$; and the resolution, $R_{5}$. The following equations were used (Yost et al., 1980):

$$
\begin{aligned}
& k=\frac{t_{R}-t_{M}}{t_{M}} \\
& \alpha=\frac{k_{2}}{k_{1}} \\
& R_{s}=\frac{\frac{\Delta t}{w_{b 1}+w_{b 2}}}{2}
\end{aligned}
$$

$$
\text { where } \begin{aligned}
t_{R} & =\text { retention time of compound } \\
t_{M} & =\text { mobile phase holdup time } \\
k_{1}, k_{2} & =\text { capacity factors of compounds } 1 \text { and } 2 \text {, respectively } \\
\Delta t & =\text { distance between two peak maxima } \\
w_{b 1}, w_{b 2} & =\text { peak width at base of compounds } 1 \text { and } 2 \text { respectively, }
\end{aligned}
$$

and all measurements are expressed in the same time units (min or sec). Figure 9 shows how these measurements were obtained from a chromatogram. The separation factors were calculated as ratios of the $k$ values for daidzein/formononetin and formononetin/coumestrol. Ratios were 
Figure 9. Retention time and peak width at base measurements ${ }^{1}$.

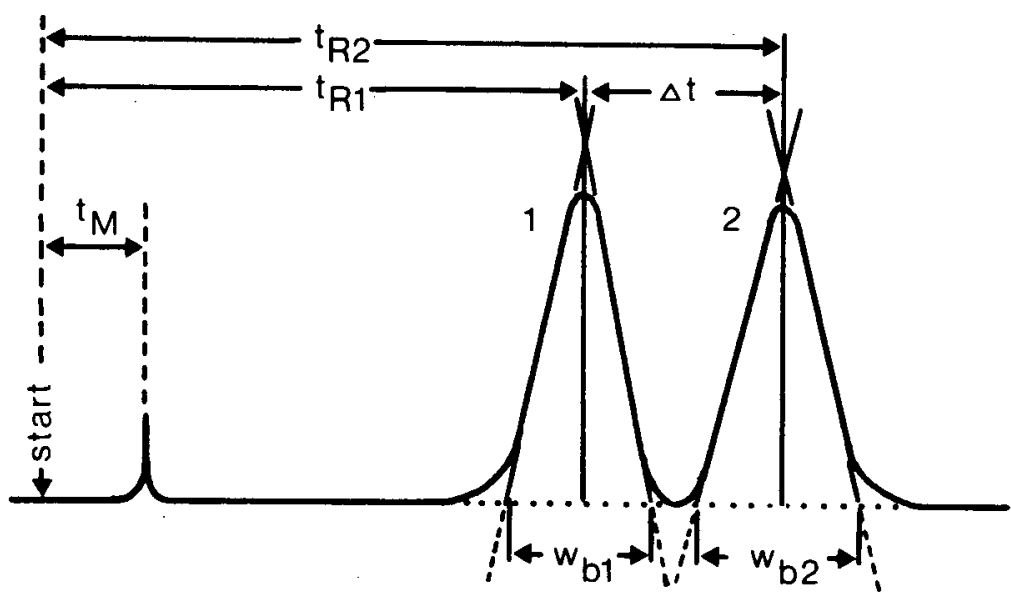

TIME $\longrightarrow$

${ }^{1}$ Adapted from Yost et al. (1980). 
obtained for the standards mix, standards extract, spiked alfalfa (Vernal) extract and alfalfa only (Treatment $X$ ) extract, and compared for tentative peak identification based on agreement of these $\propto$ values. The resolution of the two closely eluting phytoestrogens, formononetin and coumestrol, was calculated. $R_{S}$ values were obtained from representative chromatograms of the standards mix, standards extract, spiked alfalfa (Vernal) extract and alfalfa only (Treatment $X$ ) extract.

Standard solutions of daidzein, formononetin and coumestrol were prepared from respective stock solutions containing $30.0 \mu \mathrm{g} / \mathrm{mL}$ to give concentrations of $20.0,10.0,6.0,4.0,2.0,1.0,0.8,0.6,0.4$ and 0.2 $\mu \mathrm{g} / \mathrm{mL}$. HPLC-grade methanol was used for all dilutions. A standard curve for each phytoestrogen was prepared from the peak area integrator responses for $10-\mu \mathrm{L}$ injections of the standards. Triplicate injections were made for each standard solution and area counts (in $\mu V-s$ ) recorded to the nearest 100 . Linear regression analysis was performed using a Monroe 1880 programmable calculator. Regression equations were used to calculate the content of the corresponding phytoestrogen in the sample extracts.

Duplicate injections were made for each sample extract. The mean of four determinations (two sample preparations, each injected twice) was used in calculating the phytoestrogen content of the sprouts grown in each jar. For the extracts of the standards, the mean of six determinations (three sample preparations, each injected twice) was used to calculate phytoestrogen recovery. 
Preliminary peak identification was based on a comparison of retention times of phytoestrogen standards and unknown peaks in the sample extracts. To further confirm the peak identities, the chromatograms of the alfalfa samples which had been spiked with phytoestrogen standards before extraction were compared to those of the unspiked alfalfa extracts and the standards alone.

\section{E. GERMINATION OF ALFALFA SEEDS \\ 1. Sprouting preparation}

Clear glass wide mouth jars ( $800 \mathrm{~mL}$ vol) were used as sprouting containers. Jars were washed with a $1 \%$ chlorine bleach $(v / v)$ solution to limit microbial contamination, and thoroughly rinsed with distilled water before use. Cheesecloth covers $(10 \mathrm{~cm} \times 10 \mathrm{~cm})$ secured by rubber bands permitted rapid drainage yet retained seeds and sprouts; covers were replaced daily.

Seeds in $15 \mathrm{~g}$ lots were weighed into each jar, $300 \mathrm{~mL}$ distilled water was added, and the seeds were soaked for $4 \mathrm{~h}$ at room temperature $\left(22^{\circ} \mathrm{C}\right)$ in the light. At the end of this period, water was decanted and seeds were rinsed with the volume of water designated in the rinsing schedule and drained. The growth period was measured from the time the alfalfa seeds began soaking.

In order to thoroughly drain the sprouting jars, racks were constructed from $1 / 2$ inch $(1.3 \mathrm{~cm})$ wire mesh that allowed the jars to stand inverted at a $45^{\circ}$ angle and permitted adequate illumination and air circulation. Figure 10 illustrates the draining rack system with jars in place: two rows of three jars each placed approximately $3 \mathrm{~cm}$ apart . 
Figure 10. Rack used for draining sprouting jars.

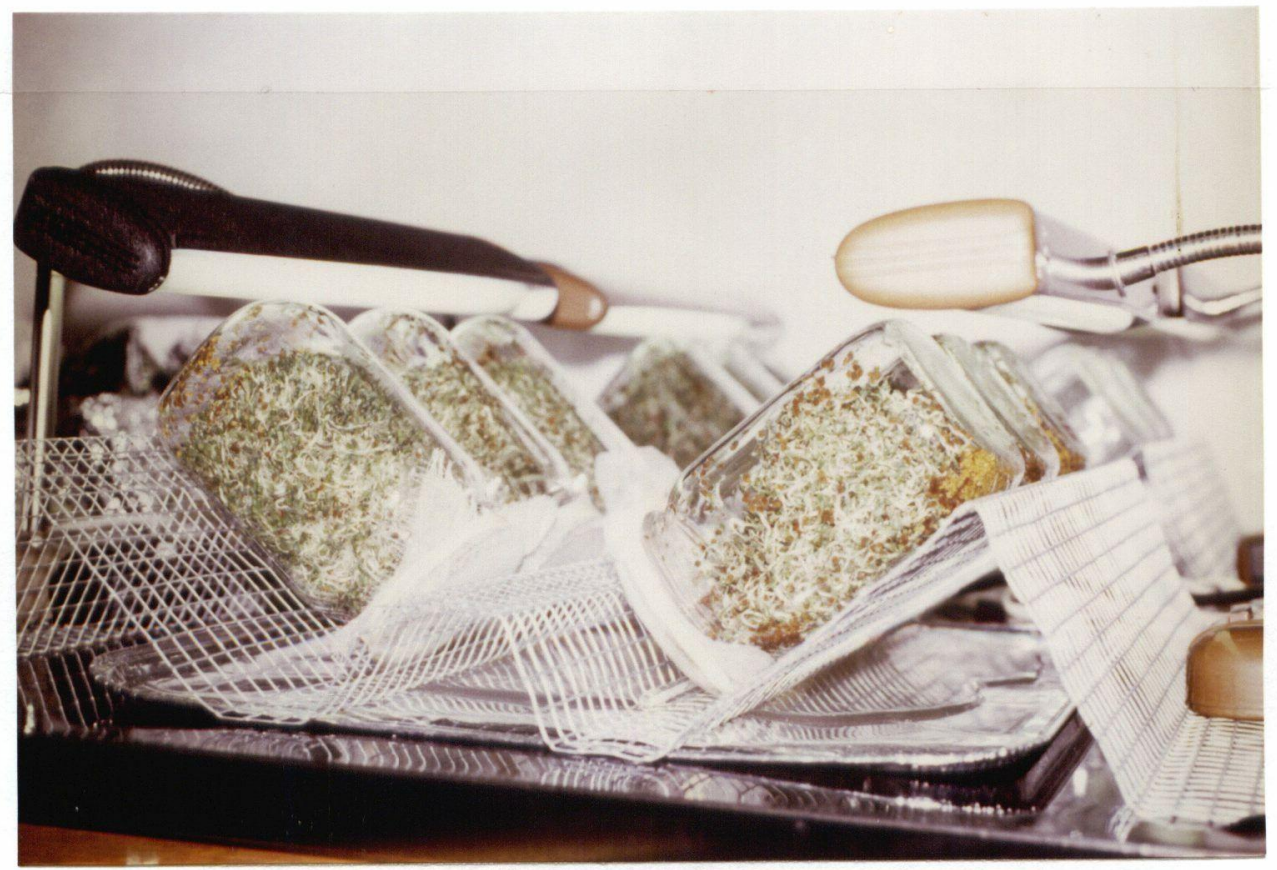




\section{Growth studies}

Growth studies were undertaken to determine the effects of light duration, rinse frequency, rinse volume and growth period, as well as alfalfa cultivar on the content of phytoestrogens in alfalfa sprouts. In all studies the ambient temperature was monitored daily for fluctuations during the growth period. A thermometor was placed on each rack directly beneath the sprout jar openings, and readings were taken 3 times per $24 \mathrm{~h}$ period at $8 \mathrm{~h}$ intervals. All water used for rinsing was distilled. The rinse volume was the quantity of water used at each rinsing time, and was applied in two successive "washes" of equal volume. Daily observations of color, size, stage of sprout development and any visible signs of contamination were recorded.

Light was provided by 15-watt cool-white fluorescent tubes positioned directly over each row of sprouting jars as shown in Figures 10 and 11. Light duration was the number of continuous hours of light per $24 \mathrm{~h}$ period that the sprouts were exposed to. A Li-cor photometer (Lambda Instrument Corp.) equipped with a photosynthetic photon flux density (PPFD) sensor was used to measure the level of light or radiation received at the sprout jar surface. The unit of measure, $\mu E m^{-2} s^{-1}$, indicates the quantity of photosynthetically active radiation (PAR) available to plants in controlled environments, the Einstein (E) being defined as a mole of photons (Tibbitts and Kozlowski, 1979). To provide total darkness for those sprouting treatments requiring a 12 to $24 \mathrm{~h}$ dark period, the sprouting racks were completely covered with aluminum foil (Figure 11). Light level measurements taken under these foil covers were $0 \mu \mathrm{Em}^{-2} \mathrm{~s}^{-1}$. 
Figure 11. Alfalfa sprouts growing under fluorescent lamps (light treatment) and under aluminum foil covers (dark treatment).

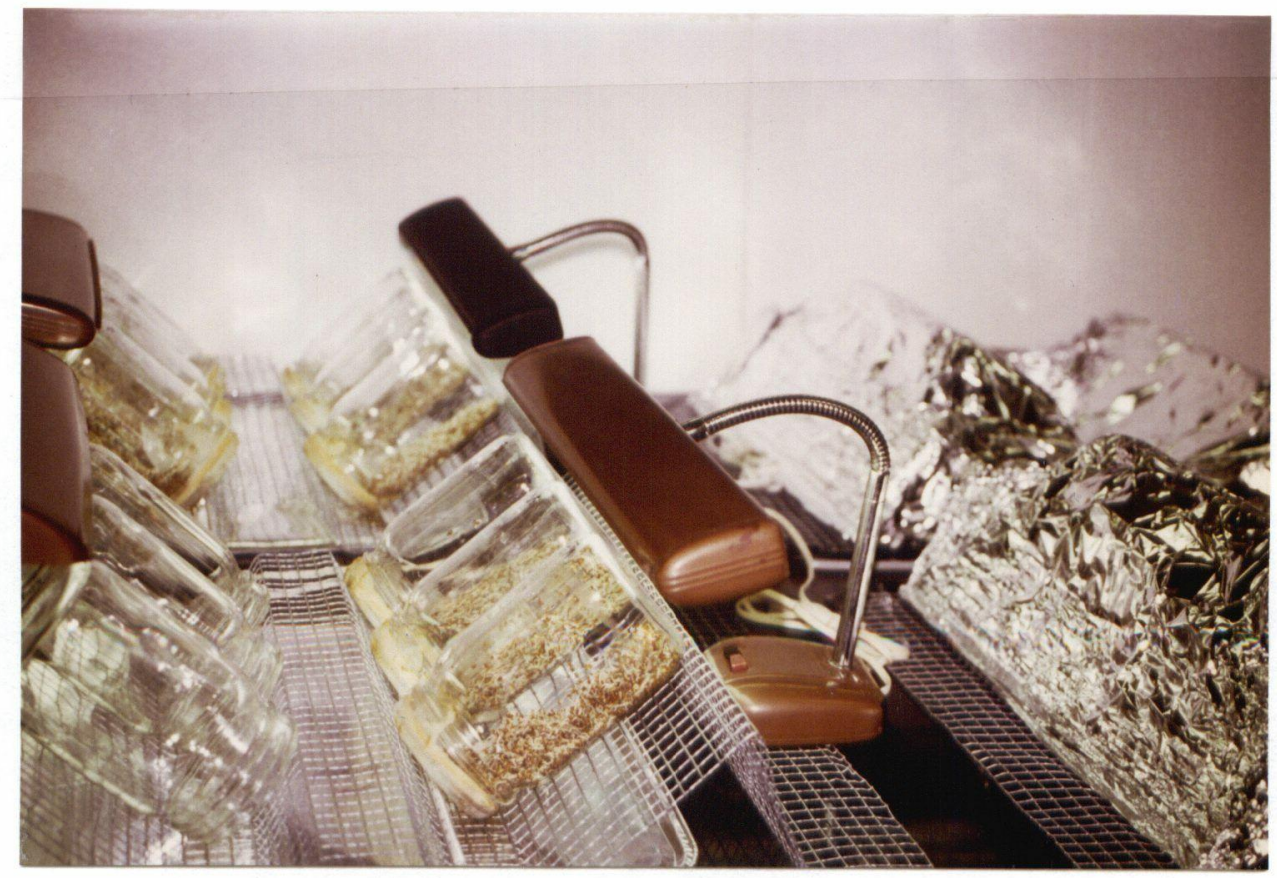




\section{(a) Standard conditions}

The purpose of this experiment was to establish growth conditions that could serve as a standard for the production of high quality alfalfa sprouts. High quality is defined here in terms of visual acceptability and yield: bright green cotyledons; white hypocotyls and radicles; 3 to $5 \mathrm{~cm}$ length. Table 2 summarizes the standard conditions used to grow sprouts from two alfalfa cutivars. The phytoestrogen content of both cultivars was subsequently measured. Conditions were chosen to incorporate those known to be used in commercial alfalfa sprout production as well as conditions recommended by Hesterman et al. (1981) to improve quality and fresh weight yield of sprouts. Sprouts of each cultivar, Moapa and Vernal, were grown in four replicate jars. One jar of sprouts of each cultivar was designated for recovery extraction studies as described in Section B. In addition, four replicate jars of Vernal alfalfa sprouts were grown for preliminary extraction trials. Each jar was labelled with a treatment code and sample number and was randomly assigned a position on the sprouting racks.

\section{(b) Trial conditions}

The purpose of this experiment was to evaluate the effect of environment on the phytoestrogen content of sprouts. The "trial" conditions were chosen to represent a wide range of treatment possibilities as summarized in Table 3. Each treatment was assigned an alphabetic code, e.g. "A". Within each treatment were three replicate jars of sprouts. The $24 \mathrm{~h}$ light and $24 \mathrm{~h}$ dark treatments were carried out on 
Table 2. Standard growth conditions for alfalfa sprouts.

\begin{tabular}{lcc}
\hline & \multicolumn{2}{c}{ Treatment } \\
\cline { 2 - 3 } Condition & MA & BB \\
\hline Cultivar & 100 & Vernal \\
Growth period, $h$ & 12 & 100 \\
Light duration, $h$ & 1 & 12 \\
Rinse volume, $L$ & 2 & 1 \\
Rinse frequency/24 $h$ & & 2 \\
\hline
\end{tabular}


Table 3. Trial growth conditions for alfalfa sprouts.

\begin{tabular}{llccc}
\hline & \multicolumn{4}{c}{ Conditions } \\
\cline { 2 - 5 } Treatment & $\begin{array}{c}\text { Growth period } \\
(\mathrm{h})\end{array}$ & $\begin{array}{c}\text { Light duration } \\
(\mathrm{h})\end{array}$ & $\begin{array}{c}\text { Rinse volume } \\
(\mathrm{L})\end{array}$ & $\begin{array}{c}\text { Rinse Frequency } \\
/ 24 \mathrm{~h}\end{array}$ \\
\hline \hline & & & & \\
$\mathrm{A}$ & 76 & 24 & 1.0 & 2 \\
$\mathrm{~B}$ & 76 & 24 & 0.4 & 5 \\
$\mathrm{C}$ & 76 & 24 & 1.0 & 5 \\
$\mathrm{D}$ & 76 & 0 & 1.0 & 2 \\
$\mathrm{E}$ & 76 & 0 & 0.4 & 5 \\
$\mathrm{~F}$ & 76 & 0 & 1.0 & 5 \\
U & 148 & & & 2 \\
V & 148 & 24 & 1.0 & 5 \\
W & 148 & 24 & 0.4 & 5 \\
X & 148 & 24 & 1.0 & 2 \\
Y & 148 & 0 & 1.0 & 5 \\
$\mathrm{Z}$ & 148 & 0 & 0.4 & 5 \\
\hline
\end{tabular}


separate sprouting racks; sprouting jars within each treatment class were randomly assigned a position on the corresponding racks. Only Vernal alfalfa was used throughout these studies.

\section{(c) Percent germination}

A simple germination trial was set up to measure the percent germination of Vernal alfalfa seeds under conditions used in the germination studies. Seeds $(15 \mathrm{~g})$ were soaked for $4 \mathrm{~h}$ in $300 \mathrm{~mL}$ water, drained and allowed to germinate for $24 \mathrm{~h}$ with periodic rinsing. Ungerminated seeds were separated manually from viable, germinated seed, dried at room temperature overnight and weighed. The difference in weight between the original quantity of seeds and the ungerminated seeds was used to calculate percent germination.

\section{Sprout harvesting}

Alfalfa sprouts were given the final rinse of the treatment schedule immediately before being harvested. Each jar was then vigorously shaken to remove excess water and the sprouts emptied onto paper towels and allowed to drain for $1 \mathrm{~h}$ (Figure 12). From each jar's contents, two samples (@20 g each) were weighed into polyethylene bags for phytoestrogen analysis, and three samples (@ $10 \mathrm{~g}$ each) for moisture analysis. All samples were frozen at $-30^{\circ} \mathrm{C}$ until analyzed. 
Figure 12. Draining of alfalfa sprouts prior to sampling and freezing.

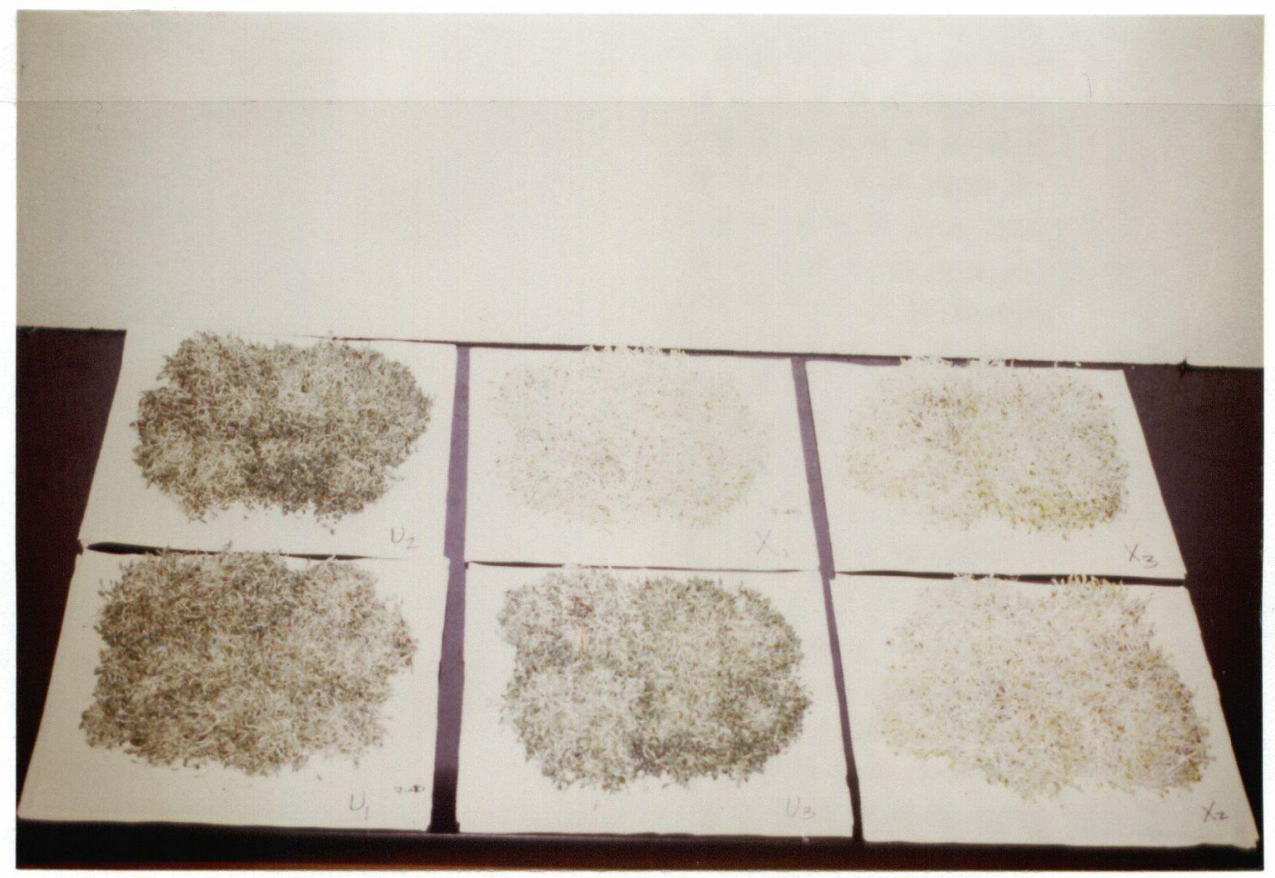




\section{F. STATISTICAL ANALYSIS}

\section{Single factor analysis of variance}

The standard (2) and trial (12) treatment combination conditions used to grow alfalfa sprouts were treated as single factor treatments (14) and analyzed in a one-way analysis of variance, using the UBC MFAV program package (Le, 1978) available for use on the UBC Amdahl $470 \mathrm{~V} / 8$ computer. The Student-Newman-Keuls multiple range test (Zar, 1974) was used to perform multiple comparisons among means for each of the three phytoestrogen variables.

\section{Factorial analysis of variance}

The data collected for each of the phytoestrogen variables under trial growth conditions were coded for a $2^{4}$ factorial design having 4 factors (growth period, light duration, rinse volume and rinse frequency) each with 2 levels as listed in Table 3. Not all of the 16 available treatment combinations were performed, since the rinsing combination of a $0.4 \mathrm{~L}$ volume applied twice/24 $\mathrm{h}$ was assumed to be insufficient for alfalfa sprout growth. As a result, data for only 12 treatment combinations were analyzed using an analysis of variance program package for an unbalanced design (GENLIN) adapted for the UBC computer (Greig and Bjerring, 1978). These analyses were carried out to determine the significance of the factor(s) and/or factor interaction(s) on the accumulation of each phytoestrogen in alfalfa sprouts. Multiple comparisons among phytoestrogen means (of 3 replicates) were performed using the Student-Newman-Keuls test. 


\section{RESULTS AND DISCUSSION}

\section{A. EXTRACTION}

\section{Extraction methodology}

The method developed for phytoestrogen extraction from alfalfa sprouts was adapted from the extraction methods reported by Beck (1964) and Francis and Millington (1965b) for the analysis of clover forage. Several modifications were made to these methods in part to account for the larger sample size in the present study and to prepare the sample extract for subsequent analysis by high performance liquid chromatography.

The ground alfalfa sample was allowed to stand as per Francis and Millington (1965b) to permit enzymatic hydrolysis of isoflavones present as glycosides. However, preliminary experiments indicated that further hydrolysis and improved extractability could be achieved by adding $2 \mathrm{~N} \mathrm{HCl}(20: 802 \mathrm{~N} \mathrm{HCl} / \mathrm{MeOH}, v / v)$ to the reflux mixture. Chromatograms from alfalfa extracts obtained without this acid showed poorer recovery of phytoestrogens. The acid may also aid in recovery of the phytoestrogens during the extraction process since isoflavones and coumestans are very stable in an acid medium (Wong, 1975).

A refluxing period of $30 \mathrm{~min}$ was chosen for the methanol/acid hydrolysis based on evidence that 7-0-glycosidic linkages would be completely hydrolyzed in 15 to $40 \mathrm{~min}$ under similar conditions (Markham, 1982). Further improvements in phytoestrogen recovery were not achieved when refluxing conditions of $45 \mathrm{~min}$ with 50:50 $2 \mathrm{~N} \mathrm{HCl} / \mathrm{MeOH}(\mathrm{v} / \mathrm{v})$ were attempted. 
The alfalfa filtrate was evaporated in a subsequent step to remove a large portion of the methanol prior to petroleum ether extraction of the lipids and chlorophyll pigments. In the presence of the total methanol volume, a complete separation of the petroleum ether and water/methanol layers could not be achieved because petroleum ether is miscible with methanol. Furthermore, there was little transfer of chlorophyll pigments to the petroleum ether phase if all the methanol was present. Evaporation to a total volume of approximately 70 to 75 $\mathrm{mL}$ resulted in an improved partition of the two phases and an efficient removal of most chlorophyll pigments from the crude extract. A pigmented sludge layer that formed at the interface was discarded with the final petroleum ether extract.

Ethyl ether was used for the extraction of phytoestrogens from the aqueous alfalfa mixture because both isoflavones and coumestrol are soluble in this solvent. Evaporation of ethyl ether under vacuum was rapid and the remaining residue could be easily dissolved in methanol for HPLC analysis.

\section{Recovery studies}

As previously described, studies were carried out to evaluate the recovery by this extraction method of a phytoestrogen standards mix and of a standards mix added to alfalfa sprouts (grown under "standard" conditions). In order to account for the quantity of phytoestrogens contributed by the alfalfa sprouts, the mean area count response obtained (by HPLC analysis) from unspiked alfalfa extracts was subtracted from the area count responses of the spiked alfalfa extracts. 
These adjusted area count values were then used to calculate recovered phytoestrogen contents. The mean contents of phytoestrogens calculated to be present were compared to an expected value of $6.0 \mu \mathrm{g} / \mathrm{mL}$ to obtain $\%$ recovery data (Table 4 ).

The recovery data for the standards mix indicate that there were only minimal losses as a result of extraction procedures involving refluxing, evaporation and phasic distribution. Recoveries of standards added to alfalfa samples were markedly lower; however, except in the case of coumestrol from Moapa alfalfa, these recoveries did compare favorably to previously reported values (Lookhart, 1979; Murphy, 1981). Wong (1962) and Sachse (1974) reported losses of formononetin in the insoluble sludge layer that formed during the extraction of clover pigments with petroleum ether. These losses were attributed to formononetin's low solubility in the aqueous/alcohol layer. Low recoveries of coumestrol have been reported in soybean extraction as a result of binding to lipid fractions (Lookhart, 1979). The low solubilities of coumestrol in common solvents and aqueous systems may also have contributed to extraction losses in the present study.

Cultivar differences in phytoestrogen contents have been well documented (Beck, 1964; Francis and Millington, 1965b; Stuthman et al., 1966; Francis et al., 1967; Loper et al., 1967); however, there are no reports in the literature of cultivar differences in extraction efficiencies. 
Table 4. Recovery of phytoestrogens using developed extraction method.

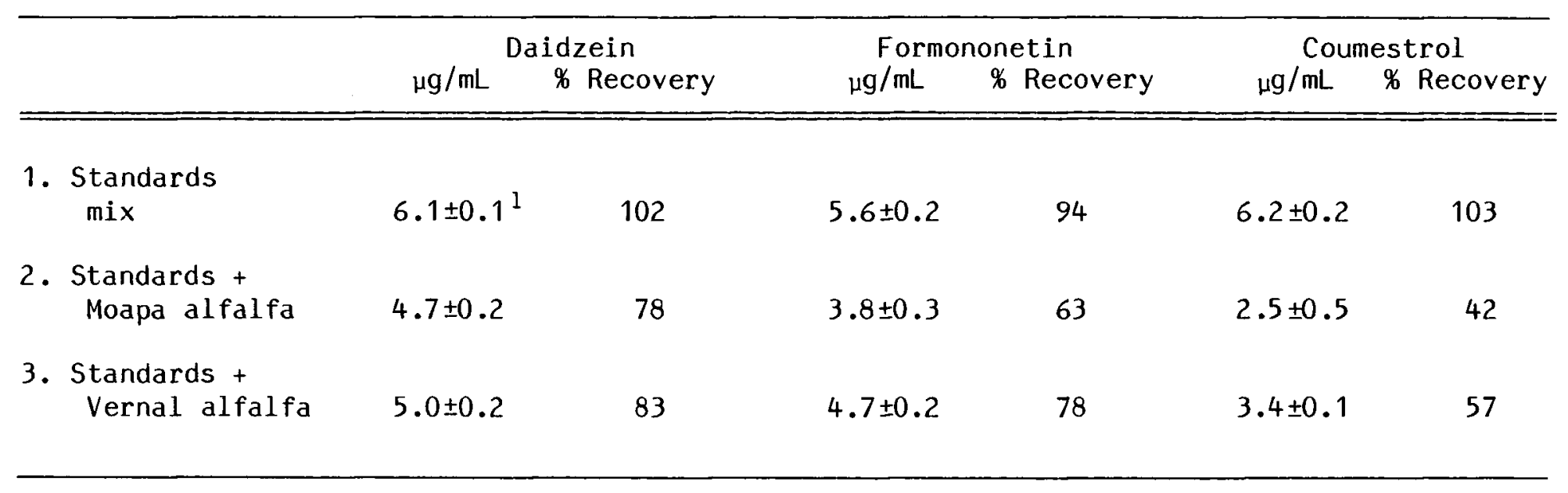

${ }^{1}$ Mean values and standard deviation of 6 determinations. 


\section{B. HIGH-PERFORMANCE LIQUID CHROMATOGRAPHY}

1. HPLC methodology

Numerous HPLC systems have been developed for the separation and detection of selected phytoestrogens. Several of these systems (Ohta et al., 1979; Murphy, 1981; Nicollier and Thompson, 1982) did not appear to adequately resolve the peaks of interest for quantitative purposes. A number of other systems were examined in this study, using a reversedphase Varian MicroPak $\mathrm{MCH}-10$ column, in attempts to resolve alfalfa sprout extracts.

Initial studies carried out with isocratic methanol/water systems (e.g. $60: 40, \mathrm{MeOH} / \mathrm{H}_{2} 0 ; 1.0 \mathrm{~mL} / \mathrm{min}$ ) showed that the elution of the phytoestrogen standards followed the expected order of Vande Casteele et al. (1982) based primarily on ring substitution of the flavonoids. Elution was in the order of decreasing polarity which is typical of reversedphase chromatography and also demonstrated by Murphy and Stutte (1978). Daidzein eluted first, followed by formononetin (less polar due to the presence of a methoxy group at $\mathrm{C}-4^{\prime}$ vs. a hydroxy group for daidzein) and finally coumestrol, eluting immediately after formononetin.

Resolution of the phytoestrogen standards alone was excellent, however, when the same high (>55\%) methanol systems were used to separate alfalfa extracts, resolution of the phytoestrogens was poor. The alfalfa extracts contained a number of peaks eluting with the void volume and interfering with the resolution of the daidzein peak. These peaks could correspond to polar, non-flavonoid compounds such as phenolic acids. Ohta et al. (1979) reported a similar observation with 
soybean extracts. Early eluting peaks were considered to be hydrophilic lower molecular weight compounds but not flavonoids.

Using solvent systems with a lower methanol concentration ( $<50 \%)$ improved the resolution of daidzein from the more polar early eluting peaks but resulted in severe band spreading and increased retention times of the later eluting formononetin and coumestrol peaks. Trial runs using an aqueous methanol gradient from 20 to $50 \%$ methanol over 20 min as described by Eldridge (1982a) to resolve isoflavones and coumestrol were attempted, but without success on the present column. Formononetin and coumestrol had not even eluted by $60 \mathrm{~min}$ because the eluting strength of the solvent system was too low. An isocratic solvent system of $52: 48 \mathrm{MeOH} / \mathrm{H}_{2} \mathrm{O}(\mathrm{v} / \mathrm{v})$ at a flow rate of $1.0 \mathrm{~mL} / \mathrm{min}$ was subsequently found to give a reasonable separation of the early portion of the alfalfa extract chromatogram. Further fine-tuning of the program was continued in order to improve the resolution of the latter half of the chromatogram.

To reduce the total time required for elution of the alfalfa extract, various gradient solvent programs were carried out. Steep gradients as used by Murphy (1981) were found unsuitable because they greatly reduced resolution of the later peaks as a result of baseline fluctuations and drift. A linear gradient program starting at 53\% methanol was demonstrated to be more desirable because baseline effects did not interfere with peak quantitation. A gradual increase to $58 \%$ methanol over 30 min was found adequate to reduce program elution time to $30 \mathrm{~min}$. Increases to greater methanol concentrations decreased the resolution between formononetin and coumestrol. Faster gradients had 
a minimal effect on retention times of formononetin and coumestrol and also caused more baseline fluctuations.

In an effort to reduce peak tailing of the eluting compounds, acetic acid was added to the water and methanol reservoirs. It was found that a $1 \%$ concentration $(v / v)$ of glacial acetic acid in the solvent mixture improved peak shape of the eluting phytoestrogen peaks and effectively reduced retention times, especially of formononetin and coumestrol. Acid has been used by other workers (Wulf and Nagel, 1976; Vande Casteele et al., 1982) to suppress ionization of the acid groups on flavonoids and phenolic acids as previously described (Materials and Methods). The most acid group of isoflavonoids is considered to be the phenolic hydroxyl at C-7 (Markham, 1982) which is present on all three phytoestrogens studied here.

In addition to acid, other workers (Murphy and Stutte, 1978; Proksch et al., 1981) have used ammonium acetate as a buffering reagent to prevent abnormal polar movement of compounds on the reversed-phase column. Murphy and Stutte (1978) reported that ortho-hydroxylated compounds, such as some phenolic acids, could undergo intramolecular hydrogen bonding so that their polar hydroxy groups would be bound and elution and separation would no longer be based on true polarity.

Neither daidzein, formononetin or coumestrol are ortho-hydroxylated, and their elution order was not affected by the presence of ammonium acetate. However, in this study $0.01 \mathrm{M}$ ammonium acetate was found effective in improving resolution, particularly the separation of daidzein from early eluting peaks. Retention times were also reduced in 
comparison to the methanol/water only solvent system, and were similar to the retention times obtained with the $1 \%$ acetic acid system.

In combination, the addition of $1.0 \%$ acetic acid and $0.01 \mathrm{M}$ ammonium acetate to both the methanol (B) and water (A) solvent reservoirs provided for an improved separation of the alfalfa extract where all three phytoestrogen peaks are sharp, resolved to baseline, and elute under 30 min using the linear gradient program from $53 \%$ to $58 \%$ methanol (reservoir B) over a $30 \mathrm{~min}$ period. The $\mathrm{pH}$ of this solvent system at initial composition conditions $(53: 47$, B/A) was 4.5 which is well within the $\mathrm{pH}$ guidelines of 2.0 to 7.5 for Varian MicroPak columns (Varian Assoc., 1978).

\section{Chromatographic parameters}

The retention times $\left(t_{R}\right)$ and the other chromatographic parameters $k$ (capacity factor), $\propto$ (separation factor) and $R_{S}$ (resolution) for the phytoestrogen peaks were calculated from chromatograms obtained for HPLC runs of standards and alfalfa extracts. The equations (1 to 3 ) and measurements (Figure 9) used for these calculations were given in the previous section (Materials and Methods). Table 5 lists the values obtained from HPLC analysis of the three phytoestrogens in a standard mix, standards extract, spiked alfalfa extract and an unspiked alfalfa extract (Treatment $X)$. Treatment $X$ sprouts were chosen for representation of the alfalfa only extract because all three phytoestrogens were detectable.

The retention times represent means of the total number of determinations made for each sample, as noted on Table 5. Coefficients 
Table 5. Retention times $\left(t_{R}\right)$, capacity factors $(k)$, separation factors ( $\alpha$ ) and resolution $\left(R_{s}\right)$ of selected phytoestrogens on MicroPak $\mathrm{MCH}-10$ using linear gradient elution as described.

\begin{tabular}{|c|c|c|c|c|c|c|c|c|c|}
\hline \multirow[b]{2}{*}{ Sample } & \multicolumn{3}{|c|}{$t_{R}(\min )$} & \multicolumn{3}{|c|}{$k$} & \multicolumn{2}{|c|}{$\propto$} & \multirow{2}{*}{$\frac{R_{S}}{F / C}$} \\
\hline & $D$ & $F$ & C & D & $F$ & $\mathrm{C}$ & $D / F$ & $F / C$ & \\
\hline $\operatorname{mix}_{\operatorname{mix}}^{\text {Standards }}$ & $\begin{array}{l}10.78 \\
\pm 0.02^{4}\end{array}$ & $\begin{array}{l}24.10 \\
\pm 0.06\end{array}$ & $\begin{array}{l}27.15 \\
\pm 0.08\end{array}$ & 3.31 & 8.64 & 9.86 & 2.61 & 1.14 & 1.99 \\
\hline $\begin{array}{c}\text { Standards }{ }^{2} \\
\text { extract }\end{array}$ & $\begin{array}{l}11.33 \\
\pm 0.18\end{array}$ & $\begin{array}{l}25.62 \\
\pm 0.44\end{array}$ & $\begin{array}{l}28.53 \\
\pm 0.46\end{array}$ & 3.78 & 9.82 & 11.06 & 2.60 & 1.13 & 1.89 \\
\hline $\begin{array}{l}\text { Alfalfa extract } \\
\text { spiked }\end{array}$ & $\begin{array}{r}11.678 \\
\pm 0.04\end{array}$ & $\begin{array}{l}26.38 \\
\pm 0.08\end{array}$ & $\begin{array}{l}29.38 \\
\pm 0.09\end{array}$ & 3.86 & 9.99 & 11.24 & 2.59 & 1.13 & 1.91 \\
\hline $\begin{array}{c}\text { Alfalfa extract }{ }^{3} \\
(\text { Treatment } X)\end{array}$ & $\begin{array}{l}11.10 \\
\pm 0.14\end{array}$ & $\begin{array}{l}24.62 \\
\pm 0.38\end{array}$ & $\begin{array}{l}27.62 \\
\pm 0.47\end{array}$ & 4.05 & 10.19 & 11.55 & 2.52 & 1.13 & 1.54 \\
\hline
\end{tabular}

${ }^{1} t_{R}$ is the mean of 5 determinations.

${ }^{2} t_{R}$ is the mean of 6 determinations.

${ }^{3} t_{R}$ is the mean of 12 determinations.

${ }^{4}$ Standard deviation. 
of variation of retention times were found in the range of 0.2 to $1.7 \%$ which is within the precision required for peak identification $(0.2$ to 2.0\%) (Johnson and Stevenson, 1978).

The $k$ values were calculated to indicate the retention characteristics of the chosen HPLC system. Yost et al. (1980) stated that $k>1$ is desirable for the first peak of interest to ensure separation from the unretained peaks at the solvent front. Also, peaks should have $k<10-15$ or analysis time is too long. Peak widths tend to increase with increasing $k$ values which makes resolution and detection more difficult. The $k$ values calculated from the corresponding mean retention times for daidzein, formononetin and coumestrol are within this recommended range (Table 5).

The $\propto$ values were calculated to determine the relative retention of the two peaks in the pairs daidzein/formononetin and formononetin/ coumestrol. These values are dependent only on temperature, column and mobile phase composition and so can serve as a reliable index for peak identification (Snyder and Kirkland, 1979; Yost et al., 1980). The $\propto$ values listed for the unspiked alfalfa extracts were derived from peaks tentatively identified by retention times as the three phytoestrogens. Based on agreement of these $\propto D / F$ and $\propto F / C$ values with the corresponding $\propto$ values of the standards and spiked alfalfa extract (Table 5) one could further confirm the identity of the phytoestrogen peaks.

Resolution was calculated to determine the actual separation of the closely eluting peaks, formononetin and coumestrol. A representative chromatogram (Figures 13-16) from each of the sample groups was used for manual measurements of peak widths. An $R_{S}$ value of 1.0 means 
Figure 13. HPLC chromatogram of phytoestrogen standards. Peaks: $D=$ daidzein, $F=$ formononetin, $C=$ coumestrol.

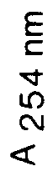

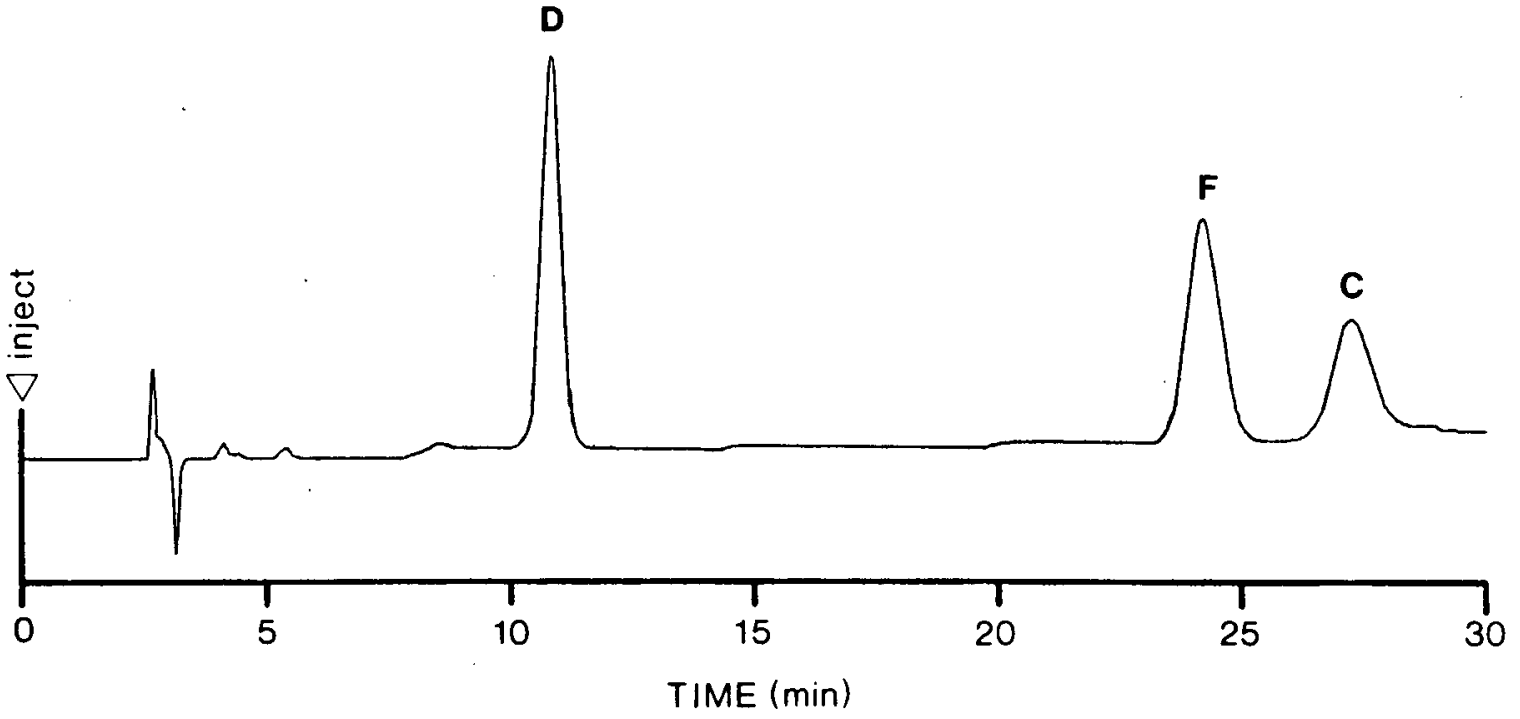


Figure 14. HPLC chromatogram of phytoestrogen standards extract. Peaks: $D=$ daidzein, $F=$ formononetin, $C=$ coumestrol.

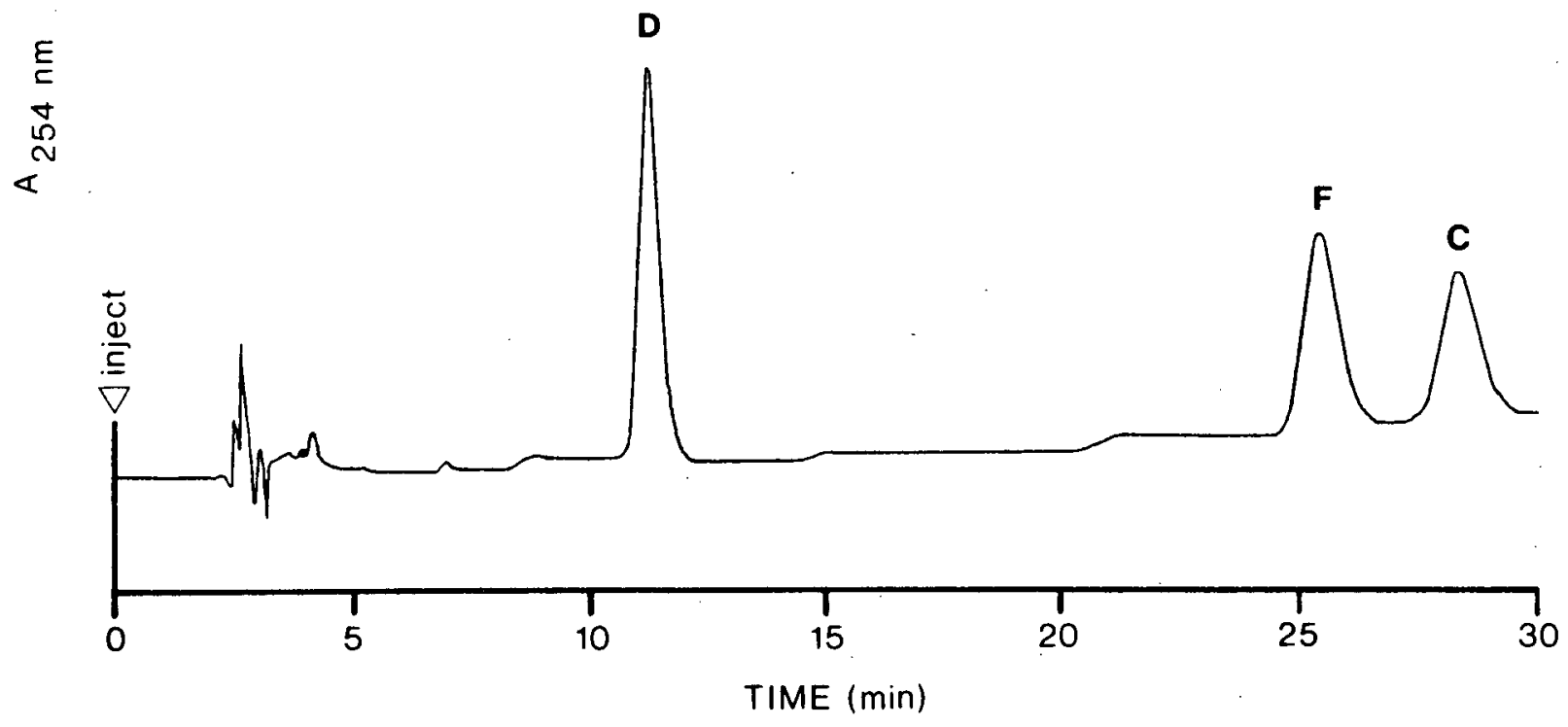


Figure 15. HPLC chromatogram of alfalfa extract spiked with phytoestrogen standards prior to extraction. Peaks: $D=d a i d z e i n$, $\mathrm{F}=$ formononetin, $\mathrm{C}=$ coumestrol.

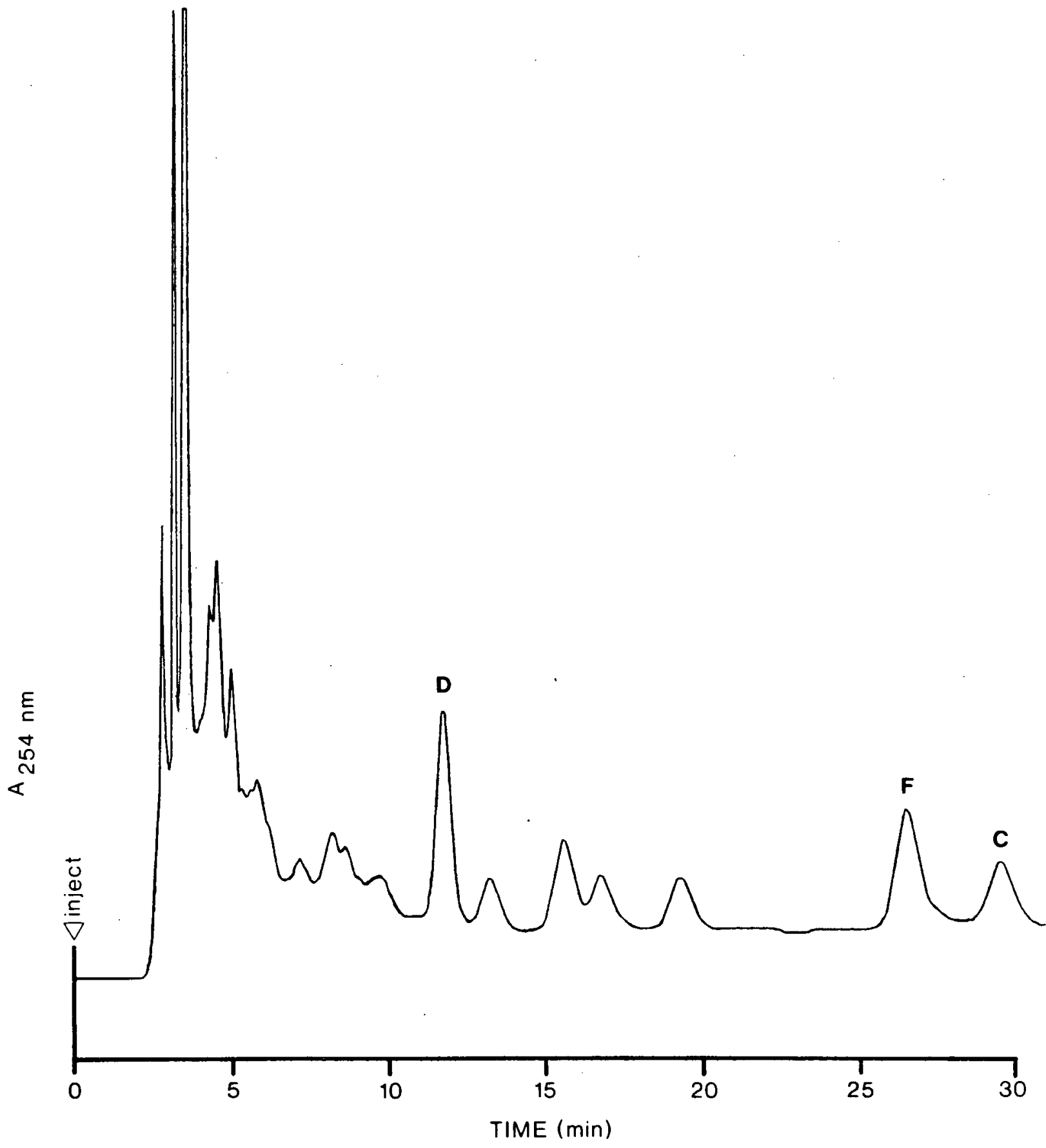


Figure 16. HPLC chromatogram of alfalfa extract (Treatment X). Peaks: $D=$ daidzein, $F=$ formononetin, $C=$ coumestrol.

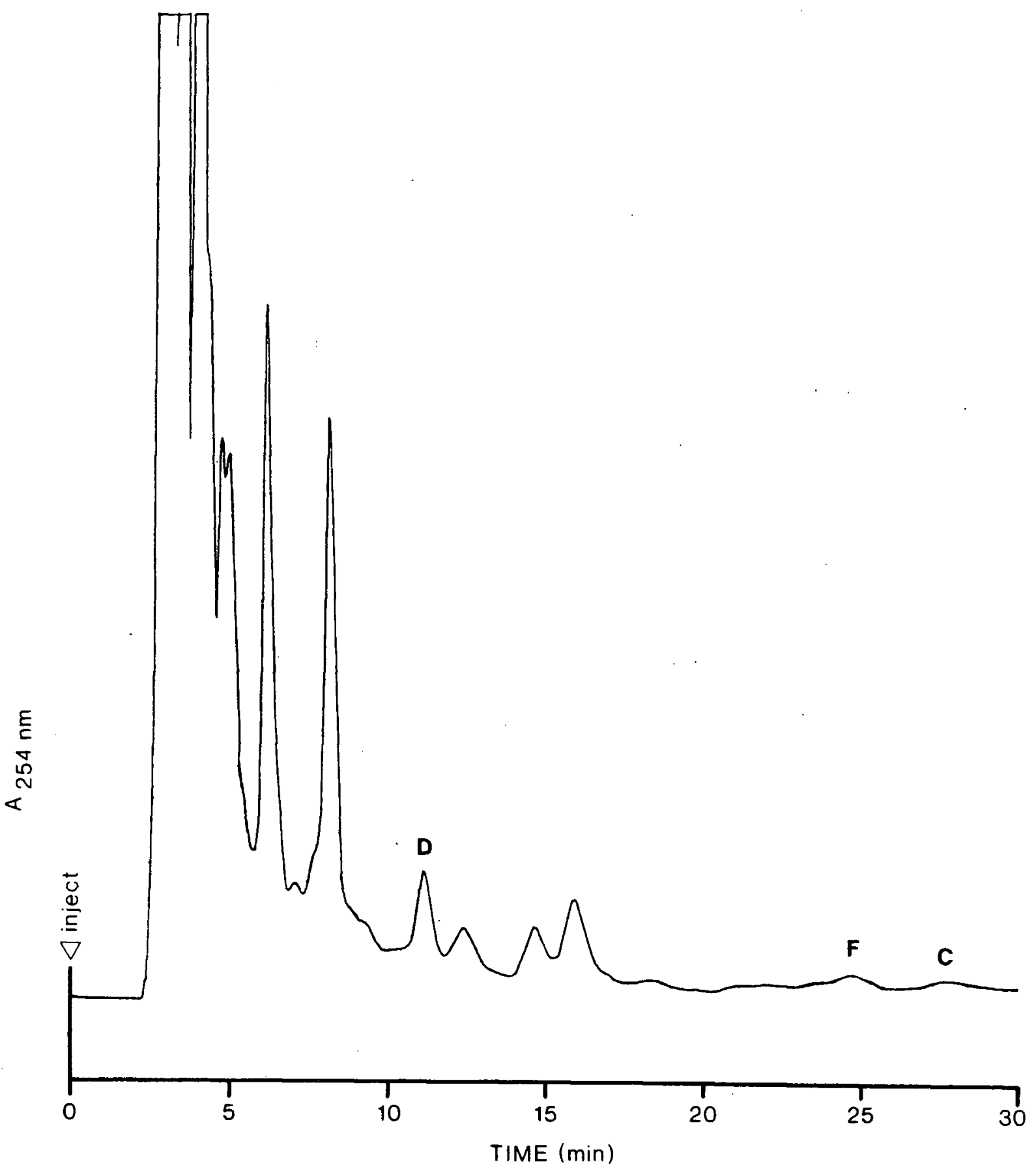


that resolution is approximately $90 \%$ complete, which is considered sufficient for peak area calculations, while an $R_{S}$ value of 1.5 represents baseline separation (Yost et al., 1980). In all samples represented (Table 5), baseline resolution of formononetin and coumestrol was .achieved, although the $R_{S}$ value for the alfalfa only extract was markedly lower in comparison to the other samples. The low concentrations of formononetin and coumestrol found in the alfalfa only extract eluted as very broad peaks which resulted in large peak width measurements, thus affecting peak resolution.

\section{Linear regression analysis}

Standard solutions of each phytoestrogen from concentrations of 0.2 to $30.0 \mu \mathrm{g} / \mathrm{mL}$ in methanol were injected in triplicate for HPLC analysis and the peak area integrator responses recorded. Injections of methanol were also made to measure any baseline response that might occur at peak retention times even in the absence of the phytoestrogens. The standard curves derived from collected peak area data were found to be well described by the following regression equations:

$$
\begin{array}{llll}
\text { Daidzein: } & Y=-0.029+3.809 X & \mathrm{r}^{2}=0.9998 & \mathrm{~s}_{\mathrm{y} \cdot \mathrm{x}}=0.524 \\
\text { Formononetin: } & Y=0.168+3.813 \mathrm{X} & \mathrm{r}^{2}=0.9982 & \mathrm{~s}_{\mathrm{y} \cdot \mathrm{x}}=1.516 \\
\text { Coumestrol: } & Y=0.592+2.707 X & \mathrm{r}^{2}=0.9992 & \mathrm{~s}_{\mathrm{y} \cdot \mathrm{x}}=0.771 \\
\mathrm{Y}=\text { area counts }(\mu \mathrm{V}-\mathrm{sec}) / 10^{4} & \\
X=\text { concentration of phytoestrogen }(\mu \mathrm{g} / \mathrm{mL} \text { in methanol })
\end{array}
$$

Some difficulties were encountered in obtaining reproducible integrator responses for the lowest concentrations of formononetin and 
coumestrol standard solutions. For this reason the integrator responses for $0.2 \mu \mathrm{g} / \mathrm{mL}$ formononetin and 0.2 and $0.4 \mu \mathrm{g} / \mathrm{mL}$ coumestrol were not included in regression equation calculations.

\section{GROWTH STUDIES}

1. Moisture determination

Moisture contents of alfalfa sprouts grown under standard and trial conditions were found to range from 88.5 to $94.8 \%$ (Table.6). There was no significant difference $(P>0.05)$ in the moisture content of Moapa and Vernal alfalfa sprouts grown under standard conditions. The moisture contents of the $76 \mathrm{~h}$ sprouts grown under trial conditions, both light and dark (A to $F)$, were all significantly less $(P \leq 0.05)$ than the moisture contents of the $148 \mathrm{~h}$ sprouts ( $U$ to $\mathrm{Z}$ ). The longer growth period presumably results in greater uptake of water by the sprouts. Hesterman et al. (1981) attributed the increase in fresh weight yield of alfalfa sprouts with longer growing periods ( 4 to 8 days) to greater water absorption. Hamilton and Vanderstoep (1979) also reported a significant difference in moisture contents between $72 \mathrm{~h}$ and $120 \mathrm{~h}$ alfalfa sprouts, but no significant difference between sprouts grown for the same length of time in light vs. dark conditions. In the present study, moisture contents of sprouts grown in the dark were greater than the corresponding sprouts grown in the light for a given growth period treatment (e.g. D vs. A), however, not all differences were significant $(P \leq 0.05)$

Nevertheless, it was because of significant differences $(P \leq 0.05)$ in moisture contents that calculations of each alfalfa sprout sample's 
Table 6. Moisture content of alfalfa sprouts grown under standard and trial conditions.

\begin{tabular}{cl}
\hline Treatment & $\begin{array}{c}\text { Moisture } \\
(\%)^{2}\end{array}$ \\
\hline STANDARD & $91.5 \pm 0.4^{\mathrm{a} 3}$ \\
Moapa & $91.4 \pm 0.2^{\mathrm{a}}$ \\
Vernal & \\
TRIAL & \\
A & $88.5 \pm 0.5^{\mathrm{b}}$ \\
B & $91.3 \pm 0.3^{\mathrm{a}}$ \\
C & $91.6 \pm 0.1^{\mathrm{a}}$ \\
D & $90.5 \pm 0.4^{\mathrm{c}}$ \\
E & $91.4 \pm 0.5^{\mathrm{a}}$ \\
F & $92.5 \pm 0.2^{\mathrm{d}}$ \\
U & $93.3 \pm 0.2^{\mathrm{e}}$ \\
V & $93.5 \pm 0.3^{\text {ef }}$ \\
W & $94.1 \pm 0.2^{\mathrm{f}}$ \\
X & $94.2 \pm 0.1^{\mathrm{f}}$ \\
Y & $93.7 \pm 0.6^{\text {ef }}$ \\
Z & $94.8 \pm 0.1^{\mathrm{g}}$ \\
\hline
\end{tabular}

${ }^{1}$ Expressed on wet weight basis.

${ }^{2}$ Mean of 3 replicates \pm standard deviation.

${ }^{3}$ Means sharing the same superscript are not significantly different $(P>0.05)$ as determined by Duncan's multiple range test. 
dry weight were made using the corresponding treatment's mean moisture content, rather than using an overall mean moisture content.

\section{Growth conditions}

(a) Percent germination

The two alfalfa cutivars used in the present study, Moapa and Vernal, were purchased as "sprouting" alfalfa (Richardson Seed Co. Ltd., Burnaby, B.C.). Alfalfa seeds sold for home and commercial sprouting purposes for human consumption must be "untreated", i.e. have had no fungicide treatment, and should have germinaton percentages of at least 85\% to be most desirable for sprouting (Kulvinskas, 1978; Hesterman and Teuber, 1980).

Moapa alfalfa was demonstrated to have high germination and greater fresh weight yield in comparison to five other alfalfa cultivars (Hesterman et al., 1981). In the present study the mean percent germination (of 3 replicates) of Vernal alfalfa seeds was found to be $82 \%$ which could still be considered as a desirable level of seed viability for sprouting.

\section{(b) Light}

Light has been demonstrated to influence the rate of respiration during germination (Mayer and Poljakoff-Mayber, 1975). Light may also indirectly affect the synthesis of flavonoid substances since photosynthesis determines the size of the sugar pool which in turn affects production of the aromatic rings via the shikimic acid pathway (Rossiter and Beck, 1967). However, Rossiter and Beck (1967) reported appreciable 
quantities of estrogenic isoflavones in clover that was grown in complete darkness, indicating that the light requirement for phytoestrogen synthesis is low. Nevertheless, growth studies were carried out to determine if light influences phytoestrogen accumulation in alfalfa sprouts.

The light level that the alfalfa sprouts were exposed to was measured in terms of photosynthetic photon flux density (PPFD) in units of $\mu \mathrm{Em}^{-2} \mathrm{~s}^{-1}$ where an Einstein (E) is the equivalent of one mole of photons. This measurement is favored for the determination of the radiation (between 400 and $700 \mathrm{~nm}$ ) that plants receive in controlled environments, rather than measuring the intensity of light produced by lamps (in lux or foot-candles) (McFarlane, 1978; Tibbitts and Kozlowski, 1979). Furthermore, the various light absorbing pigments in plants differ from the pigments responsible for human vision in that each pigment has its own absorption and action spectrum. Therefore, different plant functions respond to particular spectral bands of light with different efficiencies (McFarlane, 1979).

Some difficulty was experienced in taking light level measurements because the readings depended on the angle and position of the sensor in relation to the overhead lamps. In field studies, Tibbitts and Kozlowski (1979) recommended that measurements be made at the top of the plant canopy. In the present study the raised centre of the sprouting rack was chosen as the point for measurement with the sensor placed perpendicular to the rack. The fluorescent lamps positioned directly over the jars in addition to the overhead room lamps provided an average PPFD of $50 \mathrm{\mu Em}^{-2} \mathrm{~s}^{-1}$. The same reading was obtained when the sensor was placed 
in the centre of sprouting jars directly onto the surface of the sprouts. This light level was markedly lower than the $240 \mu \mathrm{Em}^{-2} \mathrm{~s}^{-1}$ used by Hesterman et al. (1981), however, it was considered adequate for contrast with the dark condition of $0 \mu \mathrm{Em}^{-2} \mathrm{~s}^{-1}$ used in the other growth studies (as measured with a sensitivity of $0.1 \mu \mathrm{Em}^{-2} \mathrm{~s}^{-1}$ ). Furthermore, McFarlane (1978) reported that the germination response of a plant requires a light level of only $0.1 \mathrm{\mu Em}^{-2} \mathrm{~s}^{-1}$.

\section{(c) Temperature}

The readings recorded from thermometers placed on the sprouting racks indicated that the ambient temperature remained relatively constant over a $24 \mathrm{~h}$ duration, throughout the growth periods and regardless of light or dark growth conditions. The mean ambient temperature was found to be $22.2^{\circ} \mathrm{C}$ ( $r$ ange 21.2 to $24.0^{\circ} \mathrm{C}$ ). Random temperature readings taken inside the sprouting jars were constant at $23^{\circ} \mathrm{C}$. Hesterman et al. (1981) found that a germination temperature of $21^{\circ} \mathrm{C}$ was optimal for fresh weight yield of alfalfa sprouts. Several workers (Fordham et al., 1975; Hamilton and Vanderstoep, 1979; Hsu et al., 1980) have conducted germination studies of alfalfa and other legumes at comparable temperatures of 22 to $25^{\circ} \mathrm{C}$.

\section{Alfalfa sprout development}

Observations recorded during the growth studies provide a means of identifying differences in sprout development that may occur under various growth conditions. Observations made at $24 \mathrm{~h}$ intervals included sprout length, color, maturity, as well as any visible signs of contamination and/or spoilage. 


\section{(a) Standard conditions}

After $4 \mathrm{~h}$ soaking, alfalfa seeds were swollen and seed coats had split. Following the first $24 \mathrm{~h}$ growth period, white hypocotyls (Figure 7) had emerged from the seeds and averaged $1.0 \mathrm{~cm}$ in length. The seed coats were only partially removed from the cotyledons. After the second $24 \mathrm{~h}$ growth period, the hypocotyls averaged $1.5 \mathrm{~cm}$ in length. Cotyledons had begun to develop green color as seed coats separated away from the cotyledons. At $76 \mathrm{~h}$ ( 3 days + soaking time) the hypocotyls had elongated to an average of $2.0 \mathrm{~cm}$. The cotyledons were green but remained largely folded together. At this stage, Moapa sprouts appeared to be developing more rapidly than Vernal sprouts in terms of fleshier hypocotyls and larger, spread open cotyledons. More rapid germination and subsequent photosynthesis may be related to the higher inherent seedling vigor of one cultivar compared to another, as suggested by Walter and Jensen (1970). Sprouts harvested after $100 \mathrm{~h}$ had bright green cotyledons and white hypocotyls at least $3.0 \mathrm{~cm}$ long with some pink color development at the upper portion of the hypocotyls. The sprouts appeared healthy with no visible signs of spoilage.

\section{(b) Trial conditions}

After a $4 \mathrm{~h}$ soaking period, the Vernal alfalfa seeds used in this study were swollen and the seed coats were split. A subsequent $24 \mathrm{~h}$ growth period resulted in white hypocotyls approximately $1.0 \mathrm{~cm}$ in length in both $0 \mathrm{~h}$ light ("dark") and $24 \mathrm{~h}$ light ("light") conditions. Seed coats were partially removed and cotyledons appeared slightly green in the "light" sprouts and light yellow in the "dark" sprouts. After 
the second $24 \mathrm{~h}$ growth period, the hypocotyls of the "light" sprouts averaged $2.0 \mathrm{~cm}$ in length and most cotyledons were green and had begun to spread open. The hypocotyls of the "dark" sprouts averaged $2.5 \mathrm{~cm}$ in length and were much straighter than those of the light sprouts. Cotyledons were yellow and some had also begun to spread open. Differences in sprout development in response to various growth conditions had become more apparent at this stage.

At $76 \mathrm{~h}$ the "light" sprouts generally had large, dark green cotyledons, many spread open, and hypocotyls that had become pink at the base, pale green in the centre but remained white at the tip (radicle). Treatment $A$ and $U$ sprouts had approximately $3.0 \mathrm{~cm}$ long hypocotyls and many seed coats remained among the sprout mass. Treatment $B$ and $V$ as well as $C$ and $W$ sprouts averaged $3.5 \mathrm{~cm}$ in length and most seed coats accumulated at the bottom of the jars, presumably due to more frequent rinsing. The corresponding "dark" sprouts had primarily small, yellow cotyledons (with some greening) which had only slightly spread open. The hypocotyls were white except for some pink pigmentation at the base. Treatment $D$ and $X$ sprouts averaged $3.0 \mathrm{~cm}$ hypocotyls and the seed coats remained among the sprouts. Treatment $E$ and $Y$ as well as $F$ and $Z$ sprouts averaged $4.0 \mathrm{~cm}$ hypocotyls and most seed coats had been washed out of the sprout mass. The sprouts from Treatments A to $F$ were harvested at this stage for the $76 . \mathrm{h}$ growth period. A clump of moldy seed coats was found in jar D-2. There were no other visible signs of contamination or spoilage.

After $100 \mathrm{~h}$ the "light" sprouts exhibited a thickened hypocotyl and a more pronounced long, thin radicle, or primary root. The hypocotyls were light green, with pink at the base; the radicles remained 
white. Sprouts grown with Treatment $U$ averaged $3.5 \mathrm{~cm}$ whereas Treatment $V$ and $W$ sprouts averaged $5.0 \mathrm{~cm}$ in length. The more frequent rinsing appears to encourage sprout growth. The cotyledons were dark green and spread open; epicotyls were beginning to develop at the base of the cotyledons (Figure 7). Radicles were also present in the corresponding "dark" sprouts. There was some pinking of the hypocotyls but otherwise they remained white. Sprout length averaged $5.5 \mathrm{~cm}$ in all treatments ( $X$ to $Z$ ). Cotyledons were predominantly yellow with some greening, smaller than those from the corresponding "light" sprouts, and some were spread open. Sprouting jar $\mathrm{Y}-1$ contained a much lower yield of sprouts than jars $\mathrm{Y}-2$ or $\mathrm{Y}-3$.

There was little change after $124 \mathrm{~h}$ growth other than a 0.5 to 1.0 $\mathrm{cm}$ increase in sprout length. Radicles were 1 to $2 \mathrm{~cm}$ long in all sprouts. Epicotyl development continued in the "light" sprouts but was not yet apparent in the "dark" sprouts.

After a total of $148 \mathrm{~h}$ growth, the "light" sprouts averaged $5.0 \mathrm{~cm}$ in length. Many hypocotyls and radicles were bruised or broken and numerous Treatment $U$ and $V$ sprouts were brown. This discoloration was likely the result of enzymatic browning. Francis and Millington (1965b) proposed that a polyphenol oxidase type of enzyme system was involved in the browning of crushed clover samples. Treatment $W$ sprouts had no brown discoloration and a much fresher appearance, likely due to the greater volume and frequency of water applied during the growth period. The "dark" sprouts averaged $6.0 \mathrm{~cm}$ in length. Only the sprouts in jar Y-1 showed signs of browning of hypocotyls and radicles. Cotyledons of all samples were yellow because of the lack of light, however those 
sprouts closest to the glass jar sides did exhibit some greening. These sprouts would have been unavoidably exposed to minimal amounts of light during the rinsing procedure. The difference in sprout color between "light" (Treatment U) and "dark" (Treatment $X$ ) sprouts is evident in Figure 12. The sprouts from Treatment $U$ to $Z$ were harvested at this stage for the $148 \mathrm{~h}$ growth period.

Seed coats that had not been rinsed out of the sprout mass were included in the sprout samples taken for analysis; however, seed coats that had accumulated at the bottom of the jars were not included in sampling. These discarded seed coats felt slightly slimy but no attempt was made in this study to identify the microbial flora present on the seed coats or on the alfalfa sprouts.

\section{PHYTOESTROGEN ANALYSIS}

Daidzein, formononetin and coumestrol were detected in many of the alfalfa sprout extracts as determined from HPLC chromatograms. Table 7 lists the mean content of each phytoestrogen calculated to be present in alfalfa sprouts corresponding to the various growth treatments. Analysis of the data revealed that the accumulation of each phytoestrogen varied in response to the treatments, therefore, the three phytoestrogens will first be discussed individually. Analysis of variance tables are provided in the Appendices.

The treatment combinations were coded for factorial analysis using two levels for each factor. The four factors were coded in the order of growth period, light duration, rinse volume and rinse frequency; the levels were assigned as follows: 


$$
\begin{aligned}
& \text { Growth period (G) } \quad 1=76 \mathrm{~h} \\
& 2=148 \mathrm{~h} \\
& \text { Light duration (L) } \quad 1=0 \mathrm{~h} \\
& 2=24 h \\
& \text { Rinse volume (V) } \quad 1=0.4 \mathrm{~L} \\
& 2=1.0 \mathrm{~L} \\
& \text { Rinse frequency }(F) \quad 1=2 X \\
& 2=5 x
\end{aligned}
$$

\section{Daidzein}

Single factor analysis of variance of the 12 trial treatments (A to Z) and the 2 standard treatments (Moapa and Vernal) was performed to determine the significance of the observed treatment effects. Treatment means of daidzein contents are presented in Table 7.

Both Treatments $C$ and $Y$ had a very large value for one of the three replicates which contributed to the large standard deviation of the $C$ and $Y$ means. Alfalfa sprouts in jar $Y-1$ were found to have a daidzein content of $25.9 \pm 4.5 \mu \mathrm{g} / \mathrm{g}$ alfalfa (dry weight), which was markedly greater than the other $Y$ replicates $(6.9$ and $3.7 \mu \mathrm{g} / \mathrm{g})$. This higher daidzein content may be related to contamination of the sprouts in Jar Y-1. Olah and Sherwood (1971 and 1973) also found an increased accumulation of daidzein in infected alfalfa plants. Sprouts from jar C-3 had a daidzein content of $16.3 \pm 1.2 \mu \mathrm{g} / \mathrm{g}$ alfalfa (dry weight), which differed greatly from the other $C$ replicates as in the case of Treatment $Y$. Although there were no visible signs of spoilage, some contaminated seed coats or sprouts may have been present and thereby affected the total daidzein content. An analysis of variance of treatment means carried out excluding the two extreme values (assumed to be 
Table 7. Phytoestrogen contents of alfalfa sprouts grown under standard and trial conditions.

Phytoestrogens $(\mu \mathrm{g} / \mathrm{g} \text { alfalfa })^{1,2}$

\begin{tabular}{llll}
\cline { 2 - 3 } Treatment & Daidzein & Formononetin & Coumestrol \\
\hline
\end{tabular}

\section{STANDARD}

Moapa (AA)

$2.1 \pm 0.12^{a b_{3}}$

$2.9 \pm 0.62^{\mathrm{a}}$

N.D. ${ }^{\mathrm{a}}$

Vernal (BB)

$1.0 \pm 0.20^{\mathrm{a}}$

$1.3 \pm 0.64^{b c}$

N.D.

TRIAL
A
$1.9 \pm 0.49^{a b}$
$0.5 \pm 0.44^{c}$
N.D.
B
$2.2 \pm 0.29^{a b}$
$0.7 \pm 0.67^{c}$
N.D.
c
$9.3 \pm 7.00^{a b}$
$0.3 \pm 0.46^{c}$
N.D.
D
$0.2 \pm 0.06^{\mathrm{a}}$
$1.6 \pm 0.67^{a b c}$
$0.9 \pm 0.90^{\mathrm{a}}$
E
$0.9 \pm 0.06^{\mathrm{a}}$
$1.2 \pm 0.21^{b c}$
$1.0 \pm 1.00^{\mathrm{a}}$
F
$0.7 \pm 0.12^{a}$
$0.1 \pm 0.12^{c}$
N.D ${ }^{\mathrm{a}}$
U
$5.0 \pm 0.74^{a b}$
$2.7 \pm 0.55^{a b}$
$0.6 \pm 0.51^{\mathrm{a}}$
V
$2.0 \pm 0.89^{a b}$
$0.6 \pm 0.21^{c}$
$2.1 \pm 1.53^{a}$
W
$2.5 \pm 0.49^{\mathrm{ab}}$
$0.9 \pm 1.17^{c}$
$0.9 \pm 0.76^{\mathrm{a}}$
$x$
$2.4 \pm 0.23^{a b}$
$9.0 \pm 1.36^{d}$
$5.5 \pm 1.72^{b}$
Y
$12.2 \pm 12.00^{b}$
$6.3 \pm 0.76^{\mathrm{e}}$
$3.6 \pm 0.97^{\mathrm{c}}$
Z
$6.2 \pm 0.32^{a b}$
$6.4 \pm 0.87^{e}$
$6.0 \pm 1.06^{b}$

${ }^{1}$ Expressed on dry weight basis.

${ }^{2}$ Mean of 3 replicates \pm standard deviation.

${ }^{3}$ Treatment means in a column sharing the same superscript are not significantly different $(P>0.05)$ as determined by the Student-Newman-Keuls test.

${ }^{4}$ N.D. = Not detectable. 
missing values) more clearly indicated that alfalfa sprouts from Treatments $C$ and $Y$ (as well as $U$ and $Z$ ) had significantly greater $(P \leq 0.05)$ daidzein contents from all other treatments (Appendix A-2).

Factorial analysis of variance of the treatment combinations used to grow alfalfa sprouts revealed that only the interactions of growth and light $(G \times L)$ and of light and $r i n s e$ volume $(L \times V)$ were significant $(P \leq 0.05)$ for daidzein accumulation (Table 8). The effect curve of $G \times L$ (Figure 17) shows that a marked increase in daidzein content over growth time occurred in the "dark" sprouts grown for $76 \mathrm{~h}$ vs $148 \mathrm{~h}$. It may be possible that the susceptibility of alfalfa sprouts to infection increases with time in sprouts that are grown in the dark. As previously mentioned, increased infection has been associated with increased daidzein levels (e.g. Olah and Sherwood, 1971). The effect curve of $L \times$ $V$ (Figure 18) shows that an increase in rinse volume resulted. in a decreased daidzein content in the "dark" sprouts but an increased content in the "light" sprouts. However, this interaction is only significant at $P=0.048$ and the Student-Newman-Keuls test showed that the treatment means were not significantly different $(P>0.05)$.

\section{Formononetin}

The significantly different treatment means for formononetin, as determined by single factor analysis of variance, are identified in Table 7. The formononetin contents of sprouts from Treatments $X, Y$ and $Z$ were shown to be significantly greater $(P \leq 0.05)$ than from the other treatments. 
Table 8. Significance of calculated F-values from germination factors and factor interactions for phytoestrogen accumulation as determined by factorial analysis of variance.

\begin{tabular}{|c|c|c|c|}
\hline \multirow[b]{2}{*}{ Factors } & \multicolumn{3}{|c|}{ Phytoestrogens } \\
\hline & Daidzein & Formononetin & Coumestrol \\
\hline Growth (G) & NS & * & * \\
\hline Light (L) & NS & * & * \\
\hline Rinse volume (V) & NS & NS & NS \\
\hline Rinse frequency (F) & NS & * & NS \\
\hline$G \times L$ & * & * & * \\
\hline$G \times V$ & NS & NS & NS \\
\hline$G \times F$ & NS & * & NS \\
\hline$L \times V$ & * & NS & NS \\
\hline$L \times F$ & NS & NS & NS \\
\hline$G \times L \times V$ & NS & NS & * \\
\hline$G \times L \times F$ & NS & NS & NS \\
\hline
\end{tabular}

* Significant $(P \leq 0.05)$.

NS Not significant $(P>0.05)$. 
Figure 17. Effect curve of growth and light $(G \times L)$ interaction for daidzein accumulation in alfalfa sprouts.

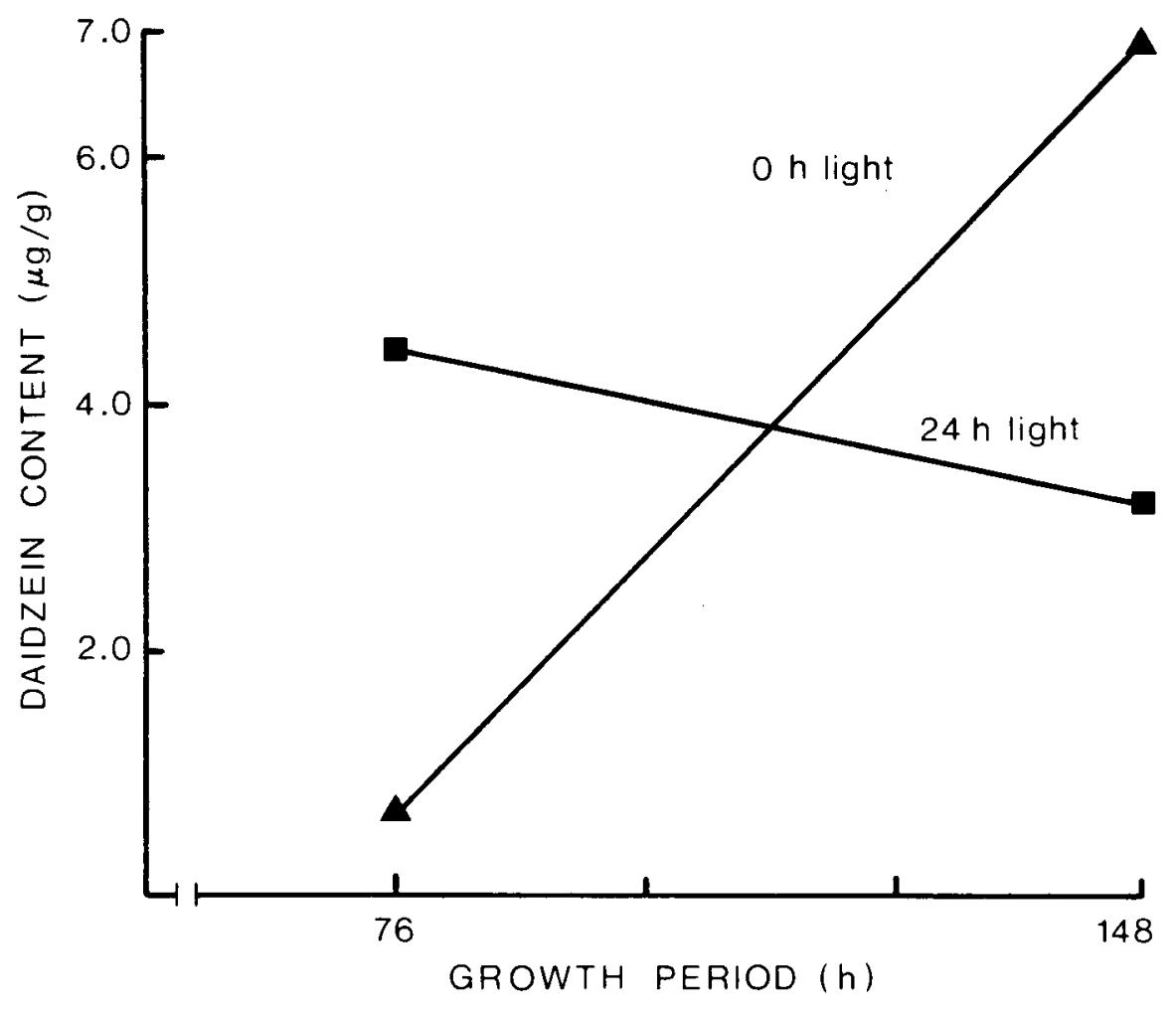


Figure 18. Effect curve of light and volume $(L \times V)$ interaction for daidzein accumulation in alfalfa sprouts.

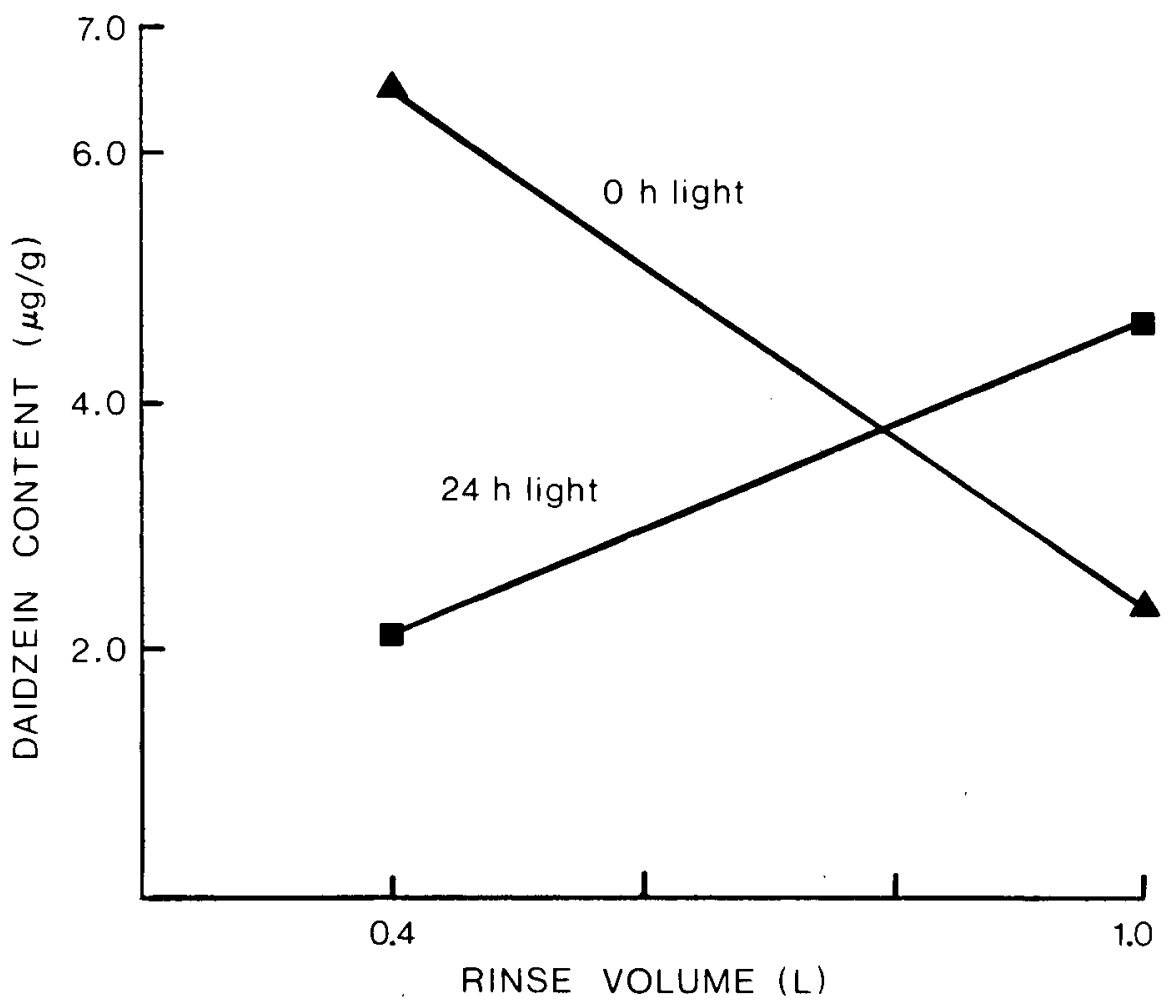


The results of factorial analysis of variance are presented in Table 8. Significant differences in formononetin content were found between sprouts grown for $76 \mathrm{~h}$ and those grown $148 \mathrm{~h}$, and between sprouts grown in the "dark" and those grown in the "light". As in the case of daidzein, the interaction of $G \times L$ (Figure 19) indicates that there is a different formononetin response of the "dark" sprouts than of the "light" sprouts over the growth period. Again, increased concentrations of formononetin may be associated with microbially contaminated alfalfa sprouts as proposed by Olah and Sherwood (1971), and the "dark" sprouts may be more susceptible to infection and subsequent phytoestrogen accumulation.

Results also showed that rinse frequency was a significant $(P \leq 0.05)$ factor in formononetin accumulation. The $G \times F$ interaction was found to be significant $(P \leq 0.05)$ as illustrated in Figure 20 , where an increase in rinse frequency resulted in a marked decrease in formononetin content in the $148 \mathrm{~h}$ sprouts but did not affect formononetin accumulation in the $76 \mathrm{~h}$ sprouts. It appears that increasing rinse frequency may serve to cleanse the sprouts during growth, as suggested by Lookhart et al. (1979a), and thereby reduce the level of contamination and phytoestrogen accumulation.

\section{Coumestrol}

The significantly different treatment means for coumestrol, as determined by single factor analysis of variance, are also identified in Table 7. Coumestrol could not be detected in many alfalfa sprout samples. Overall, the coumestrol concentrations appeared much lower than the concentrations of the other phytoestrogens, however, one must 
Figure 19. Effect curve of growth and light $(G \times L)$ interaction for formononetin accumulation in alfalfa sprouts.

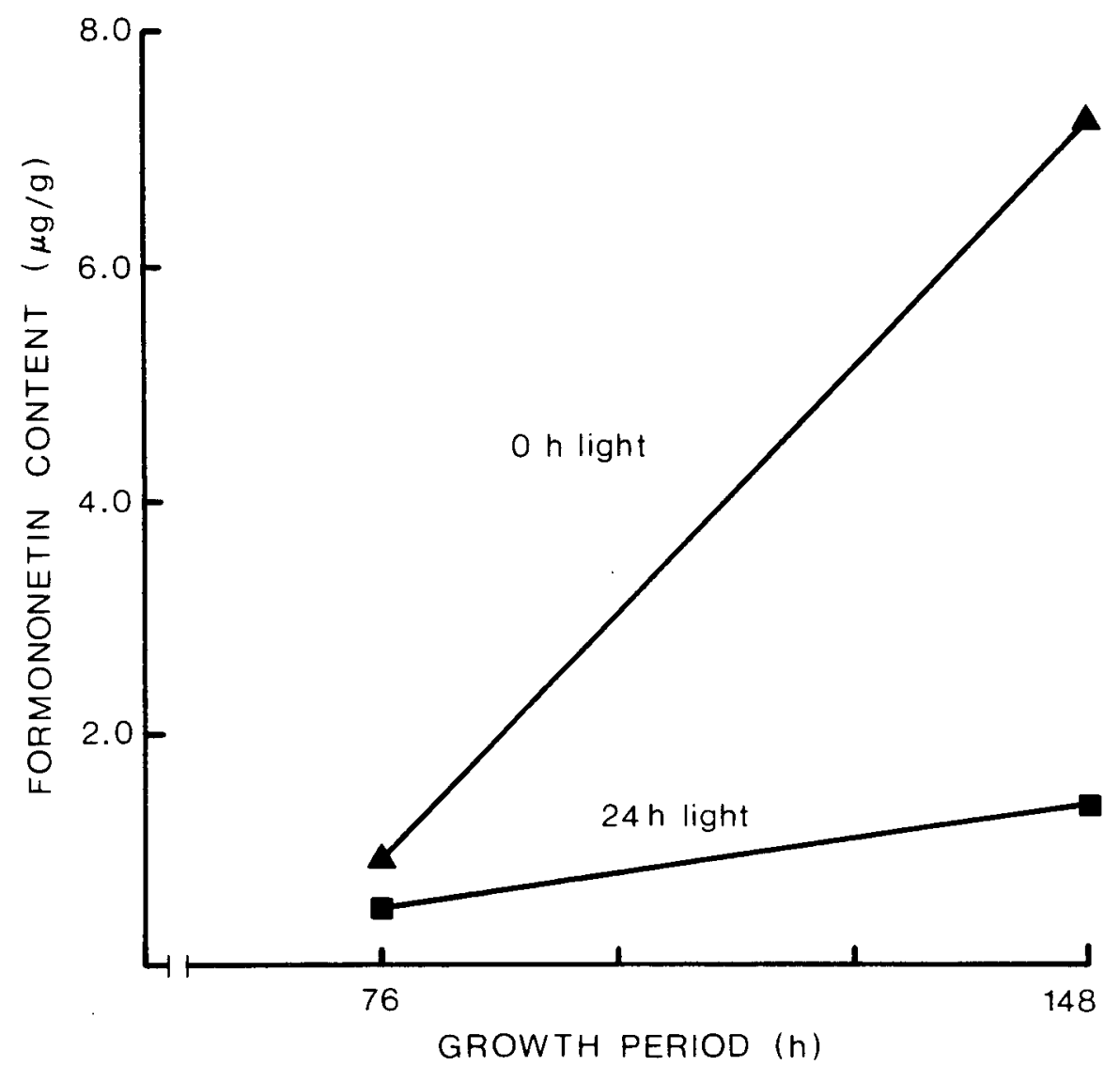


Figure 20. Effect curve of growth and frequency $(G \times F)$ interaction for formononetin accumulation in alfalfa sprouts.

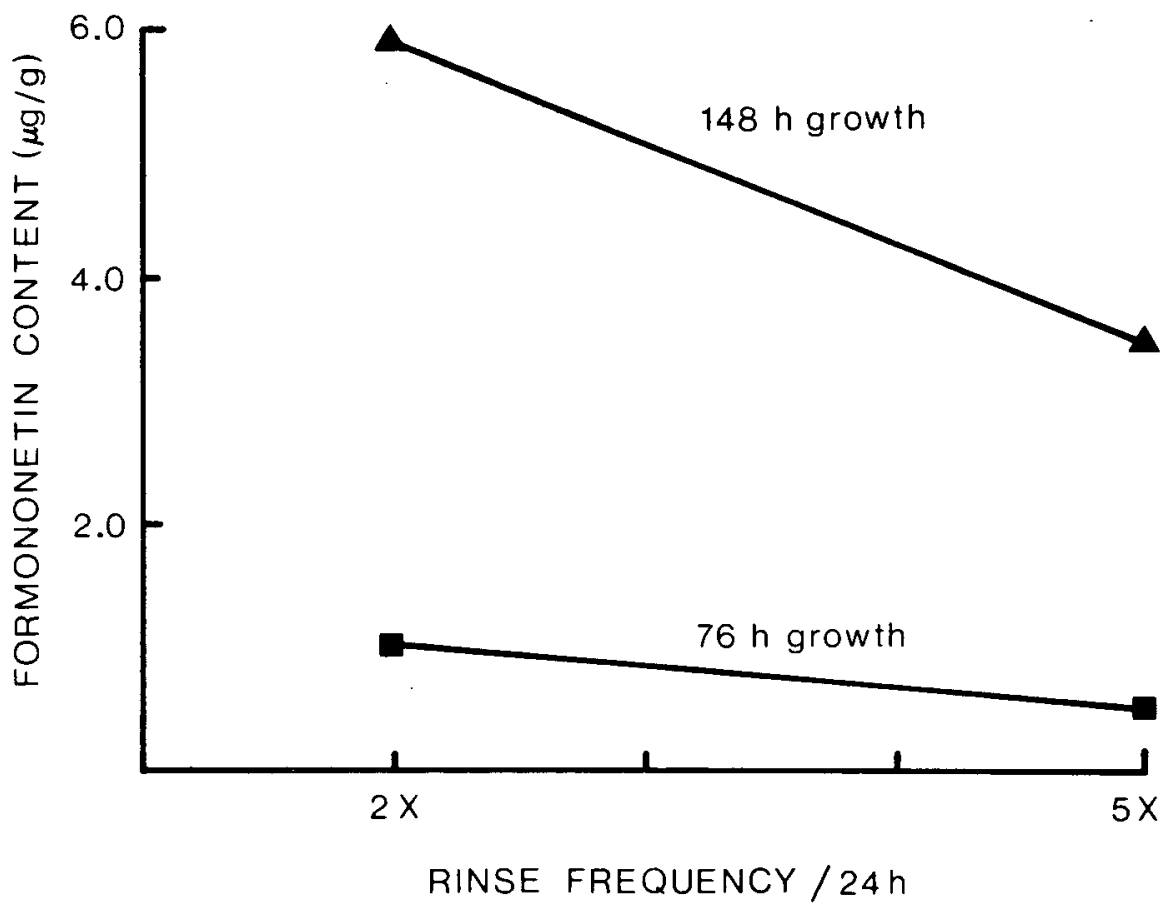


also note that the extraction efficiency for coumestrol was only $57 \%$ and that potentially the coumestrol content could be considerably higher. The coumestrol contents of the sprouts from Treatments $X, Y$ and $Z$ were once again found to be significantly greater $(P \leq 0.05)$ from the other treatments.

Factorial analysis of variance determined that several factors had a significant effect on coumestrol concentration (Table 8). Sprouts grown for $148 \mathrm{~h}$ had a significantly greater $(P \leq 0.05)$ coumestrol content than sprouts grown for $76 \mathrm{~h}$, and the same was true for $0 \mathrm{~h}$ light sprouts vs $24 \mathrm{~h}$ light sprouts. The $\mathrm{G} \times \mathrm{L}$ interaction (Figure 21) further illustrates that the response of coumestrol accumulation over the growth period diffèred markedly between "dark" and "light" sprouts. Lookhart et al. (1978) reported that removal of the hulls (or seed coats) from soy sprouts greatly reduced the total coumestrol content. In the present study, alfalfa sprouts from some treatments were observed to have lower levels of dispersed seed coats as a result of more frequent rinsing. However, rinse volume and rinse frequency were not shown to significantly $(P \leq 0.05)$ affect coumestrol accumulation.

The relationship between disease and coumestrol accumulation has been studied to a much greater extent than between disease and other phytoestrogens. The increase in coumestrol content with increasing germination time found in this study supports the increases in coumestrol reported by Knuckles et al. (1976) and Lookhart et al. (1979a and 1979b). Coumestrol accumulation that has been reported in response to microbial infection (Loper et al., 1967; Sherwood et al., 1970; 0lah and Sherwood, 1971; Wong and Latch, 1971) has also been related to increased growth time by Bickoff et al. (1969) and Lookhart et al. (1979a). 
Figure 21. Effect curve of growth and light $(G \times L)$ interaction for coumestrol accumulation in alfalfa sprouts.

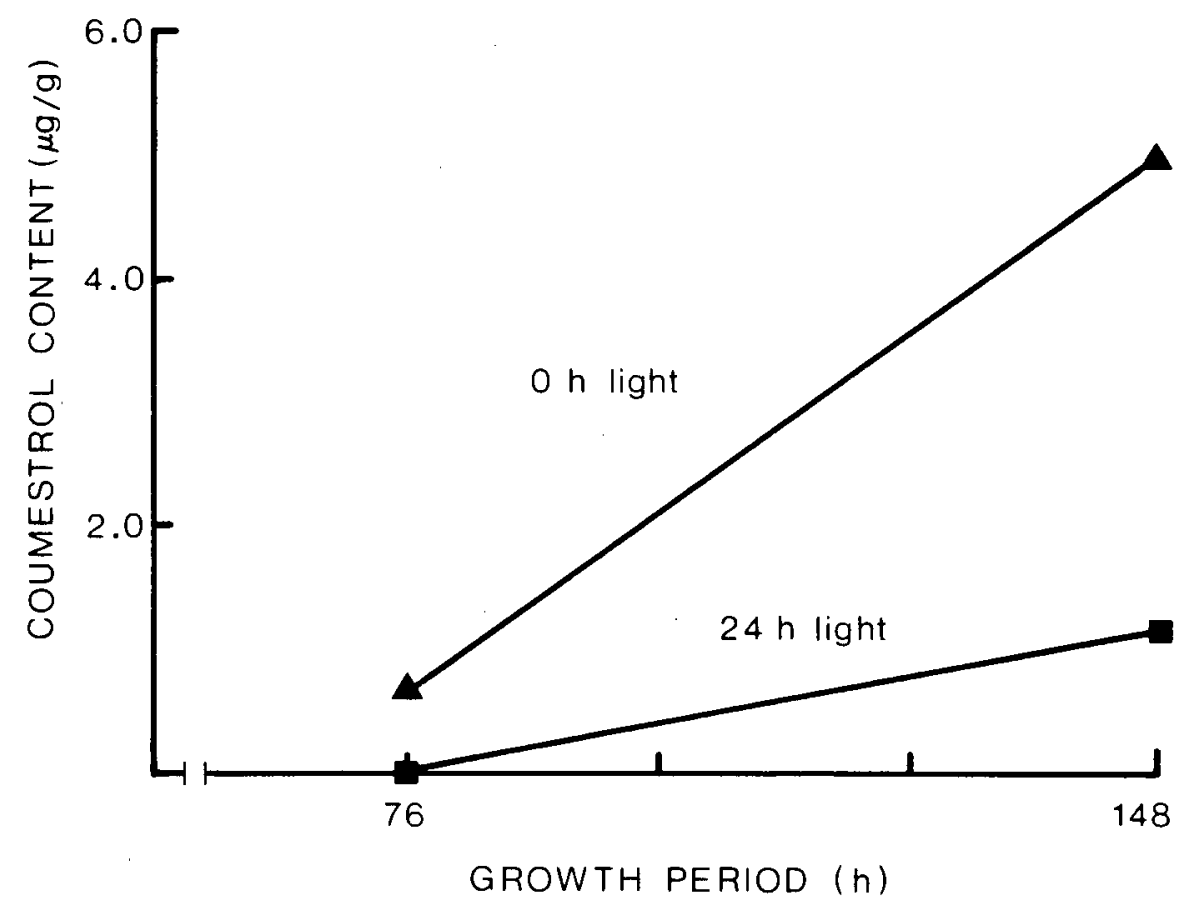


The two alfalfa samples which contained very high levels of daidzein ( $\mathrm{Y}-1$ and $\mathrm{C}-3)$ did not have higher levels of coumestrol (or formononetin) than the other treatment replicates as might have been expected if these samples were microbially infected. However, the degree of accumulation of each isoflavonoid may be a response to specific pathogens as demonstrated by many workers (Hanson et al., 1965; Sherwood et al., 1970; Wong and Latch, 1971; Lookhart et al., 1979a).

\section{General discussion}

Although the accumulation of each of the three phytoestrogens examined in this study was found to be affected by different factors, some general trends were observed. The factor interaction of growth and light $(G \times L)$ was found to be significant $(P \leq 0.05)$ in the accumulation of daidzein, formononetin and coumestrol. The effect curves (Figures 17 , 19, 21) could be interpreted to show that there was a marked increase in phytoestrogen content of the alfalfa sprouts grown in $0 \mathrm{~h}$ light conditions as the growth period was extended from $76 \mathrm{~h}$ to $148 \mathrm{~h}$. The alfalfa sprouts grown in $24 \mathrm{~h}$ light over the same growth periods did not show a similar increase in phytoestrogen content. Based on reports that these phytoestrogens accumulate in alfalfa that is microbially infected (Sherwood et al., 1970; Olah and Sherwood, 1971) it may be possible to conclude that those alfalfa sprouts grown in the dark for the longer periods are more susceptible to microbial infection than those in the light. These sprouts may have accumulated a higher content of phytoestrogens in response to an infection. 
Rinse frequency and rinse volume were examined because of the reported relationship between soy sprout cleansing and decreased coumestrol content (Lookhart et al., 1979a). However, neither factor was found to be significant $(P \leq 0.05)$ for coumestrol or daidzein accumulation in alfalfa sprouts. Rinse frequency and the interaction of growth and frequency were only demonstrated to be significant for formononetin accumulation as discussed previously.

The two alfalfa cultivars, Moapa and Vernal, were found to have a significantly different $(P \leq 0.05)$ formononetin content but daidzein and coumestrol contents were not significantly different $(P>0.05)$ (Table 7). Overall, the phytoestrogen content of these sprouts grown under standard conditions was low, i.e. not significantly different $(P>0.05)$ from trial condition sprouts of Treatments A to F. And although it was not the purpose of this study to develop optimum germination conditions, it would appear that the combination of low phytoestrogen content and good visual acceptability would make the standard conditions most desirable for alfalfa sprout germination.

The total content of phytoestrogens detected in these alfalfa sprouts ( 1 to $22 \mathrm{ppm}$ ) is minimal in comparison to the contents reported in infected forage alfalfa, which may contain several hundred ppm coumestrol alone (Bickoff et al., 1967; Loper et al., 1967); nevertheless, significantly different $(P \leq 0.05)$ phytoestrogen contents were observed in response to various growth conditions. Previous workers have reported that healthy, uninfected alfalfa contains less than 5 ppm coumestrol (Hanson et al., 1965; Bickoff et al., 1967; Sherwood et al., 1970). Alfalfa sprouts from Treatments $X, Y$ and $Z$ contained potentially 
$9.6,6.3$ and $10.5 \mathrm{ppm}$ coumestrol respectively (assuming 57\% extraction) which would appear to indicate that some coumestrol accumulation beyond the "healthy" level did occur.

Knuckles et al. (1976) reported that alfalfa sprouts and soy sprouts contained 5 and 71 ppm coumestrol respectively which was markedly higher than other vegetables tested $(\leq 1.0 \mathrm{ppm})$. In the present study, many alfalfa sprout samples contained greater than $1.0 \mathrm{ppm}$ coumestrol, and therefore could also contribute coumestrol to the diet at a level higher than that in other common vegetables. In addition, many of these alfalfa sprout samples contained levels of daidzein and formononetin which would increase the total phytoestrogen content of this food. However, unlike the diet of a grazing animal, the human diet consists of a great variety of foods and the phytoestrogens contributed by a minor dietary component such as alfalfa sprouts may have little physiological significance. But that conclusion cannot be made without more knowledge of the metabolism of phytoestrogens in man. 


\section{CONCLUSIONS}

The overall objective of this research project was to use high performance liquid chromatography to examine the isoflavonoid phytoestrogens present in alfalfa sprouts grown under selected growth conditions. A method for the extraction of phytoestrogens from alfalfa sprouts was developed which consisted of extracting aglycone phytoestrogens from ground alfalfa samples with methanol, removing lipids and chlorophyll pigments with petroleum ether and subsequently isolating the phytoestrogens using ethyl ether. The ethyl ether extract was evaporated to dryness and the final residue dissolved in methanol for HPLC analysis. Recovery of selected phytoestrogens from a standards mix ranged from 94\% (formononetin) to 103\% (coumestrol); recoveries from spiked alfalfa sprouts were found to be $83 \%$ (daidzein), 78\% (formononetin) and 57\% (coumestrol), and compared favorably to reported literature values (Lookhart, 1979; Murphy, 1981).

An HPLC method developed for the determination of phytoestrogens in the alfalfa extracts employed a reversed-phase octadecylsilane column for the separation, and UV detection at $254 \mathrm{~nm}$. Peak area integrator responses were compared to a standard curve for phytoestrogen quantitation. A linear gradient methanol/water system containing $1 \%$ acetic acid and $0.01 \mathrm{M}$ ammonium acetate at a flow rate of $1.0 \mathrm{~mL} / \mathrm{min}$ gave baseline resolution of the selected phytoestrogens in an elution time of $30 \mathrm{~min}$. This HPLC separation appears to be very suitable for the quantitative determination of the major phytoestrogens in alfalfa sprouts. 
The phytoestrogens daidzein, formononetin and coumestrol were detected using the analytical methods developed in the present study. Concentrations of formononetin and coumestrol were found to be significantly greater $(P \leq 0.05)$ in alfalfa sprouts grown for a longer period (148 $h$ vs $76 \mathrm{~h}$ ) and those grown in the dark ( $0 \mathrm{~h}$ light vs $24 \mathrm{~h}$ light). The interaction of growth and light factors was shown to be significant $(P \leq 0.05)$ for all three phytoestrogens; those alfalfa sprouts grown in the dark for the longer growth period had significantly greater $(P \leq 0.05)$ daidzein, formononetin and coumestrol contents than the alfalfa sprouts grown under the other treatment conditions. The levels of rinse volume and rinse frequency examined in the present study were found to have only a limited effect on the accumulation of phytoestrogens in alfalfa sprouts. The observed influence of growth period and light duration on phytoestrogen accumulation may be the result of increased susceptibility of the alfalfa sprouts to microbial infection; however, the microbial flora of alfalfa sprouts and seed coats were not enumerated nor identified.

The combined phytoestrogen content of the alfalfa sprouts was found to range from 1 to $22 \mathrm{ppm}$ on a dry weight basis (or less than 2 ppm fresh weight basis). The physiological significance of this level of phytoestrogens in a human food item has not yet been determined. However, the potential contribution of phytoestrogens to the human diet by alfalfa sprouts would appear to be minimal even from those alfalfa sprouts grown under unfavorable conditions of darkness and extended growth period. 


\section{REFERENCES CITED}

Andersen, J. M. and Pedersen, W. B. 1983. Analysis of plant phenolics by high-performance liquid chromatography. J. Chromatog. 259: 131.

AOAC. 1980. Official Methods of Analysis, 13th ed., p. 125. Association of Official Analytical Chemists, Washington, DC.

Batterham, T. J., Hart, N. K. and Lamberton, J. A. 1965. Metabolism of oestrogenic isoflavones in sheep. Nature 206: 509.

Beck, A. B. 1964. The oestrogenic isoflavones of subterranean clover. Aust. J. Agric. Res. 15: 223.

Bennetts, H. W., Underwood, C. J. and Shier, F. L. 1946. A specific breeding problem of sheep on subterranean clover pastures in Western Australia. Aust. Vet. J. 22: 2 .

Bickoff, E. M., Booth, A. N., Lyman, R. L., Livingston, A. L., Thompson, C. R. and DeEds, F. 1957. Coumestrol, a new estrogen isolated from forage crops. Science 126: 969.

Bickoff, E. M., Booth, A. N., Lyman, R. L., Livingston, A. L., Thompson, C. R. and Kohler, G. 0. 1958. Isolation of a new estrogen from ladino clover. J. Agric. Food Chem. 6: 536.

Bickoff, E. M., Livingston, A. L. and Booth, A. N. 1960. Estrogenic activity of coumestrol and related compounds. Arch. Biochem. Biophys. 88: 262 .

Bickoff, E. M., Livingston, A. L., Hendrickson, A. P. and Booth, A. N. 1962. Relative potencies of several estrogen-like compounds found in forages. J. Agric. Food Chem. 10: 410.

Bickoff, E. M., Loper, G. M., Hanson, C. H., Graham, J. H., Witt, S. C. and Spencer, R. R. 1967. Effect of common leafspot on coumestans and flavones in alfalfa. Crop Sci. 7: 259.

Bickoff, E. M., Spencer, R. R., Witt, S. C. and Knuckles, B. E. 1969. Studies on the chemical and biological properties of coumestrol and related compounds. U.S.D.A. Tech. Bull. No. 1408.

Biggers, J. D. and Curnow, D. H. 1954. Oestrogenic activity of subterranean clover. 1. The oestrogenic activity of genistein. Biochem. J. $58: 278$.

Biggs, R. 1975. Post-infectional compounds from the French bean Phaseolus vulgaris; isolation and identification of genistein and 2',4',5,7-tetrahydroxyisoflavone. Aust. J. Chem. 28: 1389.

Bradbury, R. B. and White, D. E. 1951. The chemistry of subterranean clover. Part I. Isolation of formononetin and genistein. J. Chem. Soc. IV: 3447. 
Bradbury, R. B. and White, D. E. 1954. Estrogens and related substances in plants. Vitam. Horm. 12: 207.

Braden, A. W. H., Hart, N. K. and Lamberton, J. A. 1967. The oestrogenic activity and metabolism of certain isoflavones in sheep. Aust. J. Agric. Res. 18: 335 .

Braden, A. W. H., Thain, R. I. and Shutt, D. A. 1971. Comparison of plasma phyto-estrogen levels in sheep and cattle after feeding on fresh clover. Aust. J. Agric. Res. 22: 663.

Busetta, B., Courseille, C., Precigoux, G. and Hospital, M. 1977. Some hypotheses about interactions between estrogen and androgen and their possible receptors. J. Steroid Biochem. 8: 63.

Carlson, R. E. and Dolphin, D. 1980. High-performance liquid chromatographic method for the analysis of isoflavones. J. Chromatog. 198: 193.

Cayen, M. N. and Common, R. H. 1965. An investigation of urinary conversion products of coumestrol in the fowl. Biochim. Biophys. Acta 100: 567 .

Cheng, E. W., Yoder, L., Story, C. D. and Burroughs, W. 1955. Estrogenic activity of some naturally occurring isoflavones. Ann. N.Y. Acad. Sci. 61: 652 .

Churỳ, J. 1967. Papierchromatographischer Nachweis von Coumestrol in Pflanzenextrakten. J. Chromatog. 27: 329.

Cox, R. I. and Braden, A. W. 1974. The metabolism and physiological effects of phyto-oestrogens in livestock. Proc. Aust. Soc. Animal Prod. 10: 122 .

Daigle, D. J. and Conkerton, E. J. 1982. High-performance liquid chromatography of 34 selected flavonoids. J. Chromatog. 240: 202 .

Dewick, P. M. and Martin, M. 1979a. Biosynthesis of pterocarpan, isoflavan and coumestan metabolites of Medicago sativa: chalcone, isoflavone and isoflavanone precursors. Phytochemistry 18: 597.

Dewick, P. M. and Martin, M. 1979b. Biosynthesis of pterocarpan and isoflavan phytoalexins in Medicago sativa: the biochemical interconversion of pterocarpans and $2^{\prime}$-hydroxyisoflavans. Phytochemistry 18: 591.

Dziedzic, S. Z. and Dick, J. 1982. Analysis of isoflavones in Bengalgram by high-performance liquid chromatography. J. Chromatog. 234: 497.

Eldridge, A. C. 1982a. High-performance liquid chromatography separation of soybean isoflavones and their glucosides. J. Chromatog. 234: 494. 
Eldridge, A. C. 1982b. Determination of isoflavones in soybean flours, protein concentrates, and isolates. J. Agric. Food Chem. 30: 353.

Engle, P. H., Bell, D. S. and Davis, R. R. 1957. The effect of ladino clover, birdsfoot trefoil and bluegrass pasture on the rate of conception among ewes. J. Animal Sci. 16: 703.

Flux, D. S., Wilson, G. F. and Wong, E. 1964. Comparison of chemical and bioassay estimates of oestrogenic potency of clover. J. Sci. Food Agric. 15: 407.

Fordham, J. R., Wells, C. E. and Chen, L. H. 1975. Sprouting of seeds and nutrient composition of seeds and sprouts. J. Food Sci. 40: 552.

Francis, C. M. and Millington, A. J. 1965a. Wether bioassay of annual pasture legumes. IV. The oestrogenic activity of annual medic pastures. Aust. J. Agric. Res. 16: 927.

Francis, C. M. and Millington, A. J. 1965b. Varietal variation in the isoflavone content of subterranean clover: its estimation by a microtechnique. Aust. J. Agric. Res. 16: 557.

Francis, C. M., Millington, A. J. and Bailey, E. T. 1967. The distribution of oestrogenic isoflavones in the genus Trifolium. Aust. $\mathrm{J}$. Agric. Res. 18: 47 .

Glencross, R. G., Festenstein, G. N. and King, H. G. C. 1972. Separation and determination of isoflavones in the protein concentrate from red clover leaves. J. Sci. Food Agric. 23: 371.

Gorski, J., Denari, J. H., Eilon, G., Frolik, C. and Slabaugh, M. 1975. Estrogen stimulation of specific protein synthesis: regulation and physical characterization of IP. J. Steroid Biochem. 6: 459.

Gorski, J., Toft, D., Shyamala, G., Smith, S. and Notides, A. 1968. Hormone receptors: studies on the interaction of estrogen with the uterus. Rec. Prog. Horm. Res. 24: 45.

Greig, M. and Bjerring, J. 1978. UBC GENLIN. A general least squares analysis of variance program. Computing Centre, UBC.

Griffiths, L. A. 1975. The role of intestinal microflora in flavonoid metabolism. In: Topics in Flavonoid Chemistry and Biochemistry. L. Farkas, M. Gabor and F. Kallay (Ed.). p. 201. Elsevier Scientific Publishing Co., New York, NY.

Grisebach, H. 1959. Zur Biogenese der Isoflavone. Z. Naturforsch. 14b: 802 .

Grisebach, H. and Barz, W. 1963a. Zur Biogenese des Isoflavone. VII. Mitt.: Über der Biogenese des Cumöstrols in der Luzerne (Medicago sativa L.). Z. Naturforsch. 18b: 466 . 
Grisebach, H. and Barz, W. 1963b. Biosynthesis of coumestrol. Chem. Ind. 1963: 690 .

Grisebach, H. and Doerr, N. 1960. Zur Biogenese der Isoflavone. II. Mitt.: Über den Mechanismus der Umlagerung. Z. Naturforsch. 15b: 284.

Guggolz, J., Livingston, A. L. and Bickoff, E. M. 1961. Detection of daidzein, formononetin, genistein and biochanin $A$ in forages. J. Agric. Food Chem. 9: 330.

Hahlbrock, K. and Grisebach, H. 1975. Biosynthesis of flavonoids. In: The Flavonoids. Part 2. J. B. Harborne, T. J. Mabry and H. Mabry (Eds.). p. 866. Academic Press Inc., New York, NY.

Hähnel, R., Twaddle, E. and Ratajczak, T. 1973. The specificity of the estrogen receptor of human uterus. J. Steroid Biochem. 4: 21 .

Hamilton, M. J. and Vanderstoep, J. 1979. Germination and nutrient composition of alfalfa seeds. J. Food Sci. 44: 443.

Hanson, C. H., Loper, G. M., Kohler, G. 0., Bickoff, E. M., Taylor, K. W., Kehr, W. R., Stanford, E. H., Dudley, J. W., Pedersen, M. W., Sorensen, E. L., Carnahan, H. L. and Wilsie, C. P. 1965. Variation in coumestrol. content of alfalfa as related to location, variety, cutting, year, stage of growth and disease. U.S.D.A. Tech. Bull. No. 1333.

Harborne, J. B. 1965. Characterization of flavonoid glycosides by acidic and enzymic hydrolyses. Phytochemistry 4: 107.

Harborne, J. B. 1969. Chemosystematics of the leguminosae. Flavonoid and isoflavonoid patterns in the tribe Genisteae. Phytochemistry 8: 1449.

Harborne, J. B., Mabry, T. J. and Mabry, H. (Eds.). 1975. The Flavonoids. Part 2. Academic Press Inc., New York, NY.

Hardin, J. M. and Stutte, C. A. 1980. Analyses of phenolic and flavonoid compounds by high-pressure liquid chromatography. Anal. Biochem. 102: 171 .

Hare, R. C. 1966. Physiology of resistance to fungal diseases in plants. Bot. Rev. 32: 95 .

Harper, H. A. 1975. Review of Physiological Chemistry. 15th ed. Lange Medical Publications, Los Altos, CA.

Hesterman, 0. B. and Teuber, L. R. 1980. Alfalfa sprouts: Methods of production, current research and economic importance. Proc. 9 th Calif. Alfalfa Symp., Fresno, CA. p. 24-28. 
Hesterman, 0. 0. B., Teuber, L. R. and Livingston, A. L. 1981. Effect of environment and genotype on alfalfa sprout production. Crop Sci. 21: 720 .

Horowitz, R. M. and Jurd, L. 1961. Spectral studies on flavonoid compounds. II. Isoflavones and flavonones. J. 0rg. Chem. 26: 2446.

Hsu, D., Leung, H. K., Finney, P. L. and Morad, M. M. 1980. Effect of germination on nutritive value and baking properties of dry peas, lentils, and faba beans. J. Food Sci. 45: 87.

Johnson, E. L. and Stevenson, R. 1978. Basic Liquid Chromatography. Varian Assoc. Inc., Palo Alto, CA.

Kelly, R. W. 1972. The oestrogenic activity of coumestans in ovariectomized ewes. J. Reprod. Fert. 28: 159.

Kelly, R. W. and Lindsay, D. R. 1978. Plasma coumestrol levels and cervical mucus responses in ewes ingesting coumestan-rich feeds. Aust. J. Agric. Res. 29: 115.

Kingston, D. G. I. 1979. High performance liquid chromatography of natural products. J. Nat. Prod. 42: 237.

Kitts, D. D. 1974. The comparative effects of naturally occurring, synthetic and plant estrogens on uterine metabolism. M.Sc. Thesis, University of British Columbia, Vancouver.

Knuckles, B. E., deFremery, D. and Kohler, G. 0. 1976. Coumestrol content of fractions obtained during wet processing of alfalfa. $\mathrm{J}$. Agric. Food Chem. 24: 1177.

Knuckles, B. E., Miller, R. E. and Bickoff, E. M. 1975. Quantitative determination of coumestrol in dried alfalfa and alfalfa leaf protein concentrates containing chlorophyll. J. Assoc. Offic. Anal. Chem. 58: 983 .

Korenman, S. G. 1969. Comparative binding affinity of estrogens and its relation to estrogenic potency. Steroids 13: 163 .

Kuć, J. 1972. Phytoalexins. Ann. Rev. Phytopath. 10: 207.

Kulvinskas, V. 1978. Sprout for the Love of Everybody. Omango D'Press, Wethersfield, CT.

Le, C. D. 1978. UBC MFAV. Analysis of variance/covariance. Computing Centre, UBC.

Lindner, H. R. 1967. Study of the fate of phyto-estrogens in the sheep by determination of isoflavones and coumestrol in the plasma and adipose tissue. Aust. J. Agric. Res. 18: 305.

Livingston, A. L. 1978. Forage plant estrogens. J. Toxicol. Environ. Health 4: 301 . 
Livingston, A. L., Bickoff, E. M., Guggolz, J. and Thompson, C. R. 1961. Quantitative determination of coumestrol in fresh and dried alfalfa. J. Agric. Food Chem. 9: 135.

Livingston, A. L., Bickoff, E. M., Lundin, R. E. and Jurd, L. 1964. Trifoliol, a new coumestan from ladino clover. Tetrahedron 20: 1963.

Lookhart, G. L. 1979. Note on an improved method of extracting and quantitating coumestrol from soybeans. Cereal Chem. 56: 386.

Lookhart, G. L., Finney, K. F. and Finney, P. L. 1979a. Liquid chromatographic analysis of coumestrol. In: Analysis of Food and Beverages: Vol. 1. G. Charalambous $(\overline{E d})$. p. 129. Academic Press Inc., New York, NY.

Lookhart, G. L., Finney, P. L. and Finney, K. F. 1979b. Note on coumestrol in soybeans and fractions at various germination times. Cereal Chem. 56: 495.

Lookhart, G. L., Jones, B. L. and Finney, K. F. 1978. Determination of coumestrol in soybeans by high-performance liquid and thin-layer chromatography. Cereal Chem. 55: 967.

Loper, G. M., Hanson, C. H. and Graham, J. H. 1967. Coumestrol content of alfalfa as affected by selection for resistance to foliar diseases. Crop Sci. 7: 189.

Lyman, R. L., Bickoff, E. M., Booth, A. N. and Livingston, A. L. 1959. Detection of coumestrol in leguminous plants. Arch. Biochem. Biophys. 80: 61 .

Lyon, F. M. and Wood, R. K. S. 1975. Production of phaseollin, coumestrol and related compounds in bean leaves inoculated with Pseudomonas spp. Physiol. Plant Pathol. 6: 117.

Markham, K. R. 1975. Isolation techniques for flavonoids. In: The Flavonoids. Part 1. J. B. Harborne, T. J. Mabry and H. Mabry (Ed.). p. 1. Academic Press Inc., New York, NY.

Markham, K. R. 1982. Techniques of Flavonoid Identification. Academic Press Inc., New York, NY.

Martin, P. M., Horwitz, K. B., Ryan, D. S. and McGuire, W. L. 1978. Phytoestrogen interaction with estrogen receptors in human breast cancer cells. Endocrinology 103: 1860.

Mayer, A. M. and Poljakoff-Mayber, A. 1975. The Germination of Seeds. 2nd ed. Pergamon Press Ltd., Oxford, England.

McClure, J. W. 1975. Physiology and functions of flavonoids. In: The Flavonoids. Part 2. J. B. Harborne, T. J. Mabry and $\overline{H .}$ Mabry (Ed.). p. 970. Academic Press Inc., New York, NY. 
McFarlane, J. C. 1978. Light. In: A Growth Chamber Manual. R. W. Langhans (Ed.). p. 15. Cornell University Press, Ithaca, NY.

McFarlane, J. C. 1979. Radiation: guidelines. In: Controlled Environment Guidelines for Plant Research. T. W. Tibbitts and T. T. Kozlowski (Ed.). p. 55. Academic Press Inc., New York, NY.

Millington, A. J., Francis, C. M. and Mckeown, N. R. 1964. Wether bioassay of annual pasture legumes. II. The oestrogenic activity of nine strains of Trifolium subterraneum L. Aust. J. Agric. Res. 15: 527.

Murphy, J. B. and Stutte, C. A. 1978. Analysis for substituted benzoic and cinnamic acids using high-pressure liquid chromatography. Anal. Biochem. 86: 220 .

Murphy, P. A. 1981. Separation of genistin, daidzin and their aglucones, and coumestrol by gradient high-performance liquid chromatography. J. Chromatog. 211: 166.

Murphy, P. A. 1982. Phytoestrogen content of processed soybean products. Food Technol. 36: 60 .

Naim, M., Gestetner, B., Kirson, I., Birk, Y. and Bondi, A. 1973. A new isoflavone from soya beans. Phytochemistry 12: 169.

Naim, M., Gestetner, B., Zilkah, S., Birk, Y. and Bondi, A. 1974. Soybean isoflavones. Characterization, determination, and antifungal activity. J. Agric. Food Chem. 22: 806.

Nicollier, G. F. and Thompson, A. C. 1982. Separation and quantitation of estrogenic isoflavones from clovers by high-performance liquid chromatography. J. Chromatog. 249: 399.

Notebloom, W. D. and Gorski, J. 1963. Estrogenic effect of genistein and coumestrol diacetate. Endocrinology 73: 736.

Ohta, N., Kuwata, G., Akahori, H. and Watanabe, T. 1979. Isoflavonoid constituents of soybeans and isolation of a new acetyl daidzin. Agric. Biol. Chem. 43: 1415.

0lah, A. F. 1970. Glycosidase and flavonoid composition of fungalinfected alfalfa. Ph.D. Thesis, North Carolina State University.

Olah, A. F. and Sherwood, R. T. 1971. Flavones, isoflavones and coumestans in alfalfa infected by Ascochyta imperfecta. Phytopathology 61: 65 .

0lah, A. F. and Sherwood, R. T. 1973. Glycosidase activity and flavonoid accumulation in alfalfa infected by Ascochyta imperfecta. Phytopathology 63: 739 . 
Patroni, J. J., Collins, W. J. and Stern, W. R. 1982. Quantitative analysis of the isoflavone phyto-oestrogens genistein, formononetin and biochanin $A$, in subterranean clover leaves by high-performance liquid chromatography. J. Chromatog. 247: 366.

Perrin, D. R. and Cruickshank, I. A. M. 1969. The antifungal activity of pterocarpans towards Monilinia fructicola. Phytochemistry 8: 971.

Pieterse, P. J. S. and Andrews, F. N. 1956. The estrogenic activity of alfalfa and other feedstuffs. J. Animal Sci. 15: 25.

Proksch, P., Wisdom, C. and Rodriguez, E. 1981. Analysis of phenolic acids by high performance liquid chromatography using a step-wise gradient. Z. Naturforsch. 36c: 357.

Prosser, C. L. (Ed.). 1973. Comparative Animal Physiology. Vol. II. 3rd ed. W. B. Saunders Co., Philadelphia, PA.

Pueppke, S. G. and Van Etten, H. D. 1974. Identification of three new pterocarpans from Pisum sativum infected with Fusarium solani f. sp. pisi. J. Chem. Soc. Perkin I: 946.

Ribéreau-Gayon, P. 1972. Plant Phenolics. Hafner Publishing Co., Inc., New York, NY.

Rossiter, R. C. and Beck, A. B. 1967. Physiological and ecological studies on the oestrogenic isoflavones in subterranean clover ( $T$. subterraneum L.). III. Effects of light. Aust. J. Agric. Res. 1 $\overline{8}$ : 23 .

Ruh, T. S., Katzenellenbogen, B. S., Katzenellenbogen, J. A. and Gorski, J. 1973. Estrone interaction with the rat uterus: in vitro response and nuclear uptake. Endocrinology 92: 125.

Saba, N., Drane, H. M., Hebert, C. N. and Holdsworth, R. J. 1974. Seasonal variation in oestrogenic activity, coumestrol and formononetin content of white clover. J. Agric. Sci. Camb. 83: 505.

Sachse, J. 1971. Die dünnschichtchromatographische Trennung einiger Isoflavone neben Cumöstrol. J. Chromatog. 58: 297.

Sachse, J. 1974. Die Bestimmung östrogener Isoflavone und Cumöstrol in Klee (Trifolium pratense L. und Trifolium repens L.). J. Chromatog. $96: 123$.

Sharma, R. D. 1979. Isoflavones and hypercholesterolemia in rats. Lipids 14: 535.

Shehata, M. N., Hassan, A. and El-Shazly, K. 1982. Identification of the oestrogenic isoflavones in fresh and fermented berseem clover (Trifolium alexandrinum). Aust. J. Agric. Res. 33: 951. 
Shemesh, M., Lindner, H. R. and Ayalon, N. 1972. Affinity of rabbit uterine oestradiol receptor for phyto-oestrogens and its use in a competitive protein-binding radioassay for plasma coumestrol. J. Reprod. Fert. 29: 1.

Sherwood, R. T., Olah, A. F., Oleson, W. H. and Jones, E. E. 1970. Effect of disease and injury on accumulation of a flavonoid estrogen, coumestrol, in alfalfa. Phytopathology 60: 684.

Shutt, D. A. 1976. The effects of plant oestrogens on animal reproduction. Endeavor 35: 110 .

Shutt, D. A., Axelsen, A. and Lindner, H. R. 1967. Free and conjugated isoflavones in the plasma of sheep following ingestion of oestrogenic clover. Aust. J. Agric. Res. 18: 647 .

Shutt, D. A. and Braden, A. W. H. 1968. The significance of equol in relation to the oestrogenic responses in sheep ingesting clover with a high formononetin content. Aust. J. Agric. Res. 19: 545.

Shutt, D. A., Braden, A. W. H. and Linder, H. R. 1969. Plasma coumestrol levels in sheep following administration of synthetic coumestrol or ingestion of medic hay (Medicago littoralis). Aust. J. Agric. Res. 20: 65 .

Shutt, D. A. and Cox, R. I. 1972. Steroid and phyto-oestrogen binding to sheep uterine receptors in vitro. J. Endocrin. 52: 299.

Shutt, D. A., Weston, R. H. and Hogan, J. P. 1970. Quantitative aspects of phyto-oestrogen metabolism in sheep fed on subterranean clover (Trifolium subterraneum cultivar Clare) on red clover (Trifolium pratense). Aust. J. Agric. Res. 21: 713.

Snyder, L. R. and Kirkland, J. J. 1979. Introduction to Modern Liquid Chromatography. 2nd ed. Wiley and Sons Inc., New York, NY.

Stuthman, D. D., Bickoff, E. M., Davis, R. L. and Stob, M. 1966. Coumestrol differences in Medicago sativa L. free of foliar disease symptoms. Crop Sci. 6: 333 .

Tang, G. and Common, R. H. 1968. Urinary conversion products of certain orally administered isoflavones in the fowl. Biochim. Biophys. Acta 158: 402 .

Tibbitts, T. W. and Kozlowski, T. T. (Ed.). 1979. Controlled Environment Guidelines for Plant Research. Academic Press Inc., New York, NY.

Vande Casteele, K., Geiger, H. and Van Sumere, C. F. 1982. Separation of flavonoids by reversed-phase high-performance liquid chromtography. J. Chromatog. 240: 81 .

Varian Associates, Inc. 1978. MicroPak analytical column installation instructions. Publication No. 03-913805-00, p. 5-4. 
Verdeal, K., Brown, R. R., Richardson, T. and Ryan, D. S. 1980. Affinity of phytoestrogen for estradiol-binding proteins and effect of coumestrol on growth of 7,12-dimethylbenz[a] anthracene-induced rat mammary tumors. J. Nat. Cancer Inst. 64: 285.

Verdeal, K. and Ryan, D. S. 1979. Naturally-occurring estrogens in plant foodstuffs - a review. J. Food Prot. 42: 577.

Wada, H. 1963. Estrogenic activity in fresh and dried forages. Jap. J. Zootech. Sci. 34: 248 .

Walter, L. E. and Jensen, E. H. 1970. Effect of environment during seed production on seedling vigor of two alfalfa varieties. Crop Sci. 10: 635 .

Wong, E. 1962. Detection and estimation of oestrogenic constituents in red clover. J. Sci. Food Agric. 13: 304.

Wong, E. 1963. Pratensein. 5,7,3'-trihydroxy-4'-methoxyisoflavone. J. Org. Chem. 28: 2336.

Wong, E. 1975. The isoflavonoids. In: The Flavonoids. Part 2 . J. B. Harborne, T. J. Mabry and H. Mabry (Ed.). p. 743. Academic Press Inc., New York, NY.

Wong, E. and Latch, G. C. M. 1971. Effect of fungal diseases on phenolic contents of white clover. N.Z.J. Agric. Res. 14: 633.

Wulf, L. W. and Nagel, C. W. 1976. Analysis of phenolic acids and flavonoids by high-pressure liquid chromatography. J. Chromatog. $116: 271$.

Yost, R. W., Ettre, L. S. and Conlon, R. D. 1980. Practical Liquid Chromatography - An Introduction. Perkin-Elmer Corp., Norwalk, CT.

Zar, J. H. 1974. Biostatistical Analysis. Prentice-Hall, Inc., Englewood $\mathrm{Cl}$ iffs, $\mathrm{NJ}$. 
Appendix A-1. Analysis of variance for daidzein content of alfalfa sprouts from Treatments AA to $Z$ ( 1 to 14).

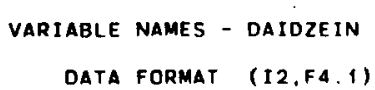

DAIDZEIN

ANALYSIS OF VARIANCE - DAIDZEIN

\begin{tabular}{ccccccc} 
SOURCE & OF & SUM SO & MEAN SO & ERROR & F-VALUE & \multicolumn{2}{l}{ PROB } \\
TREAT & 13 & $\mathbf{4 8 0 . 4 2}$ & 36.955 & & 2.6511 & $0.14915 E-01$ \\
ERROR & 28 & 390.30 & 13.939 & & & \\
TOTAL & 41 & 870.72 & & & &
\end{tabular}

GRANO MEAN 3.4762

STANDARD DEVIATION OF VARIABLE 1 IS 4.6084

FREQUENCIES, MEANS, STANDARD DEVIATIONS

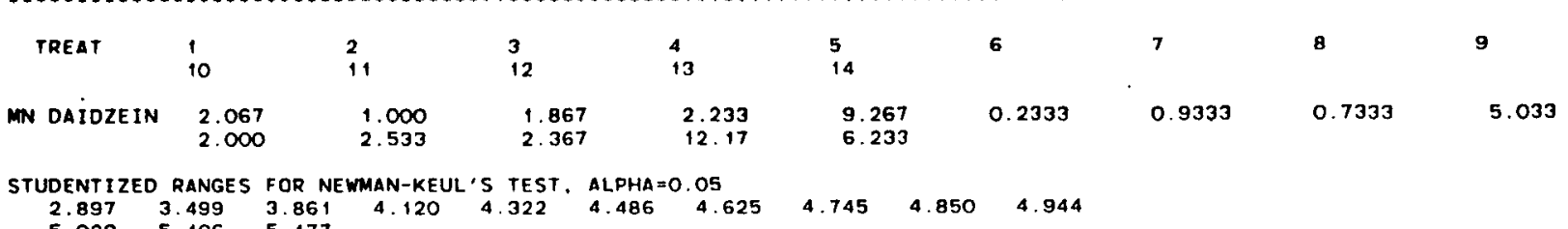

$\begin{array}{llllllllll}2.897 & 3.499 & 3.861 & 4.120 & 4.322 & 4.486 & 4.625 & 4.745 & 4.850 & 4.944\end{array}$

THERE ARE 2 hOMOgENEOUS SUBSETS (SUBSETS OF ELEMENTS, NO PAIR OF WHICH OIFFER BY MORE tHAN tHe SHORTEST SIGNIFICANT RANGe FOR A SUBSET OF THAT SIZE) WHICH ARE LISTEO AS FOLLOWS

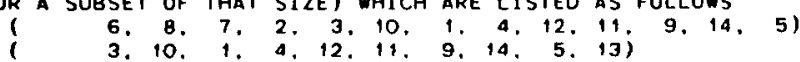

TIME FOR MULTIPLE RANGE TESTS IS $0.1272 E-01$ SECONDS.

ANALYSIS COMPLETE. 
Appendix A-2. Analysis of variance for daidzein content of alfalfa sprouts from Treatments AA to $Z$ ( 1 to 14 without $\mathrm{C}-3$ or $\mathrm{Y}-1$ values).

VARIABLE NAMES - DAIDZEIN

DATA FORMAT (I2,1X,F3.1)

DAIOZEIN

ANALYSIS OF VARIANCE - DAIDZEIN

$\begin{array}{ccccccc}\text { SOURCE } & \text { DF } & \text { SUM SO } & \text { MEAN SO } & \text { ERROR } & \text { F-VALUE } & \text { PROB } \\ \text { TREAT } & 13 & 139.19 & 10.707 & & 8.3869 & 0.26258 E-05 \\ \text { ERROR } & 26 & 33.192 & 1.2766 & & & \\ \text { TOTAL } & 39 & 172.38 & & & & \end{array}$

GRAND MEAN 2.5950

STANDARD DEVIATION OF VARIABLE, IIS 2.1024

FREQUENCIES, MEANS, STANDARD DEVIATIONS
$* * * * * * * * * * * * * * * * * * * * * * * * * * * * * * * * * * * * * * * * * * * * * * * * * * * * * * * * * * * * * * * * * * * * * * * * * *$

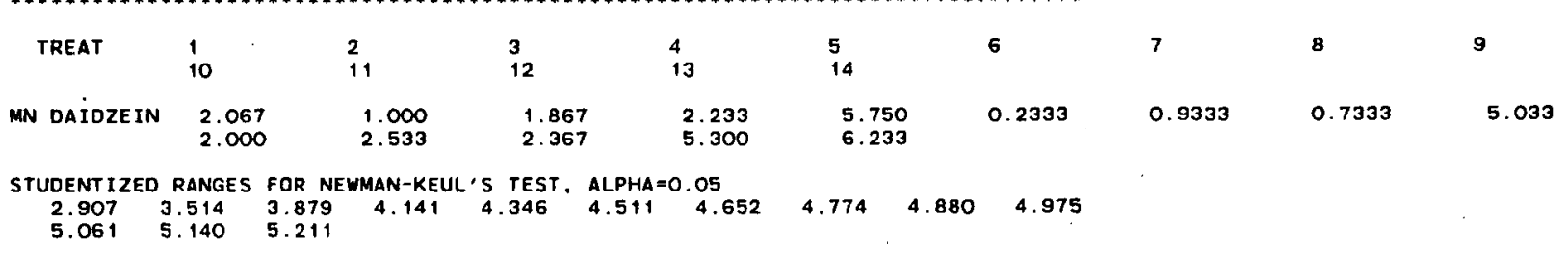

THERE ARE 2 HOMOGENEOUS SUBSETS (SUBSETS OF ELEMENTS, NO PAIR OF WHICH DIFFER BY MORE THAN THE SHORTEST SIGNIFICANT RANGE FOR A SUBSET OF THAT SIZE) WHICH ARE LISTED AS FOLLOWS

( $\quad$ 9, 8, 73,22 ;

TIME FOR MULTIPLE RANGE TESTS IS $0.1616 E-01$ SECONDS.

ANALYSIS COMPLETE. 
Appendix B. Analysis of variance for formononetin content of alfalfa sprouts from Treatments AA to $Z$ (1 to 14).

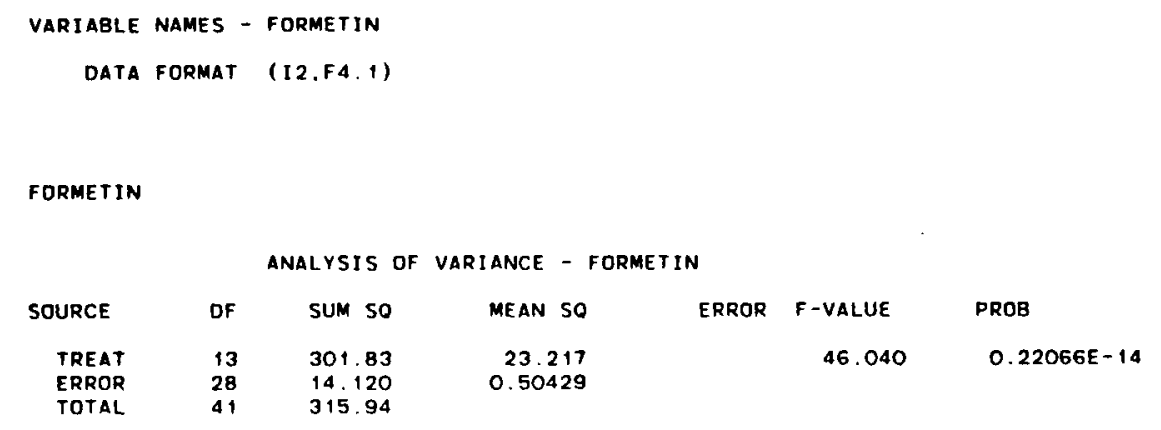

FORMETIN

\begin{tabular}{ccccccc}
\multicolumn{7}{c}{ ANALYSIS OF VARIANCE - FORMETIN } \\
SOURCE & OF & SUM SO & MEAN SO & ERROR & F-VALUE & \multicolumn{1}{l}{ PROB } \\
TREAT & 13 & 301.83 & 23.217 & & 46.040 & $0.22066 E-14$ \\
ERROR & 28 & 14.120 & 0.50429 & & & \\
TOTAL & 41 & 315.94 & & &
\end{tabular}

GRAND MEAN 2.4500

STANDARD DEVIATION OF VARIABLE 1 is 2.7760

FREQUENCIES. MEANS. STANOARD DEVIATIONS

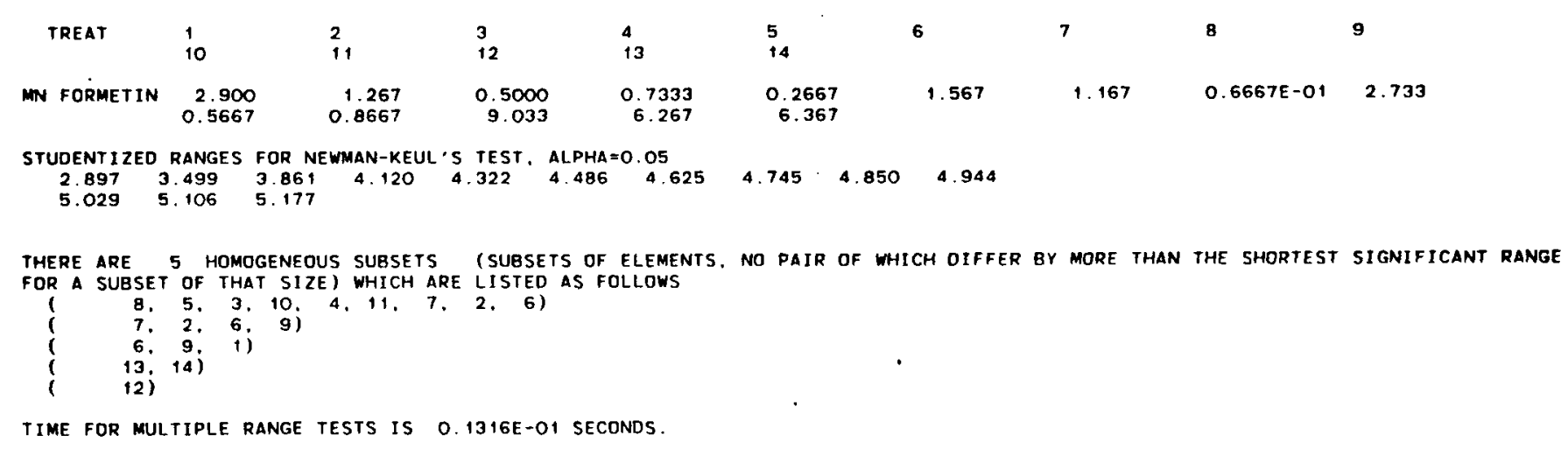

ANALYSIS COMPLETE. 
Appendix C. Analysis of variance for coumestrol content of alfalfa. sprouts from Treatments AA to $Z$ ( 1 to 14).

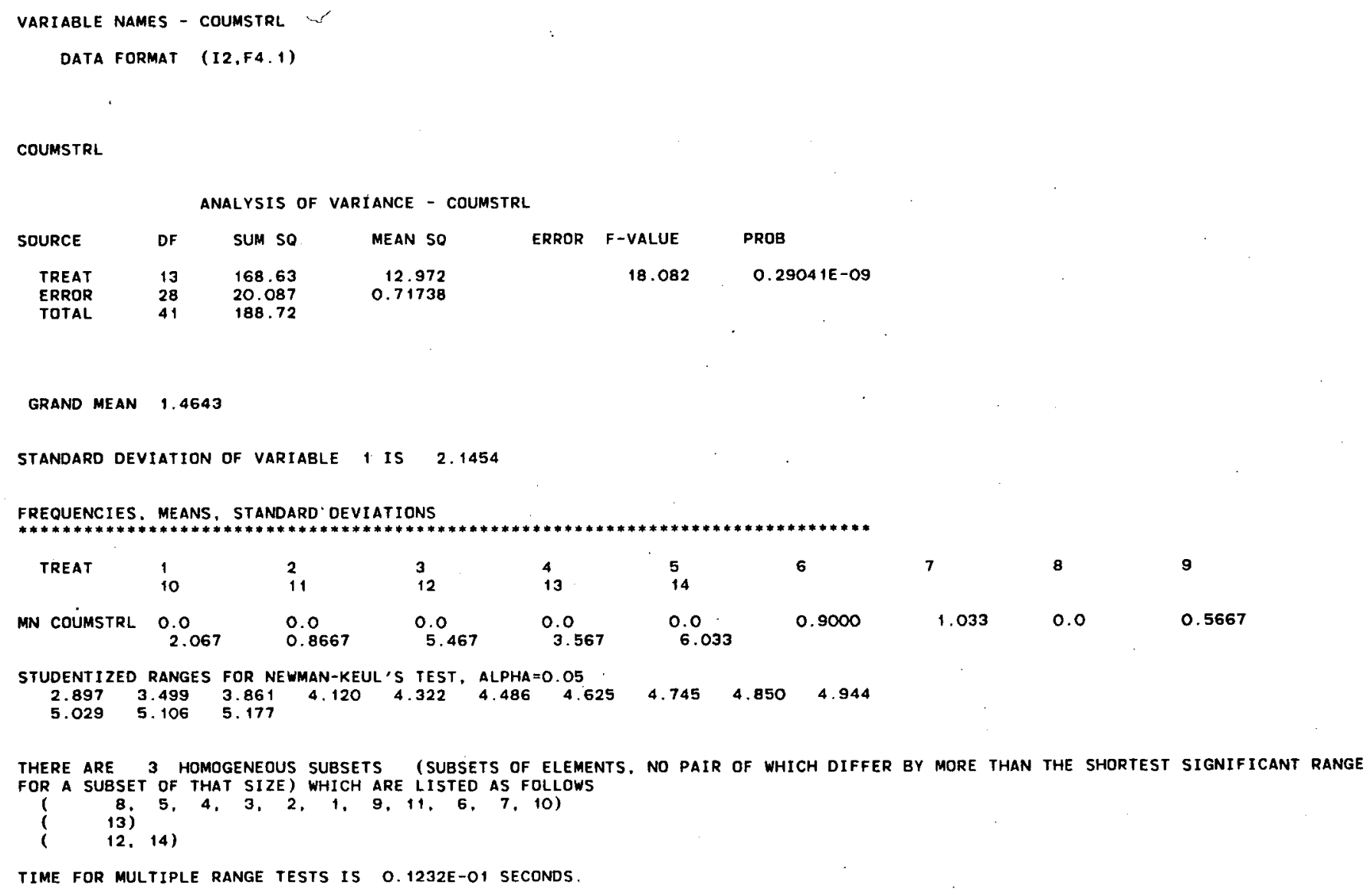


Appendix D. Factorial analysis of variance for daidzein, formononetin and coumestrol contents of alfalfa sprouts from Treatments $A$ to $Z$.

Coding of growth condition factors was explained in the Results and Discussion Section, and the treatment combinations are coded as follows:
$A=1221$
$B=1212$
$c=1222$
$D=1121$
$E=1112$
$F=1122$
$U=\begin{array}{llll}2 & 2 & 2 & 1\end{array}$
$V=2212$
$W=2222$
$x=2121$
$Y=2112$
$Z=2122$ 
TITLE, ESTROGEN ANALYSIS:
VARIABLES.G.L.V,F. OAIDZEIN, FORMETIN, COUMSTRL

MODEL, DAIDZE IN, FORMETIN, COUMSTRL $=G+L+G * L+V+G * V+L * V+G * L * V+F+G * F+L * F+G * L * F$

LEVELS $G=2, L=2, V=2, F=2$

INPUT FILE = PHYTO

FORMATE(F, O., 3F2, $0,3 F 5,1)$

OUTPUT OBSE, FREO, PRED

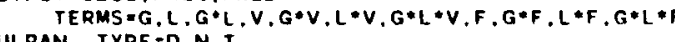

$T E R M S=G, L, G * L, V, G * V, L * V, G=L * V, F, G * F, L * F, G * L * F$

COMPUTE

$T$ me for control card processing was 0.10426 seconds. Cumulat ve $t$ ime is 0.10071 seconds.
$1+1+1+1+1+1+1+1+1+1+1+1+1+1+1+1+1+1+1+1+1+1+1+1+1+1+1+1+1+1+1+1+1+1+1+1+1+1+1+1+1+1+1+1+1+1+1+1+1+1+1+1+1+1+1+1+1+1+1+1+1+1+1+1+1+1$

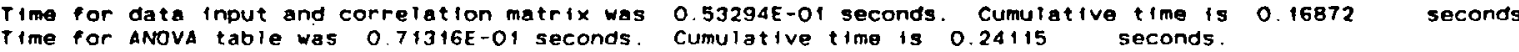

ESTROGEN ANALYSIS:

Analysis for DAIOZEIN

Analysis of variance table

\begin{tabular}{|c|c|c|c|c|c|c|}
\hline Source & $\begin{array}{l}\text { Sum of } \\
\text { squares }\end{array}$ & DF & $\begin{array}{l}\text { Mean } \\
\text { square }\end{array}$ & F-ratio & Probability & Test torm \\
\hline $\begin{array}{l}G \\
L \\
G * L \\
V \\
G * V \\
G * V \\
G * L * V \\
F \\
G * F \\
L * F \\
G * L * F \\
R e s \text { dual } \\
\text { Total }\end{array}$ & $\begin{array}{c}56.751 \\
0.17778 E-01 \\
128.44 \\
0.77042 \\
56.120 \\
70.384 \\
0.22042 \\
32.202 \\
16.007 \\
0.10667 \\
66.002 \\
390.19 \\
842.48\end{array}$ & $\begin{array}{r}1 . \\
1 \\
1 \\
1 \\
1 . \\
1 . \\
1 . \\
24 .\end{array}$ & $\begin{array}{l}56.751 \\
0.17778 E-01 \\
128.44 \\
0.77042 \\
56.120 \\
70.384 \\
0.22042 \\
32.202 \\
16.007 \\
0.10667 \\
66.002 \\
16.258\end{array}$ & $\begin{array}{l}3.4906 \\
0.10935 E-02 \\
7.9004 \\
0.47387 \mathrm{E}-01 \\
3.4519 \\
4.3292 \\
0.13558 \mathrm{E}-01 \\
1.9857 \\
0.98454 \\
0.65609 \mathrm{E}-02 \\
4.0596\end{array}$ & $\begin{array}{l}0.07397 \\
0.97389 \\
0.00968 \\
0.82951 \\
0.07549 \\
0.04831 \\
0.90828 \\
0.17214 \\
0.33098 \\
0.93611 \\
0.05525\end{array}$ & $\begin{array}{l}\text { RESIDUAL } \\
\text { RESIDUAL } \\
\text { RESIDUAL } \\
\text { RESIDUAL } \\
\text { RESIDUAL } \\
\text { RESIDUAL } \\
\text { RESIDUAL } \\
\text { RESIDUAL } \\
\text { RESIDUAL } \\
\text { RESIOUAL } \\
\text { RESIOUAL }\end{array}$ \\
\hline DAIDZEIN & $\begin{array}{l}\text { Overall mean } \\
\mathbf{3 . 8 0 0 0}\end{array}$ & $\begin{array}{r}0 \\
\text { standa } \\
4\end{array}$ & $\begin{array}{l}\text { verall } \\
\text { rd deviation } \\
.9062\end{array}$ & & & \\
\hline
\end{tabular}

Frequencies. means. Standard devistions for $G$

$\begin{array}{lrr} & & \\ \text { O MEAN } & 2.544 & 18 \\ \text { P MEAN } & 2.5444 & 5.0556 \\ \text { O STOV } & 3.9822 & 5.0556 \\ \text { S ERR M } & 0.95038 & 5.5101 \\ & & 0.95038\end{array}$

Multiple range tests

F-ratio is not signiftcant at probability 0.07397 
Frequenctes, means, standard devtations for $L$

$\begin{array}{lrr} & & \\ \text { D MEAN } & 3.7778 & 18 \\ \text { P MEAN } & 3.7778 & 3.8222 \\ \text { O STOV } & 6.0065 & 3.8222 \\ \text { S ERR M } & 0.95038 & 0.6713 \\ \end{array}$

Multiple range tests

f-ratio is not significant at probability 0.97389

Frequenctes. means. standard deviations for $G^{*} \mathrm{~L}$

$\begin{array}{lrrrr}\cdots & & & & \\ \text { O MEAN } & 0.63333 & 4.4556 & 6.9222 & \mathbf{9} \\ \text { P MEAN } & 0.6333 & 4.4556 & 6.9222 & \mathbf{3} \\ \text { O STOV } & 0.32016 & \mathbf{5 . 0 3 7 6} & \mathbf{7 . 3 7 0 0} & 1.5369 \\ \text { S ERR M } & 1.3440 & 1.3440 & 1.3440 & 1.3440\end{array}$

Multiple range tests

Ouncan test at $5 \%$ probability level

there are 2 homogeneous subsets which are 1 isted as follows

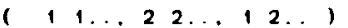

( $22 \ldots, 2 \ldots 21 \ldots)$

Newrman-keuls test at $5 \%$ probabtilty level
There are 2 homogeneous subsets which are 1 is sted as follows

( $11 \ldots 22 \ldots 12 \ldots)$

( $22 \ldots 12 \ldots 2$ 1..)

Tukey test at $5 \%$ probability level
There are 2 homogeneaus subsets which are isted as follows:

$(1, \ldots 22 \ldots, 2 \ldots)$

( $22 \ldots 12 \ldots 21 \ldots$

t the for multiple range test was $0.16081 E-01$ seconds. Cumulative time is 0.30527

seconds

Frequenctes, means, standard deviations for $v$

$\begin{array}{lrr}0 & 12 & 24 \\ \text { P MEAN } & 4.3333 & 3.5333 \\ \text { P MEAN } & 3.5611 & 3.9194\end{array}$

$\begin{array}{lll}\text { P MEAN } & 3.5611 & 3.9194 \\ \text { O STOV } & \mathbf{6 . 9 9 4 2} & 3.6071\end{array}$

$\begin{array}{lll} & \\ \text { ERR M } & 1.2868 & 0.86758\end{array}$

Muitiole range tests 
F-ratio is not signiffcant at probability 0.82951

Frequenctes. means, standard deviations for $G \cdot v$

$\begin{array}{lrrrrr} & 1.1 & 1.2 . & 2.1 . & 2.2 . \\ \cdots & & 12 & 6 & 12 \\ \text { O MEAN } & 1.5833 & 3.0250 & 7.0833 & 4.0417 \\ \text { P MEAN } & 0.81111 & 3.411 & 6.3111 & 4.4278 \\ \text { O STOV } & 0.73598 & 4.8483 & 9.4302 & 1.7707 \\ \text { S ERR M } & 1.7352 & 1.1959 & 1.7352 & 1.1959\end{array}$

Multiple range tests

F-ratio is not significant at probability 0.07549

Frequencies, means, standard deviations for $L \cdot v$
.11 . 12.2

$\begin{array}{lrrrr}\cdots & 6 & 12 & 6 & 12 \\ 0 \text { MEAN } & 6.5500 & 2.3917 & 2.1167 & 4.6750 \\ \text { P MEAN } & 5.7778 & 2.7778 & 1.3444 & 5.0611 \\ 0 \text { STIV } & 9.7705 & 2.4652 & 0.60470 & 4.2760 \\ \text { S ERR M } & 1.7352 & 1.1959 & 1.7352 & 1.1959\end{array}$

multiple range tests

Duncan test at 5\% probability level

There is 1 homogeneous subset which is 1 isted as follows:

( . $21 . .12$ 2.. 22 2..11.)

Newman-Kouls test at $5 \%$ probability level

There is 1 homoganeous subset which is listed as follows:

$(.21 \ldots .12 \ldots .22 \ldots .11$.

Tukey test at $5 \%$ probabllity level
There is 1 homogeneous subset which is listed as follows:

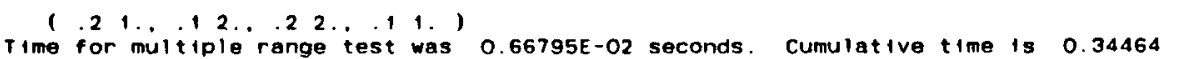

Frequencles. means. standard deviations for $G * L+V$

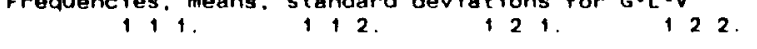

$\begin{array}{ll}0 \text { MEAN } & 0.93333 \\ \text { P MEAN } & 0.1611\end{array}$

6

3
2.2333
1.4611
0.28868

5
5.5667

5.9528
6.0105

6. 0105
1.6688

211.

212.

seconds

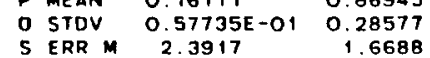

0.28868
2.3917

3
12.167
11.394
12.009

11.394
12.001
2.3917

4. 3000

Multiole range tests

F-ratio is not significant at probabllity 0.90828

Frequenctes, means, standard deviations for $F$ 


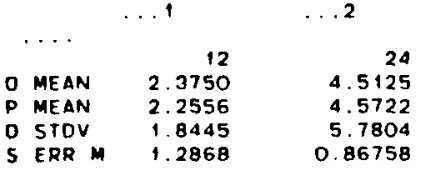

Multiole range tests

F-ratio is not significant at probability 0.17214

Frequencies, means. standard deviations for $G^{*} F$

$\begin{array}{lrrrr}\cdots & & & & \\ \text { O MEAN } & 1.0500 & 3.2917 & 3.7000 & 5.7333 \\ \text { P MEAN } & 0.93056 & 3.3514 & 3.5806 & 5.7931 \\ \text { O STOV } & 0.94816 & 4.7193 & 1.5401 & 6.6589 \\ \text { S ERR M } & 1.7352 & 1.1959 & 1.7352 & 1.1959\end{array}$

Multiple range tests

f-rat to is not significant at probability 0.33098

Frequencies. means, standard deviat fons for $L * F$

$\begin{array}{lrrrr}0 & & 12 & 6 & 12 \\ \text { P MEAN } & 1.3000 & 5.0167 & 3.4500 & 4.0083 \\ \text { P MEAN } & 1.1806 & 5.0764 & 3.3306 & 4.0681 \\ \text { 0 STDV } & 1.1781 & 7.0784 & 1.8229 & 4.3825 \\ \text { S ERR M } & 1.7352 & 1.1959 & 1.7352 & 1.1959\end{array}$

Multiple range tests

F-ratio is not significant at probabtlity 0.93611

Frequencies, means, standard deviations for $G^{*} L * F$

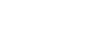

\begin{tabular}{llrrr}
$\cdots$ & \multicolumn{1}{c}{3} & & \\
O MEAN & 0.23333 & 0.83333 & 1.8667 & 5.75 \\
P MEAN & 0.11389 & 0.89306 & 1.7472 & 5.8097 \\
D STDV & $0.57735 E-01$ & 0.13663 & 0.49329 & 5.87 \\
S ERR & 2.3917 & 1.6688 & 2.3917 & 1.66
\end{tabular}

Multiple range tests

F-ratto is not stgntficant at probabritty 0.05525
$1+1+1+1+1+1+1+1+1+1+1+1+1+1+1+1+1+1+1+1+1+1+1+1+1+1+1+1+1+1+1+1+1+1+1+1+1+1+1+1+1+1+1+1+1+1+1+1+1+1+1+1+1+1+1+1+1+1+1+1+1+1+1+1+1+1$

Analysis for FORMETIN

Analysis of variance table

$$
\text { Sum of }
$$

$\begin{array}{rrrr}21.1 & 21.2 & 22.1 & 22.2 \\ 3 & 6 & 3 & 6 \\ 2.3667 & 9.2000 & 5.0333 & 2.2667 \\ 2.2472 & 9.2597 & 4.9139 & 2.3264 \\ 0.23094 & 8.2588 & 0.73711 & 0.70616 \\ 2.3917 & 1.6688 & 2.3917 & 1.6688\end{array}$




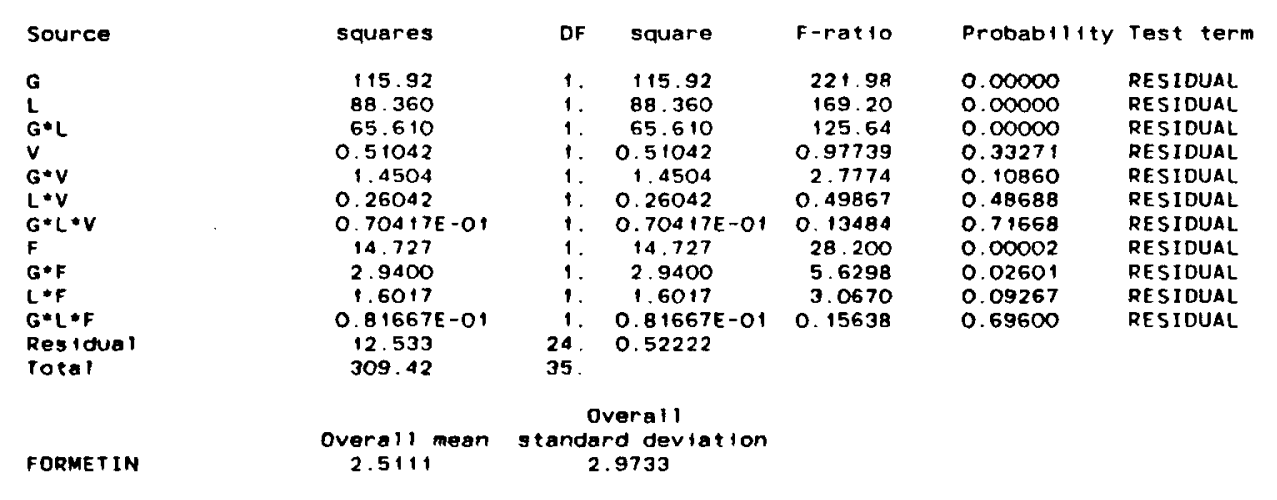

Frequencies, means, standard deviations for $G$

$\begin{array}{lrr}\cdots & & 18 \\ 0 \text { MEAN } & 0.71667 & 18 \\ \text { P MEAN } & 0.71667 & 4.3056 \\ \text { O STOV } & 0.66355 & 4.3056 \\ \text { S ERR M } & 0.17033 & 0.17078 \\ \end{array}$

$\begin{array}{llr}0 \text { STOV } & 0.66355 & 3.3078 \\ S \text { ERR M } & 0.17033 & 0.17033\end{array}$

Multiple range tests

Duncan test at $5 \%$ probability level

There are 2 homogeneous subsets which are 11 sted as follows:

( $\ldots)$

(2...)

Newman-keuls test at 5\% probabillty level

Newman-keuls test at $5 \%$ probablity level
There are 2 homogeneous subsets which are 1 isted as follows:

(1...)

( $2 \ldots)$

Tukey test at $5 \%$ probability level

There are 2 homogeneous subsets which are 1 isted as follows:

$(1, \ldots)$

Time for multiple range test was $0.66929 E-02$ seconds, cumulative time is 0.44469 seconds.

Frequenctes. means, standard deviations for $\mathrm{L}$

O MEAN $\quad 48 \quad 18 \quad 18$ 


$\begin{array}{lll}\text { P MEAN } & 4.0778 & 0.94444 \\ \text { O SIOV } & 3.4622 & 1.0083 \\ \text { S ERR M } & 0.17033 & 0.17033 \\ \text { Mult tole range tests }\end{array}$

Multiole range tests

Duncan test at $5 \%$ probablitity level

There are 2 homogeneous subsets which are 1 isted as follows:

(.2.)

$(1 .$.

Newman-Keuls test at $5 \%$ probab 111 ty level

There are 2 homogeneous subsets which are ilsted as follows

(.2..)

$(.1 .$.

Tukey test at $5 \%$ probability level

There are 2 homageneous subsets which are 1 isted as follows

(.2..)

Imé for multiple rangé test was $0.61455 E-02$ seconds. Cumulative time is 0.46163

seconds

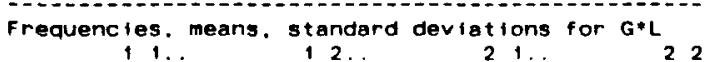

$\begin{array}{lrrrr}\cdots & & & & \\ 0 \text { MEAN } & 0.93333 & 0.50000 & 7.2222 & 1.3889 \\ \text { P MEAN } & 0.93333 & 0.50000 & 7.2222 & 1.3889 \\ \text { O STDV } & 0.75993 & 0.50249 & 1.6269 & 1.2098 \\ \text { S ERR M } & 0.24088 & 0.24088 & 0.24088 & 0.24088\end{array}$

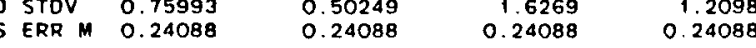

Multiple range tests

Duncan test at $5 \%$ probabllity level

There are 3 homogeneous subsets which are 1 isted as follows

(12..1 1..

( $11 \ldots 22 \ldots$

( $21 \ldots$ )

Newman-keuls test at $5 \%$ probabtirty level

There are 3 homogeneous subsets which are itsted as follows:

( $12 \ldots 11 \ldots)$

$(11 \ldots 22 \ldots)$

( $21 \ldots)$

Tukey test at $5 \%$ probability level
There are 2 homogeneous subsets which are isted as follows: 
$(12 \ldots 11 \ldots 22 \ldots)$

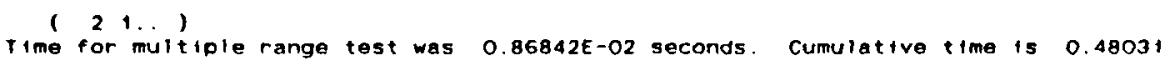

seconds.

Frequencies, means, standard deviations for $v$

. 1 . . . 2

$\begin{array}{lrr} & & 1 \\ \text { O MEAN } & 2.1833 & 2.674 \\ \text { P MEAN } & 2.7056 & 2.4139 \\ \text { O STDV } & 2.5135 & 3.2167 \\ S \text { ERR } & 0.23063 & 0.15549\end{array}$

Multiple range tests

F-ratio is not significant at probabitity 0.3327

Fraquenctes, means, standard deviations for $G * v$

$\begin{array}{lrrrr}\ldots & & & & \\ 0 \text { MEAN } & 0.95000 & 0.60000 & 3.4167 & 4.7500 \\ \text { P MEAN } & 1.4722 & 0.33889 & 3.9389 & 4.4889 \\ \text { D STDV } & 0.50100 & 0.72237 & 3.1619 & 3.4233 \\ \text { S ERR M } & 0.31098 & 0.21433 & 0.31098 & 0.21433\end{array}$

$\begin{array}{llllr}\text { D STDV } & 0.50100 & 0.72237 & 3.1619 & 3.4233 \\ S \text { ERR M } & 0.31098 & 0.21433 & 0.31098 & 0.21433\end{array}$

Multiple range tests

f-ratio is not significant at probability 0.90860

Frequenctes, means. standard devtations for $L \cdot V$

$\begin{array}{lrrrr}\ldots & & & & \\ 0 & 6 & 12 & 6 & 12 \\ \text { D MEAN } & 3.7167 & 4.2583 & 0.65000 & 1.0917 \\ \text { P MEAN } & 4.2389 & 3.9972 & 1.1722 & 0.83056 \\ 0 \text { STDV } & 2.8379 & 3.8415 & 0.4555 & 1.1866 \\ \text { S ERR M } & 0.31098 & 0.21433 & 0.31098 & 0.21433\end{array}$

multiple range tests

f-ratio is not significant at probability 0.48688

Frequenctes, means, standara deviations for G.L*V

121 122

$\begin{array}{lrrrrr}0 \text { MEAN } & 1.1667 & 0.81667 & 0.73333 & 0.38333\end{array}$

$\begin{array}{lllll}\text { P MEAN } & 1.6889 & 0.81667 & 0.13333 & 0.38333 \\ 0 \text { MEAT } & 0.55556 & 1.2556 & 0.12222\end{array}$

D STDV $0.20817 \quad 0.92610 \quad 0.66583 \quad 0.4215$

211.

221

222 .

Muletple range tests

f-ratio is not stgniffcant at probability 0.71658 
Frequenctes, means. Standard deviations for $F$

$\begin{array}{lrr} & & \\ 0 & 12 & 24 \\ \text { D MEAN } & 3.4583 & 2.0375 \\ \text { P MEAN } & 3.5556 & 1.9889 \\ \text { O STOV } & 3.5341 & 2.6033 \\ \text { S ERR M } & 0.23063 & 0.15549\end{array}$

Multiple range tests

Ouncan test at $5 \%$ probabllity level
There are 2 homogeneous subsets which are ilsted as follows:

$(\ldots 2)$

( ...1)

Newman-keuls test at $5 \%$ probability level
There are 2 homogeneous subsets which are 11 sted as follows

( ...2)

( ...1)

Tukey test at 5\% probab $11+$ ty leve

There are 2 homogeneous subsets which are 11 sted as follows

$(\ldots 2)$

Time for multiple range test was $0.61197 \mathrm{-}-02$ seconds. Cumulative time is 0.54491 seconds

Frequenctes, means. standard deviations for $G^{*} F$

$\begin{array}{lrrrr}0 \text { MEAN } & 1.0333 & 0.55833 & 5.883 & 12 \\ \text { P MEAN } & 1.0336 & 0.50972 & 5.9805 & 3.5167\end{array}$

$\begin{array}{lllll}P \text { MEAN } & 1.1306 & 0.50972 & 5.9806 & 3.4681\end{array}$

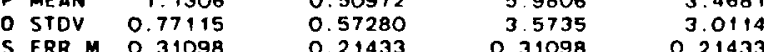

ERR M 0.31098

Multiple range tests

Ouncan test at $5 \%$ probability level

There are 3 homogeneous subsets which are ilsted as follows:

( $1.2,1.1$ )

(2..2)

( 2.1 )

Newman-keuis test at $5 \%$ probability level
There are 3 homogeneous subsets which are ilsted as follows:

$(1,2,1 \ldots 1$ 
$(2.2)$

$(2 \ldots 1)$

Tukey test at $5 \%$ probability level

There are 3 homogeneous subsets which are 115 ted as follows:

$(1,2,1 \ldots 1)$

(2,2)

Tims for multiple range test was 0.90237 - -02 seconds. Cumulat tve time is 0.56561 seconds

Frequencies. means. Standara deviations for $L=F$
1.2

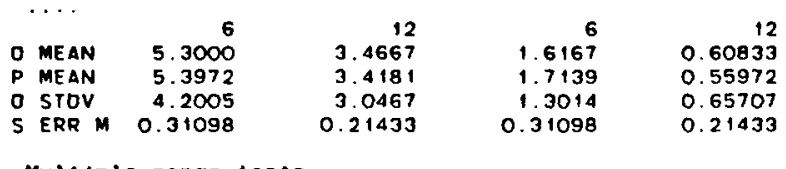

Multiole range tests

F-ratio is not significant at probability 0.09267

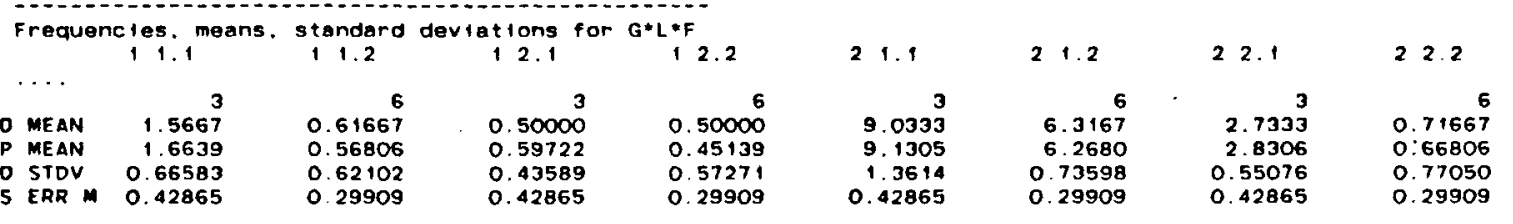

Multiple range tests

F-rat 10 is not signiftcant at probability 0.69600
$1+1+1+1+1+1+1+1+1+1+1+1+1+1+1+1+1+1+1+1+1+1+1+/+1+1+1+1+1+1+1+1+1+1+1+1+1+1+1+1+1+1+1+1+1+1+1+1+1+1+1+1+1+1+1+1+1+1+1+1+1+1+1+1+1+1$

Analysis for COUMSTRL

Analysis of variance table

\begin{tabular}{|c|c|c|c|c|c|c|}
\hline Source & $\begin{array}{l}\text { Sum of } \\
\text { squares }\end{array}$ & DF & $\begin{array}{c}\text { Mean } \\
\text { square }\end{array}$ & F-rat to & Probabillty & Test term \\
\hline G & 69.167 & 1. & 69.167 & 82.642 & 0.00000 & RESIDUAL \\
\hline L & 45.563 & 1. & 45.563 & 54.439 & 0.00000 & RESIDUAL \\
\hline G*L & 23.200 & 1. & 23.200 & 27.720 & 0.00002 & RESIOUAL \\
\hline $\mathrm{v}$ & $0.20417 E-01$ & 1. & $0.20417 E-01$ & $0.24394 E-01$ & 0.87719 & RESIOUAL \\
\hline$G \cdot V$ & 1.9837 & 1. & 1.9837 & 2.3702 & 0.13675 & RESIDUAL \\
\hline $\mathrm{L} \cdot \mathrm{V}$ & $2.600 \mathrm{~d}$ & 1. & 2.6004 & 3.1070 & 0.09069 & RESIDUAL \\
\hline$G * L * V$ & 8.2838 & 1. & 8.2837 & 9.8976 & 0.00438 & RESIDUAL \\
\hline & $0.41668 \mathrm{E}-03$ & 1. & $0.41668 \mathrm{E}-03$ & $0.49786 E-03$ & 0.98238 & RES I DUAL \\
\hline$G *$ & 1,1704 & 1. & 1.1704 & 1.3984 & 0.24857 & RESIDUAL \\
\hline$L \rightleftharpoons F$ & 0.15042 & 1. & 0.15042 & 0.17972 & 0.67539 & RE S IDUAL \\
\hline
\end{tabular}




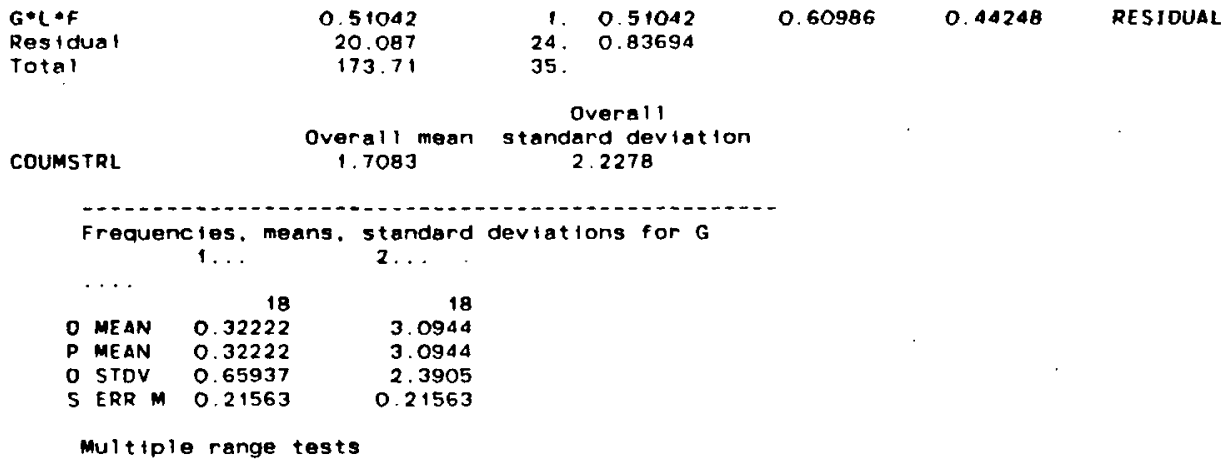


Newman-keuls test at $5 \%$ probabllity level
There are 2 homogeneous subsets which are 1 isted as follows

(.2..)

(.1..)

Tukey test at $5 x$ probability level
There are 2 homogeneous subsets which are 1 isted as follows

(.2.)

Ttme for multiple range test was 0.63810 -02 seconds. Cumulative time is 0.64552

Frequenctes. means. Standard deviations for $G^{*} L$
1

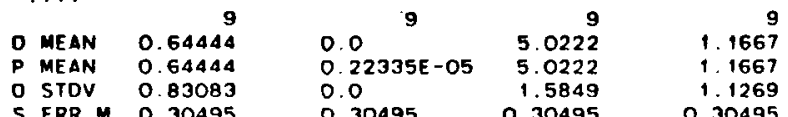

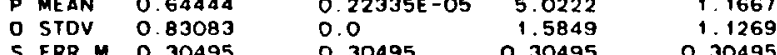

multiple range tests

Duncan test at $5 \%$ probabllity level

There are 3 homogeneous subsets which are ilsted as follows

(. $12, \ldots, 1,1$

$(11 \ldots 22 \ldots)$

( 2 1..)

Newman-Keuls test at $5 \%$ probability level
There ore 3 homogeneous subsets which are i isted as follows:

( $12 \ldots+1 \ldots)$

( $11 \ldots 22$, )

( 2 1..)

Tukey test at $5 \%$ probability level
There are 2 homogeneous subsets which are 1 isted as follows:

( $12 \ldots 1$ 1 . 22 2.)

(' $21 \ldots$ ')
rime for multiple range test was $0.986968-02$ seconds. Cumulative time is 0.66526 (n)

Frequenctes, means. Standard devtations for $v$

$\begin{array}{lrr}\text { O MEAN } & 12 & 24 \\ \text { P MEAN } & 1.6667 & 1.7292 \\ & 1.6694 & 1.7278\end{array}$ 


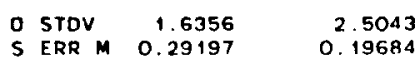

Multiple range tests

F-ratio is not significant at probability 0.87719

Froquenctes, means. Standard devtations for $G^{*} V$

$\begin{array}{lrrrr}\cdots & 6 & 12 & 6 & 12\end{array}$

$\begin{array}{lllll}\text { O MEAN } & 0.51667 & 0.22500 & 2.8167 & 3.2333 \\ \text { P MEAN } & 0.51944 & 0.22361 & 2.8194 & 3.2319 \\ 0 \text { STOV } & 0.84951 & 0.55942 & 1.4106 & 2.8043\end{array}$

$\begin{array}{llllr}0 \text { STOV } & 0.84951 & 0.55942 & 1.4106 & 2.8043 \\ S \text { ERR M } & 0.39369 & 0.27133 & 0.39369 & 0.27133\end{array}$

Multiple range tests

F-ratto is not stgnificant at probability 0.13675

Frequenctes, means, standard deviations for $L * V$

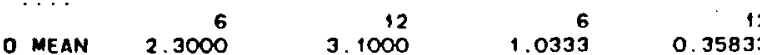

$\begin{array}{lllll}0 \text { MEAN } & 2.3000 & 3.1000 & 1.0333 & 0.35833 \\ \text { P MEAN } & 2.3028 & 3.0986 & 1.0361 & 0.35695\end{array}$

$\begin{array}{lrrrr}\text { P MEAN } & 2.3028 & 3.0986 & 1.0361 & 0.35695 \\ \text { O STOV } & 1.6444 & 2.9508 & 1.4895 & 0.55343 \\ \text { S ERR M } & 0.39369 & 0.27133 & 0.39369 & 0.27133\end{array}$

Mult tple range tests

F-ratio is not significant at probability 0.09069

Frequenctes, means. standard deviations for $G * L * V$

$111 . \quad 112 . \quad 121 . \quad 122$

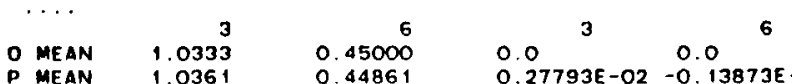

$\begin{array}{lll}\text { P MEAN } & 1.03361 & 0.4486 \\ 0 \text { STDV } & 0.0017 & 0.75299\end{array}$

6

211.

$2+2$

221.

222.

Multiple range tests

Duncan test at $5 \%$ probability leve

There are 4 homogeneous subsets which are 1 isted as follows:

(1 $122 \ldots 121 \ldots 1+2,222 \ldots 111$.

$1222.1,1,221$,

( 221.2211.$)$

(2) 2 . )

Newman-keuls test at $5 \%$ probab 114 ty level

There are 3 homogeneous subsets which are 1 isted as follows:
The 
$122 \ldots 121 \ldots 112.222 ., 111.221$.

( $2251 \ldots 21 \%$ )

( 2 1 2. )

Tukey test at $5 \%$ probability level
There are 3 nomogeneous subsets which are 1 tsted as follows:

$(122 \ldots 121 \ldots 112 \ldots 222 \ldots 111 \ldots 221$.)

$\left(\begin{array}{lllllll}2 & 2 & 1 & 2 & 2 & 1 & 1\end{array}\right.$

( $211 \ldots 212$, ' 2 for multiple range test was $0.141406-01$ seconds. Cumulative time is 0.72939 seconos.

Frequencles. means, standard deviations for $F$

...1 ...

$\begin{array}{lrr} & 12 & 24 \\ 0 \text { MEAN } & 1.7333 & 1.6958 \\ \text { P MEAN } & 1.7139 & 1.7056 \\ 0 \text { STDV } & 2.4325 & 2.1731 \\ \text { S ERR M } & 0.29197 & 0.19684\end{array}$

Multiple range tests

F-ratio is not significant at probability 0.98238

Frequencles, means. Standard deviations for $G_{1 . F} 2 \ldots 2$

$\begin{array}{lrrrr}\cdots & & & & \\ \text { O MEAN } & 0.45000 & 0.25833 & 3.0167 & 3.12 \\ \text { P MEAN } & 0.43056 & 0.26806 & 2.9972 & 3.1431 \\ \text { O STDV } & 0.75299 & 0.63311 & 2.9151 & 2.2281 \\ \text { S ERR M } & 0.39369 & 0.27133 & 0.39369 & 0.27133\end{array}$

Multiple range tests

F-ratio is not significant at probability 0.24857

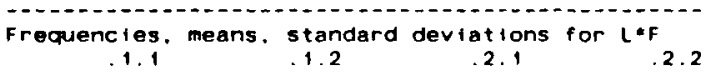

$\begin{array}{lrrrr}\cdots & & 12 & & 12 \\ \text { O MEAN } & 3.1833 & 2.6583 & 0.28333 & 0.73333 \\ \text { P MEAN } & 3.1639 & 2.6681 & 0.26389 & 0.74306 \\ \text { O STOV } & 2.7874 & 2.5568 & 0.44907 & 1.1468 \\ \text { S ERR M } & 0.39369 & 0.27133 & 0.39369 & 0.27133\end{array}$

Multiple range tests

f-ratio is not significant at probability 0.67539

Frequenctes, means, standard deviations for $G * L * F$ 


\begin{tabular}{|c|c|c|c|c|c|c|c|c|}
\hline & 11.1 & 11.2 & 12.1 & 12.2 & 21.1 & 21.2 & 22.1 & 22.2 \\
\hline $\begin{array}{ll}0 & \text { MEAN } \\
D & \text { MEAN } \\
0 & \text { STDV } \\
5 & \text { ERR M M }\end{array}$ & $\begin{array}{r}3 \\
0.90000 \\
0.88056 \\
0.90000 \\
0.54266\end{array}$ & $\begin{array}{r}6 \\
0.51667 \\
0.52639 \\
0.84951 \\
0.37864\end{array}$ & $\begin{array}{l}0.0 \\
0.0 \\
-0.19442 E-0 . \\
0.0 \\
0.54266\end{array}$ & $\begin{array}{l}0.0 \\
0.0 \\
0.97240 E-02 \\
0.0 \\
0.37864\end{array}$ & $\begin{array}{r}3 \\
5.4667 \\
5.4472 \\
1.7243 \\
0.54266\end{array}$ & $\begin{array}{r}6 \\
4.8000 \\
4.8097 \\
1.6285 \\
0.37864\end{array}$ & $\begin{array}{r}3 \\
0.56667 \\
0.54722 \\
0.51316 \\
0.54266\end{array}$ & $\begin{array}{r}6 \\
1.4657 \\
1.4764 \\
1.2660 \\
0.37864\end{array}$ \\
\hline
\end{tabular}

F-ratio is not significant at probability 0.44248 